Portland State University

PDXScholar

\title{
Writing in the Contact Zone: Three Portraits of Reflexivity and Transformation
}

\author{
Laurene L. Christensen \\ Portland State University
}

Follow this and additional works at: https://pdxscholar.library.pdx.edu/open_access_etds

Part of the Educational Methods Commons, First and Second Language Acquisition Commons, and the Teacher Education and Professional Development Commons

Let us know how access to this document benefits you.

\section{Recommended Citation}

Christensen, Laurene L., "Writing in the Contact Zone: Three Portraits of Reflexivity and Transformation" (2002). Dissertations and Theses. Paper 1886.

https://doi.org/10.15760/etd.1885

This Thesis is brought to you for free and open access. It has been accepted for inclusion in Dissertations and Theses by an authorized administrator of PDXScholar. Please contact us if we can make this document more accessible: pdxscholar@pdx.edu. 


\section{THESIS APPROVAL}

The abstract and thesis of Laurene L. Christensen for the Master of Arts in TESOL were presented August 12, 2002, and accepted by the thesis committee and the department.

COMMITTEE APPROVALS:

Kimberley Brфwn, Chair

Steve keder

Duncan Carter

Representative of the Office of Graduate Studies

DEPARTMENT APPROVAL:

Stever Keder, Chair

Department of Applied Linguistics 


\section{ABSTRACT}

An abstract of the thesis of Laurene L. Christensen for the Master of Arts in TESOL presented August 12, 2002.

Title: Writing in the Contact Zone: Three Portraits of Reflexivity and Transformation

Culture is at the core of language teaching. Because classrooms are contact zones (Pratt 1991), teachers must have a well-developed sense of their own intercultural competence so that they may better facilitate the cross-cultural discovery inherent in language teaching. Teacher preparation programs need to provide opportunities for new teachers to increase their intercultural awareness.

The purpose of this research was to qualitatively understand the experiences of pre-service teachers in a required culturelearning class at a large urban university. Specifically, the focus of this study was the completion of a mini-ethnography project designed to give the students a cross-cultural exchange. Since such contact zones can be the site of reflexivity and 
transformation, this study sought to understand the contexts in which reflexivity and transformation might occur, as well as how these changes might influence a person's intercultural competence.

This research used student writing as a primary source for illustrating change. Writing samples from all course assignments were collected from the class. Intercultural Development Inventory (IDI) Profiles were collected from three individuals who also agreed to extensive interviews. This data was used to create case study portraits of the class as well as the three individuals, illustrating a variety of experiences with the ethnography project. Change in intercultural competence was measured according to the Developmental Model of Intercultural Sensitivity (Bennett 1993) and the IDI.

Each person had a markedly different experience with the project, and each person experienced some kind of intercultural change. Overall, the results suggest that ethnography is a useful classroom tool. When used at an appropriate stage of a student's intercultural development, reflexivity and perspective transformation can occur, thus leading to intercultural competence. 


\section{WRITING IN THE CONTACT ZONE: \\ THREE PORTRAITS OF \\ REFLEXIVITY AND TRANSFORMATION}

by

LAURENE L. CHRISTENSEN

A thesis submitted in partial fulfillment of the requirements for the degree of

\section{MASTER OF ARTS \\ in \\ TESOL}

Portland State University

2002 
This thesis is dedicated to

Jürgen,

for being part of the process. 


\section{ACKNOWLEDGEMENTS}

During my education at Portland State University, I have come to value the notion of writing within a community. I appreciate the process of sharing my work with others, getting feedback from trusted readers, and seeking advice rather than suffering in isolation before an uncaring computer monitor. My support community during the writing of this thesis has been large, and I cherish this opportunity to include my gratitude here.

Above all, I thank Carol Burnell for being a constant reader and encourager. Without her "velvet hammer," I might still be back on page 35 of this project. Instead, she has been consistent in her encouragement and determined to remind me to break this project up into manageable chunks. She has given me invaluable feedback throughout the process, and she's used her keen eye for grammar to save me countless hours of editing and proofreading.

I also want to thank Dr. Kimberley Brown for being my thesis advisor and friend. She has been a steady supporter from the very beginning of this project, when I stood in her office and excitedly told her of my own experience with the ethnography. I am grateful for every minute I've had in the last few years to watch and learn 
from her. Words truly cannot express my gratitude to Kim for all she has done for me the last few years.

My utmost appreciation goes to Dr. Steve Reder and Dr.

Duncan Carter for serving on my thesis committee. I value the time you've taken to talk to me about my work in process. Your questions and comments have been helpful to me in honing my ideas and practicing the craft of ethnography.

This project would not have been possible without my research participants. I am indebted to everyone who agreed to let me take copies of their writing for the purposes of my project. I am especially grateful to Cleo, Bob, and Phillip for letting me into their lives, for sharing so much of themselves with me, and allowing me to grow from my encounters with them. I have gotten to know these three people more than I ever thought possible, and I cherish my relationships with them.

Furthermore, I will always appreciate Su-ho, my own informant for the ethnography project. Without him and our experiences together when I was taking the class, I never would have developed this idea for a thesis. I greatly value the path of self-discovery my friendship with him has sent me down. 
Thanks go to Riikka Saalonen and Päivi Koivumanaaho for their input on analyzing my data, as well as their willingness to discuss my thesis in process. Their friendship throughout the process has been encouraging.

Gracias a Estevan Herrerra and Kelly Nalty for helping me with my Spanish oral exam. Without your help, I might have not gotten to the thesis defense stage.

Thanks to Debra Clemans and Eric Lutzker for all your technical support and encouragement. Similar thanks go to John Orr and Jewel Yaguchi at the University of Portland for extending the use of my office space into the summer so that I could have a stress free work space.

I extend my gratitude to the Intercultural Communications Institute for their time in chatting with me about my research as well as making available their wonderful library on intercultural communications. Thanks also to Dr. Milton Bennett and Dr. Mitch Hammer for their consultation with me about the Intercultural Development Inventory and its interpretation. They have given me insights which have helped me better understand the experiences of Bob, Cleo and Phillip. 
There have been amazing teachers at every step of my education; these women have inspired and encouraged me, and without their support, I might not be on this path. My high school teacher Judy Kraft pushed me to realize my unlimited potential. Dr. Sharon Carson challenged me to explore new territory, both intellectually and geographically. Dr. Susan Danielson has been my mentor and friend since my beginnings here at PSU. Special thanks to her for not only offering to read my thesis anyway, but also for encouraging me to pursue linguistics and working with Kim Brown. I will always be grateful to Sue for nurturing my passions.

Heartfelt appreciation goes to Kate Hengerer for helping me find my voice and encouraging me to use it liberally throughout the following pages. Many times I wanted to reign in my voice, but I found myself thinking, "what would Kate say?" and expressing myself to the fullest.

Heather Gaddy has also encouraged and inspired me to see myself as a writer. I have greatly valued my conversations with her about my work in progress, as well as her feedback on my drafts. I appreciate her on many levels, both as a friend and colleague.

My family has been indispensable, both in this project, and in cultivating my desire for education. From the very beginnings 
when my mother put books in my crib, my family encouraged my intellectual pursuits and love of writing. My father's passion for writing went hidden for a number of years, although he always supported my own creative efforts. The fruit of these beginnings is clearly evident here, I believe. And, these pages are made possible by my family's willingness to help with childcare, thus easing the completion of this project. For that, I will forever be grateful.

Finally, I cannot truly express the gratitude I feel for the love and support I've received from those closest to me. My dogs have listened patiently as I've discussed the intricacies of Mezirow's theories. Sappho has given me moments of much needed stress relief, and Java has stayed up late nights to protect and watch over me while I write. My son Jürgen has given me inspiration to finish this project. Most importantly, though, my deepest appreciation goes to my partner Chris Rogers. Throughout every stage of this process you have been steadfast in your support of me. You've transcribed into the night, you've put up with my moodiness, helped me study Spanish, read my drafts in progress, and done just about anything to make my life easier during the process. I cannot thank you enough. 


\section{TABLE OF CONTENTS}

Dedication / i

Acknowledgements / ii

Table of Contents / vii

List of Tables / xii

List of Figures / xiii

Glossary / xiv

Chapter One

Standing on the Bridge: Introduction / 1

Revelations and Beginnings / 2

Setting the Scene / 10

The Course / 12

Chapter Two

Entering into the Contact Zone: Review of Literature / 20

Culture and Cross-cultural Experience / 22

The Developmental Model of Intercultural Sensitivity / 28

The Intercultural Development Inventory / 34

Reflection and Reflexivity / 36

Ethnography and Reflexivity / 38

Ethnography and Education / 42

Theories of Composition / 45

Composition Research / 49 
Classroom-based Composition Research / 53

Transformation / 55

Endings and Beginnings / 61

Chapter Three

The "Dance of Vigilance and Improvisation": Methodology / 64

Guiding Principles / 69

Participant Observation / 72

Collection of Documents / 74

Progress Notes / 76

Other Freewrites / 78

Cultural Artifact Assignment / 78

Letter Exchange / 81

Drafts of the Mini-ethnography / 82

Midterm Exam / 83

IDIs / 83

Interviewing / 85

Network Analysis / 87

Interpreting the Data / 90

Creating the Portraits / 93 
Chapter Four

Coming Into Focus: The Results / 95

In the Beginning / 98

The Ethnography Project / 103

After the Ethnography / 110

Class Pictures / 118

Zooming In / 120

Chapter Five

A Tourist in the Contact Zone: Bob / 121

Meeting Bob / 122

Bob's Background / 125

Bob's Network Analysis / 136

Bob's Initial IDI Profile / 139

Bob's Ethnography / 142

Bob's Final IDI Profile / 160

Reflection on Transformation / 164

Chapter Six

Living in the Contact Zone: Cleo / 166

Getting to Know Cleo / 168

Cleo's IDI Profile / 174

Cleo's Ethnography / 177

Cleo's Writing Process / 184

"What have I learned? What do you mean by that?!" / 190 
Cleo's Final IDI / 195

Cleo Confronting Mezirow / 201

Chapter Seven

"Whose Eyes are You Seeing Through?": Phillip / 204

Meeting Phillip / 206

Phillip's Initial IDI / 211

Phillip's Ethnography / 214

Phillip's Final Ethnography / 221

Phillip's Final IDI / 227

Final Thoughts on Reflexivity and Transformation / 233

Chapter Eight

Returning to the Contact Zone:

Discussion and Conclusions / 237

Returning to the Questions-

the Role of Process Writing / 239

Demographics of Difference / 246

The Role of the Intercultural Development Inventory / 250

My Role in the Contact Zone / 253

Other Considerations / 258

Applications for Language Teaching / 262

Applications for TESOL / 264

Limitations of the Study / 265 
Directions for Further Study / 267

Conclusion / 268

On Becoming: an Epilogue / 270

References / 281

Appendix A

Applied Linguistics 471/571 Course Syllabus and Ethnography Assignment / 293

Appendix B

Human Subjects Consent Forms / 304

Appendix C

Supplemental Writing Notebook / 312

Appendix D

Midterm Exam Question / 335

Appendix E

Class Beginning and Ending Freewrites / 336 
Writing in the Contact Zone xii

\section{LIST OF TABLES}

Table 3.1

Distribution of document collection / 75

Table 4.1

Gender and grade level of my research participants / 97

Table 5.4

Bob's course initial and course final IDI results / 161

Table 6.3

Cleo's course initial and course final IDI results / 198

Table 7.3

Phillip's course initial and course final IDI profiles / 229 


\section{LIST OF FIGURES}

Figure 2.1

Kramsch's model of cultural reality and cultural imagination / 27

Figure 2.2

The developmental model of intercultural sensitivity / 29

Figure 5.1

Bob's network analysis / 138

Figure 5.2

Bob's initial IDI profile / 140

Figure 5.3

Bob's final IDI profile / 161

Figure 6.1

Cleo's initial IDI profile / 175

Figure 6.2

Cleo's final IDI profile / 196

Figure 7.1

Phillip's course initial IDI profile / 212

Figure 7.2

Phillip's course final IDI profile / 228 


\section{GLOSSARY}

The terms contained in this glossary are defined in greater detail throughout the pages of this thesis. This glossary is meant only as an initial guide to these terms and abbreviations.

Culture-Culture is defined by a number of contexts, and I explore these in detail in Chapter Two. Culture, as defined by ethnographic researchers Chiseri-Strater and Sunstein (1997) is "an invisible web of behaviors, patterns, rules, and rituals of a group of people who have contact with one another and share common languages" (p. 3).

DMIS - This is an abbreviation referring to the Developmental Model of Intercultural Sensitivity. The model, which was created by M. Bennett (1986), describes how a person constructs his or her worldview vis-à-vis cultural difference.

IDI-This is an abbreviation for the Intercultural Development Inventory. Developed by M. Bennett and Hammer (1998), the IDI is a 60-item psychometrically normed and validated paper and pencil assessment tool based on the DMIS.

Reflection-Reflection is defined by Carter and Gradin (2001) as "the careful ongoing consideration of a subject" (p. 2). This can include the self, as well as other subjects.

Reflexivity - Reflexivity is explained by Qualley (1997) as “a response triggered by a dialectical engagement with the other-an idea, theory, person, culture; text, or even an other part of one's self, e.g., a past life. ... In the process of trying to understand an other, our own beliefs and assumptions are disclosed, and these assumptions, themselves, can become objects of examination and critique" (p. 11).

Transformation-Transformation is defined by Mezirow (1991) as "the process of becoming critically aware of how and why our assumptions have come to constrain the way we perceive, understand, and feel about our world; changing these structures of habitual expectation to make possible a more inclusive, discriminating, and integrative perspective; and finally, making 
Writing in the Contact Zone $\mathrm{xv}$

choices or otherwise acting upon these new understandings" ( $\mathrm{p}$. 167). 


\section{CHAPTER ONE \\ INTRODUCTION: \\ STANDING ON THE BRIDGE}

[Contact zones] refer to the space of colonial encounters, the space in which peoples geographically and historically separated come into contact with each other and establish ongoing relations. . . .A "contact" perspective...treats the relations among colonizers and colonized, or travelers and "travelees," not in terms of separateness or apartheid, but in terms of copresence, interaction, interlocking understandings, and practices.

--Mary Louise Pratt,

"Arts of the Contact Zone"

This thesis celebrates contact zones. As Mary Louise Pratt (1991) defines the term, contact zones are the places where cultures collide; although historically contact zones have been places of war and oppression, contact zones can also be places of transformation and greater understanding. This thesis is a celebration of some of these contact zones as they have happened in the context of one classroom. The students who participated in this thesis research experienced the intercultural encounter of the contact zone to varying degrees; yet, I must not forget my own experiences in the contact zone, for these experiences are the background of this project. My own higher education experience, 
including the choice to pursue degrees in both English Literature and Applied Linguistics; my own transformative encounter with the course assignment I am researching; and my development as a researcher throughout this thesis project-all of these have brought me headfirst into the contact zone. These reflexive experiences have shaped the perspective I bring to my research; therefore, before describing others' experiences in the contact zone, I would like to first describe my own.

\section{Revelations and Beginnings}

I have often thought that the reason I majored in English was because I was rebelling against science. That statement is true, in part. When I graduated from high school in a small town in North Dakota, I knew that my parents wanted me to go to college. Since neither of them has gone to college themselves, I think they hoped I would get a degree in science so I could get a good job, or maybe even go to medical school and become a doctor. Once I got to college, however, I discovered that I didn't really enjoy organic chemistry as much as I thought I would. Struggling against my parents' wishes, I turned to literature, only to discover a whole new world of thoughts and ideas-a new lens with which to see the world and myself. My parents continued to encourage me to try 
science courses, and they were very supportive of my student job in the human nutrition

research lab on campus. Yet, every time I tried another geology or biology course, I found myself daydreaming about literature.

Reading Homer's Iliad and Odyssey challenged me, not only intellectually, but to my very core of being. I began to see myself in a context, to understand that I had a lens. Although I was starting to develop these ways of seeing, when I graduated with my undergraduate degree in English (with more than a few science courses on my transcript), I wasn't any more sure of what college was supposed to mean for me than when I started.

However, after taking a few years off to work, I decided to pursue a master's degree, still not totally sure what getting a master's degree would mean to me. I went back to literature, but I quickly found myself surprised by a longing for some of the more scientific elements that had characterized my education thus far. While in my undergraduate education, I felt forced to choose between my passion for literature and my background in science, as a graduate student I felt more freedom to take the best of both. Searching to satisfy this part of me, I sought out courses in 
linguistics, a field that had been included in my undergraduate English program.

And, while at times these two fields-literature and linguistics-have seemed to be disparate, I have benefited from being in the midst of this contact zone. As a graduate student in both English Literature and Applied Linguistics, I have had the incredible opportunity to study a wide range of texts, which have included nineteenth century American writings such as Margaret Fuller's (1810-1850) poetry as well as stories of the land and sea by Herman Melville (1819-1891); writings by World Englishes theorists Braj Kachru (1982, 1992) and Alastair Pennycook (1994); Romantic poetry by John Keats (1795-1821) and Percy Bysshe Shelley (17921822); and contemporary cultural theories covering such topics as composition studies, feminism, queer theory, Marxism, and postcolonialism. While these theories and texts do not always relate directly to syntax, second language acquisition or phonology, for example, the texts and theories I bring with me have helped me construct an interdisciplinary approach that has afforded me the advantage of seeing things from many dimensions.

In the fall of 1998 , I had my first encounter with yet another contact zone; this time, a contact zone that introduced me to the 
field of intercultural communications and to my current thesis topic. That term, I took Applied Linguistics 571: Culture Learning in the Language Classroom with Dr. Kimberley Brown. The primary assignment for the class was to write an ethnographic essay about another culture. While this essay had a library research component, the majority of the information for the assignment was to come from interviews with a person from the culture we chose (see Appendix A for a copy of the syllabus for the course as well as the ethnography assignment from Applied Linguistics 571). My experience with this assignment was profound. My informant, Su-ho (a pseudonym), was a young Korean male who was an international student visiting the United States for one year. We had established a fairly close relationshipI was his tutor and we had been meeting approximately four times a week for about a month-before I began the interviews.

I approached the assignment with no unusual expectations. I enjoy writing, and the assignment was interesting to me, but I began the process of writing the paper with the same kind of general enthusiasm I bring to any classroom assignment. Initially, I expected that the assignment would be devoid of my own experience; however, through the process of writing, I soon realized 
my own subjectivity, and my essay became focused to some degree on my cross-cultural encounter. My final draft, in which I described how Su-ho had changed my understanding of his culture as well as my own, illustrated this reflexivity, or my transformative encounter with an "Other."

Su-ho, too, was profoundly changed. At the same time we had been doing the interviews, he had been struggling with some issues relating to adjustment to life in the United States, and he expressed to me difficulty in communicating with and understanding Americans he encountered, and he also began to see his own culture in a different way. After I completed the project, Su-ho wrote the following reflections, which he gave me permission to share:

It is not easy that I interview with foreigner about my culture. The reason is that I might mistake to tell the Korean culture incorrectly. But I decided to try because I wanted to help Laurene with her paper.

I had tried to tell everything I know about the Korean culture even though there were bad things. The reason is that they are our realities and that they are ones we should reform.

I have something to tell before writing more and more. The bad things I had told may be 
incorrect, that is, they are just my opinions. Frankly speaking. While I had been being interviewed with Laurene I could make a fresh thoughts about the Korean culture. I had started to tell about my family and I had talked with her about each family's happiness and sadness. While we had been talking, we could understand each different or similar culture. I gave informations about my hometown, and general relationship between men and women in Korea where is mainly the society for men. And I frankly told and asked something I didn't like about American culture. She explained me about it as much as she can. Through this interview I think we have learned each culture that means each literature, language, nationality, foods, and the way of thinking. This interview for almost 2 months, I think was a good way to understand each culture. And I am glad to help Laurene with her paper.

Su-ho and I were both transformed by these interviews. Through our meetings, we discovered similarities in our two cultures that neither of us expected, and we both began to understand American and Korean culture in a way that we had not experienced previously. We both began to understand our positions within our own cultural context more complexly. Although my understanding of the assignment had changed-I no longer felt obligated to write 
only about my informant's experience-I didn't know how to incorporate my cross-cultural experience in an essay about Korea.

At the time I turned in my final paper, I expressed to Dr. Kimberley Brown, the professor, that I wished for the opportunity to have done some process writing throughout the stages of writing the ethnographic essay. I felt like my writing and discovery process had been similar to the models of intercultural learning we had discussed in class. Writing about this process, though, didn't seem appropriate in my ethnography, the product of my efforts. Although I realize that my experience was probably the anticipated outcome of this assignment, I learned from conversations with classmates and Dr. Brown that my experience was not typical. I wondered how the addition of more process writing-both writing at various levels of formality throughout the stages of writing the essay as well as parallel writing about the method of ethnographic research-would influence the experience of a student in such a class. The process that has guided me to answer these questions about the experience of the ethnography project has led me to this thesis.

In concluding this section about my own experience with contact zones, I am reminded of my earlier feelings of uncertainty about the goals of my education. I have spent much of my 
education learning in the dark; that is, gathering in concepts, theories, stories, and data, but not knowing why. Now, as I reflect on these invaluable learning opportunities that I have had, I recognize how transformative my own education has been. Once a naive girl from the plains of western North Dakota, I now see myself as a cultural informant, giving information to people from other cultures trying to understand the culture of the United States and of Oregon. I am also a cultural informant when, as a teacher, I help my students understand academic discourse. And, above all, I now see myself spanning bridges between rural and urban, academe and the autodidactic nature of my family, and science and literature. My education has made me a cultural bridge.

Part of my own commitment to being a cultural bridge has included the desire to learn how others experienced the crosscultural interaction with an informant during the ethnography project. Therefore, the research for this thesis does not focus on my own experience of writing this ethnographic essay assignment; rather, the purpose of this thesis is in knowing about others' experiences with this assignment. To better understand each individual's approach to the project, I crafted process writing assignments, a journal of sorts, to accompany the ethnographic 
essay project with the hope that this combination might trigger reflexivity in the writers. Then, I used ethnographic methods to do a case study of the class, focusing on three students in particular in an attempt to understand their experience with the ethnographic project. Through this thesis, I hope to illustrate a better understanding of the value of ethnographic assignments in preparing pre-service teachers to teach English to speakers of other languages.

\section{Setting the Scene}

Out of my experience with the ethnography project, I learned that culture is at the core of language teaching. In my discussions with Su-ho, we often found that the difficulties he was describing in using English were not related so much to his mastery of skills, such as speaking or listening; rather, he was often puzzled by how English was being used in cultural context. For instance, he told me of his frustration when Americans would apologize, yet seem insincere in Su-ho's eyes. "In Korea," he said, "people mean it when they say 'sorry." He furthered this by telling me that he noticed that people in the U.S. apologize when they are unable to change the situation, but in Korea, an apology is usually followed by some kind of reparation. Yet, Su-ho stated that when he learned 
English, his classes focused primarily on what has been considered the skill areas-listening, speaking, reading, writing, and grammar (Damen 1987) - and not on the cultural aspects of the language that became so important to him during his sojourn here in the United States.

Like Su-ho, students of English around the world need to develop intercultural competence as part of their communicative competence because language is always interwoven with the sociocultural context in which it is produced (Hymes 1971). However, Gayle Nelson (1998) asserts that teachers of English, too, must also be interculturally competent. Noting an increase in both the number of international students studying in American schools as well as immigrants and refugees coming to the United States, Nelson observes the need for domestic teachers of English as an International Language to be interculturally competent.

Furthermore, she also points to the rise in English teaching abroad. In these contexts, teachers "engage in intercultural interactions not only with their students but with many other members of the host culture as well" (p. 18).

Due to the need for intercultural competence in English teaching environments, Nelson considers how Teaching English to 
Speakers of Other Languages (TESOL) programs prepare preservice teachers in terms of intercultural competence. Nelson surveyed 178 master's programs in TESOL. Of these, Nelson found that only about 42 per cent offered intercultural-related courses ( $p$. 26).

Portland State University's Applied Linguistics Program is one of these programs. As part of the requirements for both the master's degree and certificate program in TESOL, students are required to take one four-

credit culture course. This can be Applied Linguistics 471/571:

Culture Learning in the Language Classroom, Speech

Communication 410/510: Problems in Intercultural

Communication, or an advisor-approved course. Most students take either the Applied Linguistics or Speech Communication courses. The research for this thesis is focused only on the Applied Linguistics $471 / 571$ course.

\section{The Course}

Applied Linguistics $471 / 571$ is a Writing Intensive Course (WIC) that is also cross-listed with International Studies. This means that the students may be taking the course for a number of different reasons. They may want to teach, study, or do other work 
abroad. Other students in the course may plan to be teachers in the United States. The course goals reflect the variety of experiences and goals the students bring to the class:

- To become aware of the role that language, values, attitudes, and learning styles play in teaching and learning a second or foreign language.

- To develop a framework for incorporating a culture learning dimension into language teaching.

- To develop an understanding of the problems likely to occur when teaching persons from different cultural backgrounds.

- To investigate and report on another cultural group by carrying out an ethnographic interview project.

- To form a definition of multicultural education that is compatible with the concept of language and cultural diversity as a resource.

- To become familiar with techniques and materials that will enhance development of intercultural competence in ourselves and our language learners. 
To achieve these goals, throughout the class, students are exposed to several theories of intercultural learning. In addition, undergraduate students complete pair demonstrations of culture learning activities that are appropriate for both classroom and business settings. Graduate students meet outside of class to discuss Context and Culture in Language Teaching by Claire Kramsch (1993). All students complete a midterm essay and a book review in addition to their major writing assignment, the ethnographic interview project (refer to Appendix A for the Fall 1999 course syllabus).

The ethnographic interview project, the primary focus of my research, is completed in three drafts. Both the first and second drafts have a not-so-stringent page requirement of three to five pages; the final ethnography has no page limit (in the Fall 1999 class, one final ethnography was eight pages and another one was forty pages!). In the first draft, called The Grand Tour, students are asked to remain general in their focus. For this first draft, students should have already found an informant and completed an initial interview; however, the primary information for the first draft is usually factual country-specific information. In the second draft, students are encouraged to spend more time with their informant. 
The second draft, The Mini-Tour, should focus in on one or two themes that have emerged from the student's interviews with his or her informant. These first two drafts are not graded, but the students get written feedback on them from both the professor and the writing assistant. The final draft, which is graded, asks students to revise the first two drafts into one final paper that discusses a theme that emerged from the interview project.

Reflecting back on my own experience with the ethnography project, I wished that I had been able to document my process as I worked toward the final product of the ethnography paper. It was at this point that my interest and education in composition studies began to spark the development of a research project. My own desire to have kept a journal, or to have done some kind of process writing, as I was working on the project and my beliefs about the kind of transformation that I underwent matched with the theories about the transformative nature of composition furthered by Duncan Carter and Sherrie Gradin (2001) and Donna Qualley (1997), who describes reflexivity as a recursive process of turning back on oneself after encountering an "Other." This was the kind of experience I believe both Su-ho and I had as we came together in 
the contact zone, endeavoring to learn more about each other's culture.

Out of my experience with the course and my own ethnographic interview project and my understanding of composition, linguistics, and cultural studies, I wanted to discover how other pre-service teachers experienced this project. And, I wondered if process writing would help illuminate any resulting transformations. To answer these questions, I decided to do a case study of the class's experience with the project, focusing more specifically on three individuals who graciously allowed me the opportunity to understand their experience more fully. With these issues in mind, I developed the following questions to guide my research:

1. How do pre-service teachers use process writing to make sense of cross-cultural encounters?

2. How does the inclusion of process writing assignments influence the completion of the mini-ethnography project?

3. Is there a difference between graduate and undergraduate pre-service teachers' experience with the miniethnography project? 
4. How does the Intercultural Development Inventory (IDI) further illustrate pre-service teachers' experience with the mini-ethnography project, particularly in terms of intercultural competence?

5. What role does my research project play in the case study volunteers' experience with the mini-ethnography project? In the remaining pages of this thesis, I will endeavor to answer these questions.

As I described in the beginning of this chapter, my own education has involved learning to balance my scientific and artistic self. In many ways, this thesis illuminates that struggle. While I have chosen qualitative methods, such as using ethnographic techniques to do a case study, I also feel limited by the scientific in describing the experiences of the individuals whose lives and education I've been privileged to get a glimpse of. Like Ralph Cintron (1993), I wonder how the "generic form. . .sections titled 'Methods,' 'Discussion and Implications,' 'Conclusions' and the like-adequately deliver new information" (p. 406).

In recognition of these tensions between science and art that have risen to the surface of both my own education and the expression of this research project, I would like to acknowledge the 
double-voiced quality of my writing. Kramsch (1993) writes that double-voiced discourse is the ability to both serve one's own agenda as well as pay attention to the voice of the other. In describing the experiences of others, I have tried to unmask my own subjectivity while simultaneously respecting the voices of Cleo, Phillip, and Bob (all pseudonyms, of course), my case study informants.

Similarly, I have chosen to forego the clinical sounding term, "case study." Instead, I will refer to the individual representations of Bob, Cleo, and Phillip as "portraits." Sara Lawrence-Lightfoot and Jessica Hoffman Davis (1997) use this term to describe what might also be thought of as case study. Portraits, though, are "designed to capture the richness, complexity, and dimensionality of human experience in social and cultural context, conveying the perspectives of the people who are negotiating those experiences" (p. 3). In this way, they represent the dialogue that has taken place between Bob, Cleo, and Phillip and me, while also acknowledging the interpretive responsibility on my part. Similarly, in the chapters that describe these individuals' experiences, I have chosen to integrate the data I have collected from them with my own interpretations. 
In keeping with the scientific method, however, I am maintaining the standard format of presentation with only one modification. In the following chapter, the Review of Literature, I lay the theoretical foundation that has guided me thus far. In Chapter Three, I will detail the methods I used. This will include a description of the ethnographic techniques I followed as well as an overview of the types of data I collected. In Chapter Four, I will present a brief portrait of the class as a whole. Due to the complexity of their individual experiences, I have allotted one chapter each for the portraits of Bob, Cleo, and Phillip, respectively. Finally, I tie things together in Chapter Eight, offering a final discussion of this project, and concluding with applications of ethnography to both teaching and learning environments. Throughout each of these chapters, I hope to extend both the scientific and the artistic expressions that have characterized my own experiences in the contact zone. 


\section{CHAPTER TWO}

\section{ENTERING INTO THE CONTACT ZONE:}

\section{REVIEW OF LITERATURE}

In approaching this review of literature, I am once again drawn to Sara Lawrence-Lightfoot, who writes that the portraitist enters the setting with a perspective, a framework, and a guiding set of questions that are the result of her previous experience, her reviews of the literature, and her conceptual and disciplinary knowledge. Before she embarks on data collection, she tries to articulate the contours of this framework, discern her anticipatory schema, and register her preoccupations. This is an early selfreflective, self-critical exercise that increases her consciousness about the lens she brings to the field. (p. 213) In the previous chapter, I described how my own experience with the ethnography project sparked my passion for discovering how other students understand the project. I also presented my guiding questions. These are only two parts of the context of my research. As Lawrence-Lightfoot advises, before I could begin my work in the field, I had work that had to be done in the library, including defining the terms that are central to my work, such as culture, 
reflexivity, and transformation. In addition, I must explore similar work that others have completed; the meaning they have gathered will help me frame my own expectations.

My work in the library has been in yet another contact zone. The terms I'm defining and the established research I'm exploring exist in spaces of ideological collision, not to mention on different floors of the library. Culture, for example, has had one set of meanings to [social] science and another to art [literature]. I haven't necessarily felt like I've had to settle on one definition from one discipline, but rather, my task has been to understand the tensions among definitions. And, ultimately, I have tried to locate what these terms mean in the context of my project.

This review of literature reflects the interdisciplinary nature of my research, incorporating information from a variety of fields, including anthropology, linguistics, composition studies, and communication studies. In consideration of the range and breadth of the topics covered here, a roadmap is in order. Therefore, in this review of literature, I begin by defining the term that is at the core of my research: culture. Expanding on that term, I then describe my understanding of cross-cultural experience. This is followed by a detailed discussion of the Developmental Model of Intercultural 
Sensitivity (DMIS), a model created by Milton Bennett (1993) to explain how people experience cultural difference. This model is one of the theoretical foundations for my research, and I have devoted some time to discussing it, as well as the Intercultural Development Inventory (IDI), the assessment tool based on the DMIS. Following an explanation of the IDI, I turn to three other terms central to my research: reflection, reflexivity, and ethnography. I explore ethnography in a variety of contexts, including how it relates to reflexivity and education. Stressing the connection between reflexivity and composition, I turn to understanding theories of composition as well as methods of composition research, and more specifically, composition research. Finally, I conclude this review of literature by investigating the notion of transformation and its connection to adult learning. In all of my library explorations that are reported here, I have found points of convergence as I have spanned the boundaries of academic disciplines.

\section{Culture and Cross-cultural Experience}

My initial library explorations began with the term "culture." While I haven't necessarily approached understanding my informants' experiences as a cultural one (although they certainly are representatives of the student culture), the focus of the 
ethnography project on culture and cross-cultural experience led me to begin here.

"Culture" redefined within the context of language teaching has been a recent project of TESOL educators. Atkinson (1999) has extensively reviewed the views of culture in TESOL to move beyond not only uncritical views of specific cultures but also limited views of culture as such "big C" artifacts as architecture, poetry, and drama. Atkinson draws on interdisciplinary notions of culture to establish six principles of culture:

1. "All humans are individuals" (p. 641). Atkinson states that this principle is a crucial reminder that focusing too much on culture and not on the individual can lead to reductive stereotypes.

2. "Individuality is also cultural" (p. 642). On the other hand, humans "are individuals in context" (p. 642), and knowing something about a person's social group can help reduce uncertainty.

3. "Social group membership and identity are multiple, contradictory, and dynamic" (p. 643). This principle relates to our capacity to belong to more than one group at a time. 
4. "Social group membership is consequential" (p. 645). Here, Atkinson refers to the idea that becoming a member of a group is a process.

5. "Methods of studying cultural knowledge and behavior are unlikely to fit a positivist paradigm" (p. 646). Because culture is context-based, we cannot remove people from their context/culture to study them. Naturally, this principle provides support for my own choice of a ethnographic case study.

6. "Language (learning and teaching) and culture are mutually implicated, but culture is multiple and complex" (p. 647). In this principle, Atkinson problematizes the notion that language teaching is culture teaching. He is not arguing against teaching culture in the language classroom, as he states that language and culture are inextricably intertwined. Rather, he is observing the challenge of the language teacher.

Atkinson's principles of culture have framed the term within the context of language teaching, and they have implications relevant to my own findings. I will return to his discussion in Chapter Five. 
In the meantime, in framing "culture" in the context of my own project, I have looked for a definition more interdisciplinary in focus. I'm drawn to Raymond Williams' (1958) statement that "culture is ordinary" (Williams p. 4). Uncovering the day to day differences among us all is the emphasis of the ethnography project, and the definition that seems most appropriate.

Searching for a more formal definition, I turn to composition teachers and researchers working in the field of ethnographic writing. Drawing on the work of anthropologists, Chiseri-Strater and Sunstein (1997) define culture as "an invisible web of behaviors, patterns, rules, and rituals of a group of people who have contact with one another and share common languages" (p. 3). This definition alludes to what Milton Bennett (1998) refers to as subjective culture--the ordinary stuff of our daily experience, with a focus on what defines one group as different from another group rather than the institutions created by a culture (also referred to as objective culture) (p. 3).

Individuals from different cultures can have a variety of contact experiences: Dallmayr (1996) provides a framework for understanding these interactions. He suggests seven modes for cross-cultural encounters. The first of these possibilities, 
"conquest," has been generally associated with colonial expansion (p. 3). "Conversion," the next of these modes, can often but doesn't necessarily have to accompany conquest (p. 9). "Assimilation" and "acculturation" can be a different outcome of conquest. Dallmayr defines these two terms in relation to an ideology of power:

While assimilation is usually applied to policies in some Western or Westernizing nations, the term acculturation tends to have a broader and more indefinite application, extending from domestic contacts to global interactions between the hegemonic Western culture and developing non-Western societies. (p. 14)

In addition, Dallmayr asserts that neither of these-assimilation and acculturation-must necessarily be fully realized; rather, partial assimilation, or cultural borrowing, may also occur (p. 18). One example of cultural borrowing given by Dallmayr is the adoption of pagan traditions by Christianity (p. 19). In contrast to cultural borrowing, different cultures sometimes choose to live parallel, separate identities. Dallmayr calls this mode "liberalism and minimal engagement" (p. 24). In opposition to this term, however, is conflict and class struggle, the mode that Dallmayr observes is often the result when more than one culture must compete for the same 
scarce resources (p. 28). Finally, Dallmayr suggests that another mode of cultural encounter is "dialogical engagement," which he considers the most genuine because of its commitment to communication between cultures (p. 31). Ethnographic writing that encourages reflexivity is located within this intercultural mode of dialogical engagement.

Another theorist who describes cultural encounter as a dialogical engagement is Claire Kramsch (1993). She suggests that in any cross-cultural event, there is a kaleidoscope of both facts and realities, which can be brought together in a number of different combinations. She illustrates this set of reflections through a figure representing two sets of concentric circles, given below in Figure

2.1.
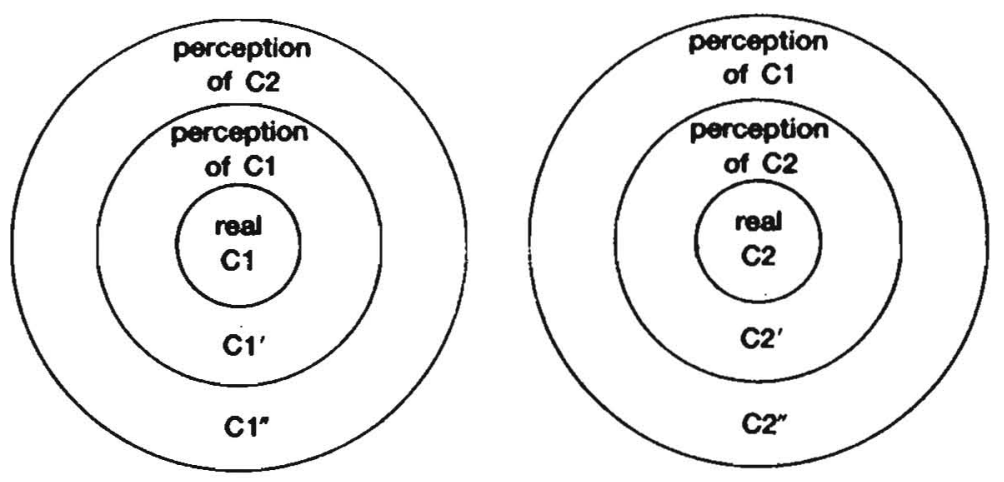

C1' $=$ C1 perception of self $\mathrm{C1}^{\prime \prime}=\mathrm{C1}$ perception of others C2' $=$ C2 perc3ption of self $C 2 "=C 2$ perception of others

Figure 2.1 Kramsch's Model of Cultural Reality and Cultural Imagination 
Kramsch suggests, for example, that a German learner of American English (C1) has an image in her head of the United States ( $\mathrm{C} 1$ ") that is influenced by certain German understandings of the United States. This may be far from what a United States American has as an image of herself (C2) or even further from the real C2 (p. 208). Thus, for a German learner to discover what others think of her German culture can be enlightening. In addition, the German learner may be surprised to discover how US-Americans characterize their own US-American culture.

\section{The Developmental Model of Intercultural Sensitivity}

While Dallmayr describes possible approaches of crosscultural encounter, and Kramsch looks at the complex set of possibilities related to cultural understandings and misunderstandings, Milton Bennett (1993) theorizes about what how cross-cultural encounter shapes an individual's worldview. Milton Bennett's model, the Developmental Model of Intercultural Sensitivity (hereafter referred to as the DMIS), which is based on a constructivist paradigm, focuses on people's response to cultural difference (p.24). The model is based on stages, although he cautions that movement between stages should not always be seen as linear. He describes three ethnocentric stages and three 
ethnorelative stages, and along with these descriptions, he also suggests interventions appropriate for people in that stage. See Figure 2.2 below for a visual description of the DMIS. As this model provides a substantial theoretical foundation for my research, a full description of the model here will provide necessary insight for understanding subsequent discussions of the model as it is used to describe Bob, Cleo, and Phillip.

The first of the three ethnocentric stages, denial, is characteristic of a person who pays little, if any, attention to cultural difference. People in this stage can be isolated or choose to

\section{EXPERIENCE OF DIFFERENCE}

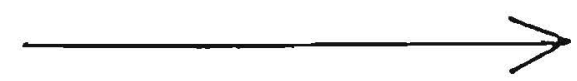

\section{DEVELOPMENT OF INTERCULTURAL SENSITIVITY}

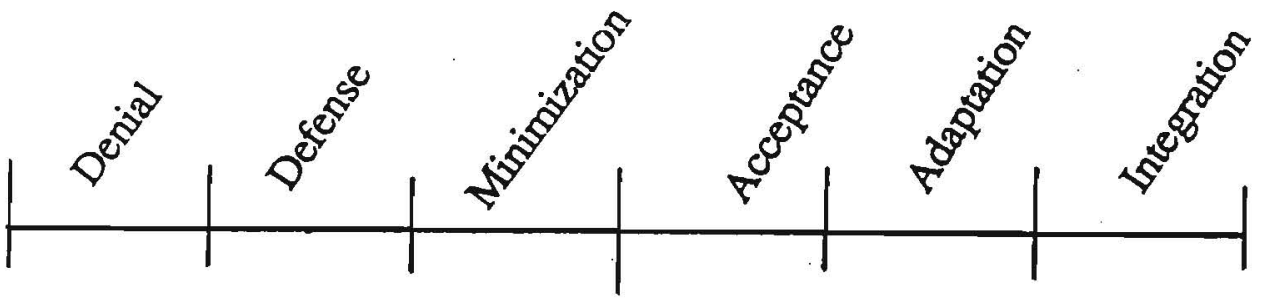

\section{ETHNOCENTRIC STAGES}

ETHNORELATIVE STAGES

Figure 2.2 The Developmental Model of Intercultural Sensitivity 
separate themselves from other cultures. Because people in this stage do not have categories for understanding difference, they don't experience cultural difference. Bennett suggests that people in this stage may state that "all Asians look alike," for example (p. 31). For people in this stage, Milton Bennett recommends introducing them to "cultural awareness activities" with the primary purpose of recognizing difference (p. 38). "Foods, flags and festivals" has its purpose here.

Once a person becomes aware of difference, he or she often begins to feel uncomfortable with these differences. Defense, the second ethnocentric stage, acknowledges this tension. In this stage, people respond negatively to cultural difference, either by denigrating other cultures or declaring their own culture to be superior (pp. 35-37). Another possible response in this stage is what Milton Bennett terms "reversal": "a denigration of one's own culture and an attendant assumption of the superiority of a different culture" (p. 39) ; this response is most common in the case of long-term sojourners. In order to move people out of defense, a facilitator would want to focus on the "commonality of cultures in terms of what is generally good" (pp. 40-41). This is particularly important because pushing a person in this stage too far will most 
likely result in a retreat back to defense rather than movement forward, to minimization.

The third and final stage of ethnocentrism is minimization, "an effort to bury difference under the weight of cultural similarities." At this stage, cultural differences are acknowledged and not negatively valued, but the focus is on similarity while difference is ignored. People in this stage may believe in physical universalism-that is, that we all have the same biological needs ( $\mathrm{p}$. 42)-or transcendent universalism-that we are all subject to the same spiritual laws, for instance (p. 43). Movement out of minimization is impeded by a "paradigmatic barrier" according to Bennett. He states that a person must make a "conceptual shift from reliance on absolute, dualistic principles of some sort to an acknowledgement of nonabsolute relativity" (p. 45). Oftentimes, a greater awareness of one's own culture is what is needed to make the shift to an ethnorelative perspective.

The first ethnorelative stage, acceptance, is characterized by acknowledgment and respect of cultural difference (p. 47). In this stage, people generally have respect for both behavioral and value differences, yet people do not usually know how to put their beliefs 
into action. At this point, an appropriate intercultural activity might be a simulation (p. 51).

In the second ethnorelative stage, adaptation, people continue to internalize respect for other cultures while building skills for engaging positively in cultural difference (p. 52). Milton Bennett suggests that these new skills are acquired in an "additive process" such that one can maintain his or her own worldview while engaging in another culture (p. 52). To be successful in this stage, a person must possess both empathy, "the ability to experience differently in a communication context" (p. 53) and pluralism, which includes both the commitment to the belief that difference exists and the internalization of multiple frames of reference (p. 55).

People who are in this stage have a strong desire for intercultural interaction, and Bennett suggests that activities in this stage should be relevant to people's day-to-day experiences (p. 58).

While Milton Bennett maintains that adaptation is, for many people, "good enough," a final ethnorelative stage, integration, describes people whose worldview has synthesized multiple frames of reference. People in this stage will often evaluate difference by context (pp. 60-61). Additionally, they will often see themselves as what Janet Bennett (1993) describes as a "constructive marginal": 
"someone who operates outside of normal cultural boundaries." This type of person is in contrast to what Janet Bennett (1993) terms an "encapsulated marginal." While an encapsulated marginal feels "alienated, troubled by ambiguity, and never at home" (p. 113), the constructive marginal is "intrigued by complexity and never not at home" (p. 113). While Milton Bennett (1993) suggests that the integration stage and constructive marginality are the final stage of his model, he advises that a person in this stage is, of course, not at the end of the learning process (p. 65).

Application of the DMIS has extended quite naturally to learning. Following the support for tailoring the content of intercultural trainings to both the learning styles and comfort levels of the group as advocated by Janet Bennett (1993) and William Gudykunst, Ruth Guzley, and Mitchell Hammer (1996), Milton Bennett asserts the DMIS's practicality in tailoring training/educational activities to a group's profile according to the DMIS. More specifically, Gayle Nelson (TESOL 2000) asserts that introducing "foods, flags, and festivals" is appropriate to students characterized by the denial stage, while cross-cultural simulations and projects like the mini-ethnography project are more appropriate for students with worldviews presented in the ethnorelative stages. 
Finally, Janet Bennett, Milton Bennett, and Wendy Allen (1999) suggest a connection between a language learner's intercultural competence and their competence as a language learner. In recognition of the gradual process by which a person moves through the stages, they recommend stage appropriate language learning activities.

Research studies using the DMIS have been limited. Turner (1991) used the model to describe the experience of United States American expatriates in Kuwait. Yamamoto (1994) looked at Japanese students' experiences in the United States. However, since these initial studies, Milton Bennett and Mitch Hammer have developed an instrument by which to measure a person's position on the DMIS.

\section{The Intercultural Development Inventory}

This instrument, the Intercultural Development Inventory (1998), is a 60-item psychometrically normed and validated paper and pencil self-assessment tool based on the DMIS. Bennett and Hammer describe this connection further:

[T] $T$ he IDI is a measure of the primary constructs identified in the developmental model. As such, the IDI both contributes to further refining the developmental model as well as 
providing an empirical method of assessing or profiling respondents in terms of their general orientations toward cultural differences that are identified in the model. (p. 19) The IDI presents a set of unidimensional scales that measure both ethnocentric and ethnorelative stages in the DMIS. However, the IDI in the version used for this research does not account for the final ethnorelative stage, integration. Instead, the IDI divides the Adaptation stage into Cognitive and Behavioral Adaptation. A more recent version (2001) includes the Integration stage as part of the measurement; however, this version was not available at the time of my data collection.

Due to the relatively recent development of the IDI, this instrument has been used in very few research studies. One recent study, conducted by Young-kun Park (2001) is worth mentioning. Park used the IDI as a pre- and post-test with Japanese students on a short-term study-abroad program in the United States. Park used the results from the IDI to assess the effectiveness of direct instruction of American culture on increasing students' intercultural competence. Her results suggest that direct instruction did support the students' slight increase of intercultural competence. Although Park's study examines the context of 
language teaching, little research is available on the development of teachers' intercultural competence, especially that of using the IDI. While research is one use for the IDI, and training is perhaps the most common use for the instrument, one other purpose of the IDI is for personal reflection. Milton Bennett (1993) suggests that reflection is what is needed in moving through the ethnorelative stages, and he argues that this is particularly difficult due to the fact that few cultures place much value on the art of reflecting (p. 53). Personal reflection is the primary reason for including the IDI as part of the course goals for the culture learning class. By taking the IDI at the beginning and end of the course, students can better understand themselves and their intercultural competence.

Similarly, the IDI has helped me create a picture of Cleo, Bob, and Phillip, although I have relied more on other types of data, such as personal interviews and writing samples, in creating the portraits of these three individuals.

\section{Reflection and Reflexivity}

Perhaps composition theorists and textbook authors Duncan Carter and Sherrie Gradin (2001) define reflection best when they term it to be "the careful, ongoing consideration of a subject. . . .To reflect on something," they continue, "is to focus your attention on 
it, to play around with it in your mind, perhaps to analyze it, perhaps to think about its significance or how it connects to other things. ...” (p. 2). Similarly, Jack Mezirow (1991) states that reflection is a crucial element in adult education. He distinguishes reflection, a method of cognitively organizing information, from introspection in that reflection requires a critique (p. 15)

While Mezirow sees reflection as a crucial step in the process of perspective transformation, which will be discussed at length later in this chapter, Carter and Gradin view reflection as a step leading to reflexivity. Simply put, Carter and Gradin suggest that reflexivity involves "learning to see yourself and your culture through the lens of another culture" (p. 5). Examining reflexivity in more detail, they call on their colleague, Donna Qualley, quoted here:

Reflexivity is a response triggered by dialectical engagement with the other-an idea, theory, person, culture, text, or even an other part of one's self....By dialectical, I mean an engagement that is ongoing and recursive as opposed to a single, momentary encounter. In the process of trying to understand an other, our own beliefs and assumptions are disclosed, and these assumptions, themselves, can 
become objects of examination and critique (p. 11).

This reflexivity is at the heart of my research, and a term that I want to dwell on. I have explored the concept of reflexivity at length, beginning with its roots in anthropology and ethnography. In the true recursive spirit of reflexivity's definition, I turn back to Donna Qualley for expansion on her definition as well as additional connections to ethnography, the composing process, and composition as a discipline.

\section{Ethnography and Reflexivity}

Crapanzano (1986) likens ethnography to translation, particularly in that both can only be provisional. The ethnographer is an interpreter who "presents languages, cultures and societies in all their opacity, their foreignness, their meaninglessness; then like the magician, the hermeneut, Hermes himself, he clarifies the opaque, renders the foreign familiar, and gives meaning to the meaningless" (p. 50). Because the ethnographer is always interpreting something that Crapanzano defines as "foreign," the ethnographer has the dilemma of making tentative, mediated meanings sound definitive. In this definition of ethnography, the researcher maintains an authoritative position as a scientist. 
While other anthropologists have acknowledged that ethnography might consider objectivity to be a goal, they also recognize that the research process calls objectivity into question. Lenclud (1996) wonders about the connection between cultural differences, as described by an anthropologist, and the presentation of these differences as "fact" (p. 7). However, Lenclud suggests that the positioning of cultural differences-which he argues may not actually be so different-as fact is fused to values. But, Lenclud concludes, somewhat abruptly, that the observation of the interrelationship between fact and values does not oblige an anthropologist to commit to exclusive subjectivity.

In contrast, Kleine (1990) raises the question of the difference between the obvious and the hidden agendas of doing ethnographic research. He suggests that the obvious answer to the question of "what exactly, do we know when we do ethnography?" is that it leads to a greater understanding of the individual or group of individuals that are the subject of the ethnography (p. 117). However, Kleine argues that since ethnography is no longer considered to be firmly rooted in an arhetorical, scientific, positivist paradigm, researchers must question their own assumptions about what they know and what they think they are actually studying (p. 
118). Kleine is pointing to the reflexivity that accompanies ethnographic research.

Reflexivity, a critical and transformative turning backward on the self after an engagement with an "Other," has been frequently described by anthropologists. Reflexivity is usually described in terms of ethnography, as the anthropologist/researcher studies a different cultural group. Turner (1982) describes the constructed nature of the ethnographic account, which puts the researcher in a state of "in-betweenness." Turner writes that

the liminal period is that time and space betwixt and between one context of meaning and action and another. It is when the initiand is neither what he has been nor is what he will be. Characteristic of this liminal period is the appearance of marked ambiguity and inconsistency of meaning. (p. 113) Koepping (1998) discusses both the subjectivity and ethics of writing the experience of others. Koepping suggests that part of reflexivity is the inherent subjectivity involved in ethnography: a researcher can never escape the "participant-observer paradox." Koepping explains the contradiction in anthropological writing:

We may try to be faithful to the original and we may strive to 
adjust the found truth and translate it into our idiom (or stick to a hopeful re-construction of the original truth), but interpretation is always removed by several steps from its experiential setting. (p. 7)

Koepping acknowledges the recognition of the researcher's own subjectivity as well as the constructed nature of ethnography, which is the culmination of the genuine engagement with an "Other."

Sunstein (1996) defines ethnography as a dialogical process that "refers to both the procedure and the product of our research" (p. 179). Furthermore, she suggests that ethnography involves performance between the researcher, the informants, the texts, and the readers:

Ethnography is the relationship between what goes on in a culture and how it appears on the page, a relationship dependent as much upon writers' lenses and tools as it is on those of a researcher....ethnography must describe culture through the perspectives and words of those inside...as well as outside. (p. 179)

Sunstein also observes that reflexivity is crucial to the performance of fieldwork, the mediated experience of collecting and processing data. She suggests that reflexivity is positioned between the data, 
which refers back to the informant, and the written product, which refers forward to the reader. Reflexivity, then, is the "presence [of] monitoring our assumptions, our emerging theory, and our changing questions" (p. 191).

\section{Ethnography and Education}

Ethnography as a method of research has crossed the boundary from its origins in anthropology and has found applicability in a variety of education settings, including the teaching of social work (Lee, M. \& Green, G., 1999), Writing Centers (Neuleib, J. and Scharton, M., 1994), composition programs (as discussed below), and foreign language classrooms (RobinsonStuart, G. and Nocon, H., 1996), among others. Most interestingly, ethnography has also been used in classroom-based situations with students (as in the mini-ethnography), including with secondlanguage learners as described by Liebman, J. (1988), and in conjunction with study abroad programs, as Jurasek (1995) explains.

Tice (1998) notes that education in any content area can be considered a "border crossing," or cross-cultural encounter. Border crossings are not limited to curriculum that focuses on intercultural or multicultural awareness (p. 43). Such a pedagogy that would 
allow students to become conscientious citizens was previously advocated by John Dewey, according to Fishman and McCarthy (1998); furthermore, Dewey promoted experiential learning that was grounded in genuine student interest. An ethnographic essay assignment, in its focus on reflexivity, can be one experiential assignment to create cross-cultural transformation.

Lee and Greene (1999) observe that reflexivity is a crucial element in the development of the self: "A person's sense of self...is socially constructed....a person defines her or his self by reflexively becoming an object of one's observations" (p. 3) of imagining oneself in the gaze of another person. In a social work education setting, the authors engage students in a social constructivist (the notion that knowledge is not located within an individual but rather created through interaction with others) curriculum that builds students' understanding of how culture and society help form an individual's self definition. Central to their pedagogy is a destabilizing of their role of instructor as all-knowing. Rather, Lee and Greene focus on curiosity and dialogical interaction, primarily through conversation.

While dialogical interaction frequently means conversation, it can also include composition. Qualley (1997) advocates for a 
reading and writing pedagogy in a composition classroom that involves not only dialogical interaction between teacher and student but also between students and other students. Reading, writing, and engaging with other members of the class results in reflexivity. Qualley attributes the value of reflexivity to the fact that it "separates the critical thinker from the critic, and distinguishes the skeptic from the cynic. Critics and cynics do not see the need to identify or examine the assumptions that form the basis of their critique. They are simply the agents of that critique, never the subjects. The genuine critical thinker is reflexive, self-critical as well as critical..." (p. 17).

Qualley not only advocates the connection between composition studies and reflexivity, she describes methods for classroom implementation. For example, she argues that merely introducing an "other"-such as a multicultural text-into a class does not necessarily mean that students are engaging with the text. In addition, teachers must present opportunities for students to be both receptive and tentative. She reminds readers that the English word "essay" comes from the French root word for "to try;" essays do not necessarily require an objective conclusion. Rather, Qualley promotes writing assignments that give students opportunities to 
open themselves to a view of the "Other." In addition to reading and writing, Qualley also advocates dialogue and collaboration as pathways to reflexivity.

While the research for this thesis focused specifically on ethnography in terms of reflexivity, other forms of writing-even other forms of communication-can, of course, lead to reflexivity. As Qualley observes, dialogic engagement may take place with different parts of oneself. Naturally, journaling, freewriting, and essay writing are likely places of reflexivity. However, ethnography is an obvious choice for the promotion of reflexivity because the "Other" is a cultural one.

\section{Theories of Composition}

Qualley's incorporation of reflexivity into her classroom methodology is not surprising considering the shift in composition theory and pedagogy that has been occurring over the past twenty years or so. Early models of composition focused on product; this "current traditional" (Faigley, 1986, p. 527) model, which emphasized outlining before writing, correcting grammatical mistakes, and teaching specific formats, such as exposition, description, narration, and argumentation, has been the predominant model for composition throughout this century. 
Faigley (1986) observes a possible paradigm shift in composition studies in response to a lack of theoretical research in the field: "Paradigm, pre-paradigm, or no paradigm, nearly everyone seems to agree that writing as a process is good and 'current-traditional rhetoric' is bad. It would seem, therefore, that any disciplinary claims must be based on some shared definition of process" (p. 527).

Faigley points to three different types of process-based composition: expressivist, cognitivist, and social epistemicist. Expressivism was made popular by Elbow(1981), who, in his Writing With Power, offers process techniques that emphasize creativity and spontaneity through writing personal narratives. Elbow suggests that writers should think of writing as an organic, developmental process in which you start writing at the very beginning-before you know your meaning at all-and encourage your words gradually to change and evolve. Only at the end will you know what you want to say or the words you want to say it with. (p. 15)

Although Elbow is not the first to mention freewriting, he advocates it as part of the discovery process of writing. 
Another type of process writing, known as the cognitive view of writing, attempts to locate underlying universals of the composing process. Emig (1971), an early cognitivist in the field of composition, introduced the research paradigm, as she incorporated "think-alouds" and case study techniques in an attempt to define the composing process (Faigley p. 533). Other researchers, including Flower and Hayes (1980) have searched for links between cognitive psychology and the composing process.

Finally, other composition theorists have sought to locate the composing process within a social context. Faigley explains the social view of composition, often referred to as social epistemicism:

It rejects the assumption that writing is the act of a private consciousness and that everything else-readers, subjects, and texts-is "out there" in the world. The focus of a social view of writing, therefore, is not on how the social situation influences the individual, but on how the individual is a constituent of a culture. (p. 535)

This social view of composition can take a number of approaches. For example, Bizzell (1993) discusses the importance of demystifying academic discourse in the writing classroom. Berlin (1996) advocates a Marxist approach to composition that breaks 
down some of the disciplinary divisions between composition, literature, and cultural studies to place composition pedagogy within the frameworks of cultural studies and rhetoric. Taking a much different process approach, Murray (1998), in part, advocates revision not only as part of the writing process, but as a life activity. Murray writes that

when we revise we do not so much revise the page as revise our thinking, our memory, ourselves-who we are. The words we revise stand for something. They are not blank checks but stand for what we think and what we believe and what we care about and how we see the world. (p. 1) Of course, this definition of revision is not so different from Qualley's notion of reflexivity.

While all three of these process approaches have been seen as separate, Gradin (1995) argues for dissolution of the process categories in writing instruction. Gradin reconfigures these categories, arguing for a social expressivist approach, which combines both personal and academic writing as well as an emphasis on both social awareness and social action. She writes that teachers must aid students in realizing their individual responsibility: 
A better world may become a reality through socialexpressivist rhetorics and teaching philosophies that celebrate self-discovery, personal experience and the experience of others, empathy and awareness, and the imagination as well as reason. (p. 166)

For Gradin, rhetoric becomes the central focus of composition (and academic) pedagogy.

\section{Composition Research}

In his monumental work, Steven North (1987) surveys the practice of research in the field of composition. North examines the process of professionalization that has been only recent in the history of composition, and he posits that research in the field has been part of this process. In the field of Composition [North's emphasis], North describes three groups: the Practitioners, the Scholars, and the Researchers. While he appreciates the historical role they have played in the shaping of the field of composition, North finds fault with the Practitioners, for relying solely on experience, and Scholars, for relying exclusively on theory. North turns to the third group, the Researchers, to suggest that they have blended both theory and practice and this synthesis has encouraged the professional status of Composition. 
Composition research's evolution has followed a path similar to that of composition theory, and current research also tries to blend the personal, the cognitive, and the social in that composition research positions itself as a collaborative form of research (Mortensen \& Kirsch, 1996, p. vii). Composition research scrutinizes the researcher and the subject, the self, the text, and the context in an attempt to acknowledge the socially constructed nature of language, identity, and writing. As such, this research maintains that a researcher has an ethical responsibility to confront these interacting contextual factors by acknowledging the lens of the researcher, bringing together the personal with the professional. Sunstein (cited in Mortensen and Kirsch, 1996) explains the complexity of this ethical position: "Our guilt, our art, and our scholarly rigor are both professional and at once a dilemma and a delight" (p. xiv). Sunstein is acknowledging the reflexivity that must accompany research in composition studies.

Composition research, like anthropological research, has a close relationship with reflexivity. Sunstein (1996), Sullivan (1996), and Qualley (1997) discuss the relationship between reflexivity and writing, particularly in terms of research in composition studies. Sullivan explains that ethnography and reflexivity cannot be 
separated when the focus of the ethnography is writing communities. Similarly, Qualley describes reflexivity in the context of her own experience, first as an expatriate teacher living and working in Australia, and later, as a teacher in the United States as she develops a pedagogy designed to use reading and writing to develop reflexivity in her students. Focusing primarily on research, Sunstein observes that the process of fieldworking invokes reflexivity:

The data collection refers back to the 'other,' our informant, and forward toward another 'other,' the reader. But as we do it we must retain a reflexive presence-monitoring our assumptions, our emerging theory, and our changing questions. . .we must own up to our own position as mediators between the field site and the text. (p. 191) Reflexivity on the part of the researcher establishes the validity of the study. While this type of ethnographic work acknowledges its own constructed nature, reflexivity, in part, helps define the elements that mediate the construction of knowledge.

Furthermore, Sewell (1997) observes that because reflexivity is a natural outcome of composition research in that it involves working closely with other people through ethnographic and case 
study techniques, researchers must be trained to be prepared for the effects of reflexivity. Composition researchers study the familiar, with whom complex relationships are developed. In the nature of the relationship between researcher and subject, Sewell sees the potential for the breakdown of trust if the researcher presents her or his results in a manner that is not respectful to the subject (p. 52). Sewell concludes by arguing that researchers should conceive of reflexivity as mindfulness: "a position in which researchers-amidst piles and boxes of data-keep the needs, fears, and anxieties of research participants always in mind" (p. 52). Similarly Fishman and McCarthy (1996) assert that the production of the research text must account for the representation of the diverse voices that initiated the research experience, the negotiation process between the researcher and informants, and the evolution of the research design (p. 155). Researchers must take on the responsibility of allowing engagement with the "Other" - the research subject-to influence every stage of the research process. Researchers must ultimately admit that the research text is a socially constructed one.

Furthermore, researchers must also acknowledge their position of power, which can be accomplished in part by trying to 
legitimate the research text, the narrative told about the subject.

Newkirk (1992) suggests this can be done by including the "polyvocality" of the fieldwork data, which means to "allow discordant voices into the account, voices that complicate the moral judgments readers will make" (p. 148). In addition, Mountford (1996) points to methodology that works to legitimate the research text. She advocates that the researcher be aware of his or her physical presence in the fieldwork environment, be thoughtful of the subject's expectations (p. 218), notice moments when the researcher doesn't connect with the informant as well as moments when they do (p. 219), and use the words of the informant in the research text as much as possible (p. 221). Thus, researchers must not only be aware of their position of power in the research setting, they must also employ a methodology that destabilizes that power in order to construct a legitimate research narrative.

\section{Classroom-based Composition Research}

While classroom based research is a common phenomenon, and numerous classroom-based studies have been published, two studies stand out as examples with respect to composition research in content based instruction: Chiseri-Strater (1991) and Fishman and McCarthy (1998). 
Chiseri-Strater's classroom ethnography follows two students beginning in their composition classroom with instructor Qualley. Chiseri-Strater describes the writing classroom in terms of a process-based, collaborative environment where students work in small writing groups to complete a group writing project. ChiseriStrater looks at how two students in particular incorporate classroom freewrites and journals with their own private writing as they move to classes in their content areas.

Similarly, Fishman and McCarthy (1998) conduct a classroom based research study to discover how students make sense of the content area-philosophy-through classroom interaction and writing assignments. In this case, McCarthy acts as the researcher and Fishman as the content teacher as the two model a collaborative research design. In response to a Writing Across the Curriculum (WAC) seminar, Fishman invited McCarthy into his classroom in an effort to improve his pedagogy. Ultimately, the techniques Fishman employs-such as question letters (see Appendix 2), audiotaped responses to students, and a focus on the writing process-stem from Fishman's own interest in Deweyan pedagogy. These tools, though, spark in the students a commitment to the Deweyan principles of courage, interest, and 
concern for community. As students foster these principles, we as teachers hope they may also be transformed.

\section{Transformation}

I have saved the discussion of the key term, transformation, for the end of my literature review because I believe this term is the thread that connects everything thus far. Transformation is a primary goal of education, a result of cross-cultural encounter, the tenet of the development of intercultural sensitivity, the result of the experience of reflexivity, an occurrence in the writing process, and a common side-effect of research. Transformation happened to me when I completed the ethnography project some years ago, and transformation has been occurring again as I finish this research.

In making the connection between the concepts described above and that of transformation, I turn to Taylor, whose (1994) research on intercultural learning serves to illustrate the connections among these concepts and terms. From his interviews with adults who had an intercultural experience (living in another culture for at least two years), Taylor describes a process of transformative learning that begins with a moment of "cultural disequilibrium" (p. 169). These are times when a person is "thrown off balance" because his or her way of doing something is 
challenged. This is the kind of contact with an "Other" that reflexivity describes. In response to this moment, Taylor suggests that in order for the experience to become transformative, the person must achieve some awareness, which he terms "reflective orientation" (p. 170). Taylor explains this term further: "A reflective orientation is a cognitive process whereby participants make a conscious connection between their cultural disequilibruim, possible learning strategies, and necessary change towards competency" (p. 170). Taylor explains that when something is in a person's awareness, the person can experience a transformative learning experience; however, if something is out of a person's awareness, a person cannot have such an experience. So far, Taylor is observing the link between cross-cultural experience and reflexivity. Although Taylor does not mention it, writing serves to complete this connection. Writing, with its focus on metacognitive process, is one tool for bringing something into a person's awareness.

While not focusing exclusively on the nature of transformation within the intercultural experience, Mezirow (1991) has explored transformation within the context of adult education. Mezirow asserts that transformation is a phenomenon unique to adult 
learning because prior learning (such as that of elementary and secondary education) serves to establish a perspective. Only after a perspective is formed can it be transformed. Mezirow further defines perspective transformation as the process of becoming critically aware of how and why our assumptions have come to constrain the way we perceive, understand, and feel about our world; changing these structures of habitual expectation to make possible a more inclusive, discriminating, and integrative perspective; and finally, making choices or otherwise acting upon these new understandings. (p. 167)

This definition includes the concept of reflexivity in that we become aware of our own cultural context. Further, Mezirow's theory fits with Bennett's DMIS in that perspective transformation results in inclusion and integration. Finally, perspective transformation involves action.

Like Taylor, Mezirow asserts that perspective transformation is the result of a "disorientating dilemma" (p. 168). This can be a negative event, such as a death of a loved one, divorce, or loss of a job. However, Mezirow suggests that a disorienting dilemma can also be "any challenge to an already established perspective" (p. 
168) and can include texts as well as cross-cultural experiences. Once a person experiences the disorienting dilemma, the transformation begins. Mezirow describes the following phases of the process:

1. a disorienting dilemma

2. self-examination with feelings of guilt or shame

3. a critical self-assessment of epistemic, sociocultural, or psychic assumptions

4. recognition that one's discontent and the process of transformation are shared and that others have negotiated a similar change

5. exploration of options for new roles, relationships, and actions

6. planning a course of action

7. acquisition of knowledge and skills for implementing one's plans

8. provisional trying of new roles

9. building of competence and self-confidence in new roles and relationships

10. a reintegration into one's life on the basis of conditions indicated by one's new perspective. (pp. 168-169) 
This process was delineated by Mezirow through his own field research with adult learners.

In addition to his own research on perspective transformation, much other subsequent research on this process has been conducted (including, among many, many others, Morgan, 1987; Candy, 1989; Gould, 1990). No research to date has focused on perspective transformation specifically within the context of language teacher education, however.

In relation to my own research, I hypothesize that the miniethnography project may set up a "disorientating dilemma" because the experience of interviewing a cultural other may well challenge a person's already established perspective. However, as Mezirow himself suggests, not all disorienting dilemmas may lead to transformation. This is primarily because the person may not have an already established perspective. He discovered that adults tend to progress toward their own meaning perspectives, and interestingly (especially to the purposes of my study), he found that perspective transformations were more likely to occur after the age of thirty (p. 193). Further, because perspective transformation involves action, Mezirow found that some adults are resistant because they feel overwhelmed and immobilized by the change ( $p$. 
171). Mezirow cautions that perspective transformation cannot occur on demand. Although the educator and/or learner may desire perspective transformation, this type of learning may not happen, in part, due to the limitations described above (p. 202). Finally, Mezirow discusses the limitations of research on transformative learning. He suggests that one problem is "finding a way to gain access to the meaning schemes and subjects of the research" (p. 221). He continues by arguing that some research methodologies, such as observation, are limited because they reveal behavior only and not the thought-process critical to transformation. Instead, Mezirow suggests more appropriate methodologies; among them, case study, participant observation, and open-ended interview (p.221)-methods used for the research of this thesis. With these methods, Mezirow advises that researchers "look for similarities and differences in perception, thought, judgement, feelings, and action, preferably in real life, rather than contrived situations" (p. 221).

Because of my own transformative experience connected with both the mini-ethnography and the culture learning class in general, I have, to a large degree, looked for similarities and differences between my experiences and those of Bob, Cleo, and 
Phillip. While I know that 1 have not limited them to my own experiences, I have most certainly kept myself and my own transformation present as a point of comparison throughout the process of this project. Likewise, I recognize that following Mezirow's theory, I was open to the experience of perspective transformation; not every student in the culture learning class may be in such a position. However, exploring the conditions under which a student might or might not undergo a perspective transformation in relation to the mini-ethnography is an interesting and useful project. A better understanding of students' experiences with the project can help teachers of the culture learning course assess the usefulness of the project for both the undergraduate and graduate students in the course.

\section{Endings and Beginnings}

As I conclude my review of literature, I find myself with this project in the midst of a contact zone of disciplines-anthropology, education, linguistics, composition. Yet, I am reminded that the key concepts of my research-writing, cross-cultural experience, reflexivity, and transformation-are terms shared by each of these disciplines. Furthermore, in entering into the contact zone, I bring these terms together to study the experience of pre-service language 
teachers and their experience with reflexivity and transformation through the process of writing a mini-ethnography project.

In quoting Lawrence-Lightfoot at the beginning of this chapter, I suggested that the literature review would give me a framework by which to enter into the contact zone as well as one in which I could explore my own expectations. Before moving on to Chapter Three and the methods of my research, I would like to briefly address my expectations.

Initially, I was hesitant about my expectations. I wanted to leave myself open for possibility. Yet, I knew that leaving myself completely open was impossible. Instead, I realized that I was resistant to acknowledge my expectations. Upon further reflection, however, I realized that I should expect that some students may experience transformation and some may not. Age, resistance, disinterest, or even prior transformation may all be factors contributing to students in the course not experiencing a transformation associated with this project. Other expectations of mine included specifics about student writing: I expected that disequilibrium could be an impediment to writing. Maybe students would write less? Maybe they would describe a struggle? On the other hand, I also hoped that they would write more about 
themselves in the project. Finally, I imagined them saying they want to include more about culture and cultural awareness into their teaching. These expectations are not necessarily anticipated answers to my research questions, but rather outcomes of the framework I have constructed in this review of literature. While these expectations are less formal than my research questions, in Chapter Eight I'll turn back to these as well. 


\section{CHAPTER THREE}

THE “DANCE OF VIGILANCE AND IMPROVIASATION":

METHODOLOGY

When I was in high school, I was fascinated with jazz music.

A saxophone player, I listened to Charlie Parker and Miles Davis any chance I got, and I dreamed of being able to someday improvise a solo like they could. I attended summer music camps, where I learned to improvise, but in my high school, the jazz band director was unwilling to encourage much improvisation, and his attitude both pleased and frustrated me. I was happy because improvisation seemed a big risk, in addition to the fact that I often imagined lyrical riffs in my head but struggled to translate them to my fingers. On the other hand, I desperately wanted to learn to improvise, and I knew that in order to learn, I would have to take the risk of trying to play without notes on the page. True to form, though, the one solo I got that year was a beautifully written saxophone part for My One and Only Love. No room for improvisation. Yet, imagine my surprise when, at a competitive music festival I heard my name called-I won an honorable mention for best improvised solo part! 
In The Art and Science of Portraiture, Jessica Hoffman Davis (1997) suggests the qualitative researcher must both follow a methodology and be open to the context of the research itself: the inconsistencies, individuals, and surprises unique to the project. Hoffman Davis states that " $[t]$ he researcher's stance becomes a dance of vigilance and improvisation" (p.43). This perspective speaks volumes to me as I contemplate the methodology of my project. Throughout the process, I have struggled to balance both the vigilance and the improvisation. This process continues through the writing phase, and I find that I am still struggling. I realize now that while I am drawn to the spontaneity of improvisation, thinking of my earlier days playing jazz saxophone, I also feel more allegiance, as a researcher, to vigilance. I want my methodology to be sound; I want to rely on the processes that have been tested by others, just like the musical notes preprinted on the page. I went into this project assuming that treating my informants the same would result in the generalizability of my work. But, what I've realized from this project is that not only is the process of qualitative research cumulative and recursive, but that context is crucial to my project. 
Rather than making generalizations, I wanted to know what theories apply to the experience of the pre-service teachers I interviewed. I wanted to understand the process these pre-service teachers went through as they completed the ethnography project for the class. Then, I wanted to know what lessons I, and others, can draw from their experiences. These desires-to really get to know the people whom I interviewed-forced me out of the "laboratory, establishing experimental conditions for a controlled, systematic examination of the phenomena under study" (LawrenceLightfoot, 1997, p. 41). Naturally, I couldn't treat each informant the same, as I had first believed I could, because the context-the real sites of learning, writing, and processing the project-weren't the same for each student.

Similarly, my research questions themselves required a variety of approaches. In asking such questions as how pre-service teachers use process writing to make sense of cross-cultural encounters, and how does the inclusion of process writing assignments influence the completion of the mini-ethnography project, I needed to look to the writing samples I collected. While the writing samples served useful for understanding how graduate and undergraduate students might experience the mini- 
ethnography differently, the interviews with Bob, Cleo, and Phillip were necessary to have a more rich understanding. Of course, to answer my question about how the IDI further illustrates the preservice teachers' experience with the ethnography project, I needed to collect and analyze the pre-and post-test IDIs. And, finally, my own research journal, along with my interviews, were useful in knowing how my research influenced my research participants' experiences with the project. I'll describe these various approaches to my research questions in the following pages.

To best answer my research questions, I used a combination of ethnographic and case study techniques. This research is ethnographic in that it hopes to describe the experience of a group-pre-service teachers taking the Applied Linguistics 471/571 Culture Learning course. In addition, this study also employs elements of case study in that I have focused the extent of my research on three students. In addition, I have relied heavily on what Hoffman Davis and Lawrence-Lightfoot term "portraiture." They define portraiture in detail as a method of qualitative research that blurs the boundaries of aesthetics and empiricism in an effort to capture the complexity, dynamics, and subtlety of human experience and 
organizational life. Portraitists seek to record and interpret the perspectives and experience of the people they are studying, documenting their voices and their visions-their authority, knowledge, and wisdom. The drawing of the portrait is placed in social and cultural context and shaped through dialogue between the portraitist and the subject, each one negotiating the discourse and shaping the evolving image. (p. xv)

I was drawn to this method particularly for its boundary-crossing. As a student of literature, I appreciate the creative, narrative aspect of the portrait. And, as someone studying linguistics, I also find myself supportive of the empiricism of science. Portraiture seems the synthesis of what otherwise appear the divergent paths that I am both vigilantly and improvisationally dancing down.

The roadmap for my path appears in the following pages, where I will first describe some of the theories of ethnography that guided the practice of my methodology. Then, I will explain in detail my specific data gathering techniques as well as the types of data that I chose to gather for this study. Finally, I will clarify how I established the validity of my data, and I will include the triangulation processes that I used. 


\section{Guiding Principles}

Watson-Gegeo (1988) defines ethnography in terms of its anthropological roots; she writes that ethnography is "the study of people's behavior in naturally occurring, ongoing settings, with a focus on the cultural interpretation of behavior" (p. 576). In the case of this thesis, the naturally occurring, ongoing setting is the Applied Linguistics 471/571 course. The behaviors being investigated are both the writing process used by the pre-service teachers in this course as well as their cultural interactions with the people they have chosen as informants for their mini ethnography project.

Furthermore, Watson-Gegeo suggests that the goal of ethnography is "to provide a description and an interpretiveexplanatory account of what people do in a setting. ..., the outcome of their interactions, and the way they understand what they are doing (the meaning interactions have for them)" (p. 576). Similarly, the purpose of this thesis is to describe the pre-service teachers' encounter with the ethnography project and to understand their experience, both in writing the ethnography as well as in interacting with their informants. 
As ethnography focuses on how people interact in a particular setting, ethnography emphasizes group behavior; as Watson-Gegeo explains, "ethnography focuses on people's behaviors in groups and on cultural patterns in that behavior" (p. 577). In the case of my research project, the group I am focusing on is the pre-service teachers in the Applied Linguistics 471/571 course. In examining the cultural patterns of pre-service teachers' behavior, I am considering both the group as well as the individual. This research project involves a case study of a part of the classthose pre-service teachers who gave me permission to collect their writing samples-and three specific individuals whose experiences are described more fully in the case studies that follow.

By considering both the group and the individual case studies, my research maintains the holistic aspect of ethnography. Watson-Gegeo suggests that "[e]thnography is holistic; that is, any aspect of a culture or a behavior has to be described and explained in relation to the whole system of which it is a part (Watson-Gegeo, p. 577 citing Diesing, 1971; Firth, 1961). By using writing samples from both the group and the individual case studies, individual and group differences are more apparent. Furthermore, not all of my data fits neatly within the lines of my expectations; yet, in treating 
my data holistically, I have considered everything. Ultimately, the descriptions of both the class as a whole and the case studies of Bob, Cleo, and Phillip include representative samples of their experiences, not just the data that seems most flattering to them or my initial hypothesis.

A final principle of ethnography is that the "data collection begins with a theoretical framework directing the researcher's attention to certain aspects of situations and certain kinds of research questions" (Watson-Gegeo p. 578). Ultimately, the notion that writing triggers reflexivity as described by Qualley supports and guides this entire research project. Doing the miniethnography project triggered my reflexivity; I want to observe this experience in others. In addition, I have been inspired by Mezirow's theory of perspective transformation in adult learning; this has given me an additional framework for understanding both the process and the outcome of reflexivity.

Though guided by theory, however, "ethnographic observation and interpretation are not determined by it" as WatsonGegeo explains

Each situation investigated by the ethnographer must be understood in its own terms. With regard to the research 
process, this means that the ethnographer shifts the focus of observation to include phenomena and interactions outside the scope suggested by prior theory, both to correct for what may be missing from or misleading in prior theory and to search for interactions, patterns of behavior, and other phenomena significant to and perhaps unique in the situation under study. (Watson-Gegeo p. 579)

In this respect, I have thought of this research project as a jigsaw puzzle. Each piece of data has been a piece of the puzzle, and as I have continued putting pieces in place, I've been able to see more and more of the picture. When I began this project, I had an idea of what the picture might be; yet, I have tried to remain open for other possibilities, letting each piece define itself as the process unfolds.

\section{Participant Observation}

My research required me to be a participant observer as I collected data, which included writing samples from all class members who agreed to take part in my study; interviews, network analysis, and pre- and post-class IDI results from those who volunteered as case study informants for my study.

My role as a teaching assistant for this Writing Intensive Course put me in a unique position as both a peer to the members 
of the class as well as an instructor, in that I was responsible for reading and responding to all of the class's informal writing assignments as well as drafts of the mini-ethnography.

Due to the fact that my status as teaching assistant for the course carried with it some authority, I wanted to be especially thoughtful in gaining permission to conduct my research in this course. My human subjects proposal stated that I would assure all students that their participation or non-participation in the course would not affect their grade in the course. Furthermore, Dr. Kimberley Brown, the professor for the course, and I agreed that I would not reveal the identities of any student who participated in my research until after the grades for the course were turned in. All students who participated, either by giving writing samples or by volunteering to be a case study, gave written, informed consent. (See Appendix B for copies of the Human Subjects Consent Forms.) I selected all of the students who agreed to be a part of the class sample to take part in my study. Of those who agreed, five initially indicated interest in participating in the case study. One of those students agreed somewhat hesitantly (she wrote on the form, “only if you can't find anyone else"), so I did not ask her to participate, but kept her data as part of the class sample. Of the 
remaining four, I began interviews with each of them. Ultimately, time constraints made it impossible for me to maintain a consistent interview schedule with one of the four informants, so I could not fully and accurately analyze her data. From the four original participants, I am presenting three in-depth case studies.

Interestingly, two students who agreed to be part of my class data approached me at the end of the term to discuss their projects in more depth. At that time, they not only agreed to be interviewed, but they asked to be interviewed. They both expressed disappointment in having not been willing to participate in my case studies during the term. Of these, I used one tape transcript to pilot test my data analysis. I kept their information as part of the class data only, however.

\section{Collection of Documents}

I collected writing samples from all students who agreed to take part in my study. However, I collected more data from the three people who agreed to be in the case studies. See Table 3.1 for a description of which documents I collected from the class, and which documents I collected from Cleo, Bob, and Phillip. These documents will be described in detail in the following pages. 
From the class members who were not primary informants, I collected progress notes, the Grand Tour and Mini Tour, as well as final copies of the ethnographies. From my primary informants, I also asked for copies of their midterm exams. I filed written work from my primary informants according to their chosen pseudonym. For the members of the class, I assigned a number to each person, and I kept track of their writing

\begin{tabular}{|c|c|c|c|c|}
\hline Document & Class & Bob & Cleo & Phillip \\
\hline $\begin{array}{l}\text { Progress } \\
\text { Notes }\end{array}$ & collected & collected & collected & collected \\
\hline $\begin{array}{c}\text { Other } \\
\text { Freewrites }\end{array}$ & collected & collected & collected & collected \\
\hline $\begin{array}{l}\text { Drafts of } \\
\text { Ethnography }\end{array}$ & collected & collected & collected & collected \\
\hline $\begin{array}{l}\text { Cultural } \\
\text { Artifact }\end{array}$ & $\begin{array}{l}\text { collected } \\
\text { two } \\
\text { samples }\end{array}$ & $\begin{array}{l}\text { did not } \\
\text { collect }\end{array}$ & $\begin{array}{l}\text { did not } \\
\text { collect }\end{array}$ & $\begin{array}{l}\text { did not } \\
\text { collect }\end{array}$ \\
\hline $\begin{array}{c}\text { Letter } \\
\text { Exchange }\end{array}$ & $\begin{array}{l}\text { did not } \\
\text { collect }\end{array}$ & $\begin{array}{l}\text { did not } \\
\text { collect }\end{array}$ & $\begin{array}{l}\text { did not } \\
\text { collect }\end{array}$ & $\begin{array}{l}\text { did not } \\
\text { collect }\end{array}$ \\
\hline $\begin{array}{l}\text { Midterm } \\
\text { Exam }\end{array}$ & $\begin{array}{l}\text { did not } \\
\text { collect }\end{array}$ & collected & collected & collected \\
\hline IDIs & $\begin{array}{l}\text { did not } \\
\text { collect }\end{array}$ & collected & collected & collected \\
\hline $\begin{array}{l}\text { Network } \\
\text { Analysis }\end{array}$ & $\begin{array}{l}\text { did not } \\
\text { collect }\end{array}$ & collected & collected & $\begin{array}{l}\text { did not } \\
\text { collect }\end{array}$ \\
\hline
\end{tabular}


using numbers. After the data collection phase was over, I filed the sheet that connects names with numbers along with the human subjects forms (i.e. separate from the data itself).

Not only did I collect a wide variety of writings from my research participants, but I also collected a large quantity of writing from them. This writing represented a great deal of time spent considering various aspects of the ethnography—the content as well as the process. Each informal writing (twelve of these, in total, per person) signified about ten minutes of actual writing. Other writings, such as the drafts of the ethnography, were longer, indicating several hours invested in interview time, library research, and writing. Overall, the data I collected represents just the surface of each person's investment in the ethnography project itself.

\section{Progress Notes}

Reflecting back on my experience with the ethnography assignment, I regretted not keeping a journal as I completed the project. When I was finished with the project, I wanted to look back on how I was feeling initially. I wanted to be reminded of the struggles I had in choosing a focus for my mini tour.

Unfortunately, the only access I had to these past impressions was 
my memory, which was altered by the experience I had with the ethnography project. The idea of keeping a journal wasn't suggested as a part of the process, and I also doubt that I would have kept one if we were encouraged, but not required, to do some writing about the process. These thoughts were in mind when I designed the set of informal writing assignments called Progress Notes (See Appendix C for the Supplemental Writing Notebook, a course packet which contains the Progress Notes and other informal writing assignments).

Not exactly a journal, these assignments are structured to address key issues appropriate to each part of the process. The initial Progress Notes ask students to first describe their own cultural background. Then, students are asked to say a little about their assumptions and knowledge of the culture they've chosen to investigate as well as to introduce their informant and how they established rapport with that person. Later Progress Notes call for students to discuss the themes they've chosen to focus on for the Mini-tour and also to describe any difficulties they have encountered with the project. The last few Progress Notes require students to reflect back on the process: was the project challenging or effortless? Were students' initial expectations of the project met? 
What factors contributed to their success or failure with this project?

\section{Other Freewrites}

In addition to the Progress Notes, I collected three other freewrites. Two of these were included in the packet with the Progress Notes. These included a freewrite about defining ethnography, inspired by the required reading by Mary Louise Pratt (1996), and a freewrite about the position of the ethnographer in relation to the informant's culture, prompted by the required reading by Clifford Geertz (1996). Both of these freewrite ideas were taken from prompts written by Bartholomae and Petrosky in Ways of Reading (1996). In addition to these freewrites, I also collected a freewrite done in class on the last day. We asked the class again to define their cultural background, and I collected copies of this writing sample for all the students who agreed to be in my study.

\section{Cultural Artifact Assignment}

This in-class assignment was one I modified from a similar assignment by Chiseri-Strater and Sunstein (1997). The purpose of this assignment is to give the students a chance to experience the process of the ethnography in miniature. In considering the 
inclusion of this assignment in the course, I thought back to my own experience with my ethnography project. I wasn't sure how to begin, or what to focus on. And, I also wasn't sure where the project was going. I hypothesized that including this artifact exchange in the course might help students envision the outcome of the ethnography. In addition, the cultural artifact project asks students to think about and practice their skills as an interviewer, and many students have commented informally that this in-class project helped prepare them for the interview aspect of the ethnography.

The cultural artifact exchange requires students to bring an object to share with another student. In doing this project in the class, I told students about this requirement in advance so that they could be thoughtful in bringing something to class. However, knowing that some students would forget, I was also prepared to encourage them to share something they had with them. Phillip was one student who forgot, but he had his passport with him and shared that with his partner. Later, he told me that he had forgotten how much his travels in Europe meant to him, and how much he enjoyed sharing that part of his experience with another person. 
The complete directions for the cultural artifact exchange can be found in Appendix C. The idea behind the exchange is that pairs of students interview each other about the artifact each has brought to class. They then write a page about the artifact and its significance to the owner. The owner has the chance to read and respond to the writer, who makes revisions based on the owner's suggestions. Finally, the writer reflects on the process, focusing largely on their impressions of themselves as an interviewer.

I don't doubt the effectiveness of this assignment. While on the one hand, this assignment was completed early in the term, and the assignment does ask the students to take some risks in sharing part of themselves with another student, many students have casually commented to me that they enjoyed the assignment and that it helped them with the ethnography. However, including more concrete data to that effect has been difficult. One difficulty I had in collecting this assignment was that the class somehow paired themselves such that those who were participating in my study worked with a person who was not. Therefore, I felt that I could not collect samples from those participants because I would be collecting their writing about students who chose not to be in my study. In only two cases did my research participants work with 
each other, and I did collect these samples. However, because I have such a small set of this data, I have had difficulty including it as part of my overall findings, and I have chosen not to discuss the cultural artifact exchange in my results.

\section{Letter Exchange}

The letter exchange was another assignment I found difficult to connect to my results. This assignment, which is included in the Supplemental Writing Notebook, is reprinted in Appendix C. Created by Fishman and McCarthy (1998), the letter exchange assignment asks students to write a letter to another student in the course, posing a specific question or problem relating to the ethnography. The student includes a copy of their ethnography draft along with the letter. Students exchange letters and drafts and then write a response to each other. I thought that this assignment would be particularly useful in exposing the students' process and/or problems with the ethnography project. Unfortunately, the time constraints of the class made completing this assignment impossible. Therefore, I am unable to include samples of this document in my results. 


\section{Drafts of Mini-ethnography}

The Mini-ethnography is completed in drafts. The first draft, called The Grand Tour, asks the students to give a broad overview of the culture they've chosen to study. They should talk a little about their informant and her or his background, how they established rapport with their informant, and any other information the student wishes to write about. This draft often has very general information about the country, including geographic, historical and political information. In addition, the students are required to include a map of the country with this draft. In the following draft, the Mini Tour, students have the opportunity to explore one or two themes relating to the culture. Often these themes include education or family, but sometimes become much more focused. One student wrote about the importance of saunas in Finnish culture, for example. Cleo focused her Mini-Tour on 1975, the year that served as a dividing line for her Vietnamese informant's experience. Finally, I also collected final drafts of the Miniethnography. For the majority of students, the final draft is a synthesis of the first two. Usually final drafts range from ten to twenty pages. However, this term, one of my participants turned in a final paper of over forty pages! Collecting drafts of the 
ethnography project has been crucial to my research because by looking at the differences in the drafts, we can gain insight into the process by which the students learned about their informant and his or her culture.

\section{Midterm Exam}

The midterm exam is a take-home essay that is usually completed around the sixth week of the term. The question itself comes in the course packet that the students buy on the first day of class, so the students have ample time to prepare their answer. A copy of the midterm question appears in Appendix D. For the midterm, students are asked to synthesize three theories related to intercultural communication, give their own definition of culture learning, and say why it is important for a teacher to have a welldeveloped definition of culture learning. I collected copies of the midterm exam from my three primary informants because I found that while they were completing the midterm, they spoke of them and from them often. The midterm was an important illustration of their understanding at that point in the term.

\section{IDIs}

I collected copies of the Intercultural Development Inventory from Cleo, Bob, and Phillip at both the beginning and at the end of 
the term. They took the IDI as part of the course, although they did not see their results in detail until the end of the term. Because I wanted to use the IDI for triangulation purposes, I also did not see their results until the end of the term. In fact, I did not examine their IDI profiles in detail until after I had made some determination about each of them from their interviews and writing samples.

The IDI results are presented in a series of graphs which are intended to be interpreted by a trained administrator. The primary graph gives the mean scores for each of the subscales of the IDI: Denial, Defense, Minimization, Acceptance, Cognitive Adaptation, and Behavioral Adaptation. Other graphs included with an IDI report illustrate subscales of each of the primary scales; these subscales are designed to assist in the interpretation of the overall scale, but are intended to be referred to minimally.

In presenting the IDI results for each of the three case study participants, I have tried to be mindful of the fact that all readers may not be trained to interpret the IDI. Furthermore, while the IDI results are described in detail in each case study portrait, I maintain that the IDI itself is only one tool I have used in order to understand the experience of Bob, Cleo, and Phillip. I have used 
the IDI in conjunction with the DMIS as part of my interpretive process of understanding my data. While the IDI has been supportive as a triangulation instrument, the majority of my interpretation has been as a result of my interactions with $\mathrm{Cleo}$, Phillip, and Bob, including my interviews with them as well as my analysis of their writing samples using the frameworks of the DMIS, the notion of reflexivity, and the theory of perspective transformation. On the other hand, it is important to note that the IDI was extremely reliable as a triangulation instrument. As I noted above, I did not refer to the IDI profiles until I had already analyzed the majority of my data; yet, I found in each case that the IDI profiles were consistent with my interpretation of $\mathrm{Bob}, \mathrm{Cleo}$, and Phillip's experiences at the point in the class that they took the IDI. Furthermore, having the IDI as a point of discussion helped bring out information from Phillip, Cleo, and Bob that I might not have otherwise thought to ask. While I kept the focus of my research on the other elements, especially the writing and interview dimensions, the IDI was invaluable to my interpretation.

\section{Interviewing}

I conducted in-depth interviews with Bob, Cleo, and Phillip over the entire term. We met on a regular basis, on an almost- 
weekly schedule. These interviews were largely open-ended, although I approached the first few interviews with two guiding questions each time. I asked them to tell me about their own cultural background, why they chose their informant, to discuss their understanding of culture learning, and to talk a little about their writing process. In the last interview, I asked them to tell me if they thought they had experienced reflexivity, and I also wanted them to share what they learned from the ethnography process. After the term was over, we met one more time to discuss their IDI results; however, only Bob really discussed much about his IDI results. Beyond the two general questions, I left the interviews open to where my informants wanted to take them. For the most part, we had no trouble finding things to say, and most of the interviews went on longer than the hour we had planned.

The interviews were taped, recording approximately twenty hours of conversation with each informant. The tapes were transcribed, and then analyzed along with the writing samples from each informant. The analysis of the data will be discussed in more detail below. 


\section{Network Analysis}

My experience interviewing each of my three informants was very different. Since Cleo and I knew each other from other courses, the interviews were often chatty and informal. Although I had never met Phillip prior to the interviews, he told me that he really enjoys getting to know people. We easily established rapport, and the interviews that followed were casual, yet focused. Often they ended only because of constraints in our schedules. Bob, on the other hand, was more challenging to interview. I often felt like he wasn't sure what I was asking with my questions, and he frequently didn't elaborate on my questions without prompting, as my other informants did.

To gather more information from Bob, I decided to conduct a network analysis, following the procedure outlined by Marion Dobbert (Ethnographic research, 1982, pp. 157-163). During one of our meetings, I gave Bob a sheet of paper and asked him to draw a diagram of all the people he comes into contact with on a regular, weekly basis. I then asked him to label the box he drew for each person with the cultural background of that person. The results of Bob's network analysis are reported in the section on Bob in Chapter Five. 
Asking Bob to complete the network analysis was very useful in understanding him because I was able to gather information I had been previously unsuccessful in obtaining. While Bob was very serious and responsive to all of my interview questions, I noticed a certain effort in completing his network analysis that was different. He spent considerable effort completing the drawing, often erasing and redrawing the boxes for each person. Then, we talked at length about the diagram.

Feeling the need to "treat each informant the same," I set about completing the network analysis with Cleo and Phillip. Cleo and I actually completed a diagram; however, I have decided not to include it as part of my description of her. To some degree, Cleo had a difficult time completing the diagram. She voiced that she wasn't particularly certain what I was asking her to do. And, while I don't doubt that she took this task seriously, the process of completing the analysis lacked the depth of our previous conversations. What little extra information, if any, I learned from her network analysis wasn't related to her experience with the class, the ethnography project, or intercultural exchange in general. Phillip and I tried to set up times for him to complete the network analysis, but we weren't able to arrange a time that worked with 
our busy schedules. And, after my experience with Cleo, I realized that Phillip's network analysis would be unlikely to yield any new information, as he had already described to me in great detail the people he encounters on a regular basis and their cultural backgrounds. With some reluctance, I decided not to ask Phillip to complete the network analysis.

I suggest that I was reluctant to give up on Phillip's network analysis because of my own belief that I should try to treat each of my informants the same. I've asked them the same questions and collected the same writing samples. However, in many other ways, I haven't treated them all equally, nor, as I've realized, is it possible to treat Phillip, Bob, and Cleo the same. Cleo and I have a relationship as graduate students in the same program. Phillip and I live in the same neighborhood, and we've occasionally met in a local restaurant, whereas I've been unable to do that with either Cleo or Bob. In many ways, Bob and I've maintained the most professional distance, and I realize now that while that may be partly due to aspects of Bob I still don't understand, I also recognize that Bob and I had less in common from the start, fewer points of convergence to facilitate establishing rapport. 
Writing in the Contact Zone 90

\section{Interpreting the Data}

Although I kept a journal during the data collection phase of this research, I did not attempt to analyze my data in my journal. Rather, I used if to record observations and keep track of information. I saved the analysis until I had collected all of my data, in part because I needed to consider it holistically. Watson-Gegeo (1998) concurs:

comprehensive data treatment. . the analysis must be carried out on all the materials or data collected.... When illustrative examples are presented in an ethnographic report, they should be the result of a systematic selection of representative examples, in which both variation and central tendency or typicality in the data are reflected. (WatsonGegeo, p. 585)

In addition, although it was not my original intention, some time has passed between the data collection phase and the subsequent analysis and writing of the case studies. While this time distance may have lessened my momentum, it has made understanding the data holistically much easier, perhaps because my own lens has changed. 
To ensure the validity and accuracy of the portraits I have created, I have relied heavily on triangulation, explained by Watson-Gegeo as "the putting together of information from different data sources and/or data collected through different research methods, such as participant-observatons, interviewing, network mapping, and surveys (citing Fielding \& Fielding, 1986)" (WatsonGegeo, p. 584). Of course, triangulation is essential in qualitative research because it helps ensure the accuracy of interpretation and supports the validity of the results.

In approaching my data, I have used a variety of triangulation devices. The IDI itself has served as a form of triangulation because I collected all of my data without considering the IDI. Only after the term had ended did I ask my informants to talk about the IDI. Only in the case of Bob did the discussion prove to be of use; Phillip and Cleo both focused the conversation more on the instrument itself, tending not to speak directly about their own results.

Finally, I pilot-tested the analysis of my data with two colleagues who have had extensive training on the IDI and DMIS. An interview was volunteered at the end of the term by a student from my class data. We examined her interview transcript along 
with her writing samples, but not her IDI. Throughout this process, it was determined that the interpretation of the data must include an individual, holistic approach, involving discovering themes that emerge from Phillip, Cleo and Bob, rather than trying to impose a framework, or set of coding patterns on them.

In contrast, in considering the class data, I did use the DMIS as a framework for analysis. Because I did not have supporting interviews or individual IDI profiles, I could not create as rich a picture of the class. Therefore, my primary focus has been twofold: first, to understand and characterize the class's experience with the Progress Notes and the ethnography, and second, to observe evidence of change according to the DMIS. To do this, I sought patterns of phrasings in the writing that illustrated statements characteristic of a certain stage on the DMIS.

A final form of triangulation involves getting feedback from my case study participants. Because I wanted to portray Cleo, Bob, and Phillip sensitively and respectfully, I felt that it was important to get their feedback on what I had written about them. After I completed the portraits of Phillip, Cleo, and Bob, I contacted them to ask them to read what I had written and give me feedback. Unfortunately, I was unable to get in touch with Bob to have him 
read his section, but I was able to contact both Phillip and Cleo. Although I was initially a little nervous about sharing with them what I had written, this process was one of the most enjoyable parts of finishing this thesis. The amount of time that had passed between when they took the class and now helped them look outside themselves and really "see" what I had written. Cleo told me that what I had written about her was a gift, and hearing her say that almost made us both cry.

\section{Creating the Portraits}

In actually writing the portraits of Bob, Cleo, and Phillip, I had to approach them individually. Throughout the process of writing, I felt like they were present with me, almost as if I were spending the interview time all over again. Obviously, with all of their writing samples, their IDIs, and the extensive interviews I conducted with each of them, I had considerable data to synthesize. One of the bittersweet elements of ethnography is that not everything can be included! What I have chosen to include however, is like jazz: both improvisational and simultaneously structured. I have tried to give the reader an insight into the reality of each of the people behind the portraits. And, I have tried to present an honest account of their process with the ethnography 
project. To best understand their experiences, however, a glimpse into the class as a whole is necessary. Understanding the class and the students in it provides a context to know Bob, Cleo, and Phillip better. What follows, then, are four portraits. In presenting these portraits, I am straying somewhat from the usual thesis format, that is, one chapter allotted for "Results." Instead, I have crafted rather detailed portraits of the class as well as each of the individuals.

In Chapter Four, I present a glimpse of not the whole class, but the fourteen students who agreed to be a part of the study. Then, Chapter Five introduces Bob's portrait. Chapter Six presents Cleo. Finally, Chapter Seven illustrates Phillip. In considering each portrait, I hope that my readers/viewers will share in my dance of improvisation, while at the same time appreciating my attention to vigilance. 


\section{CHAPTER FOUR \\ COMING INTO FOCUS:}

THE RESULTS

In the late morning on an unusually sunny fall day, students make the trek from the main buildings of the Portland State campus, up the hill to the $6^{\text {th }}$ Avenue building. Once used as a parking garage, and later as a beauty college, this older building now serves as the meeting space for Applied Linguistics 471/571, also known as International Studies 397. Footsteps echo in the stairway, as out-of-breath students complain about the building's apparent lack of an elevator. Hoping they are in the right place, they shuffle into a large grey-clad classroom, the large white dry erase board one of the only contrasts to the grey chairs, grey walls, and grey-blue carpet. At least the narrow slits for windows won't let in the usually grey skies.

What difference is lacking in the physical space is made up for by the students. Representing a variety of cultural backgrounds, including Korean, Japanese, US-American, MexicanAmerican, Chinese, and Filipino, among others, the students are from places rural, urban, and everywhere in-between. Both men and women, they range in age from early-twenties to early-sixties. 
They have had a variety of life experiences, and although their primary majors are Applied Linguistics, International Studies, and Education, other majors are represented.

As the writing assistant for the course, I had the opportunity to get to know seventeen of them better. Three of these-Cleo, Bob, and Phillip-will be presented in much more detail later in this chapter. The other fourteen students I came to understand only through their writing and other limited contact I had with them as the writing assistant for the course. I had only limited contact with the remaining eighteen or so students who were either registered for the class as International Studies 397 or who chose not to participate in my research.

The students who agreed to share their writing with me included students who were registered for the class under either Applied Linguistics 471 or 571 . No International Studies students took part in my study. Of the students who participated, not all were Applied Linguistics majors; some were taking the class to fulfill requirements for other departments, including the Education Department and the Foreign Languages Department. Some students were completing a certificate in Teaching English as a Second or Other Language, while others were pursuing a major in 
Linguistics or a Master's in TESOL. I did not collect specific data from the students; I only know which section each student was registered for. The breakdown of the students, by grade level and gender, appears in Table 4.1. This information is presented to show only that the writing samples I collected were from both male and female

\begin{tabular}{cccc}
\hline & Female & Male & Total \\
\hline Undergraduate & 6 & 2 & 8 \\
Graduate & 7 & 2 & 9 \\
Total & 13 & 4 & 17 \\
\hline
\end{tabular}

Table 4.1 Gender and grade level of my research participants

students as well as both graduate and undergraduate students. In presenting the writing samples from the class in the following pages, I have used pseudonyms. In some cases, these false names were chosen by the writer; in other cases, I chose the names. While the names reflect the gender of the writer, and in some cases, the ethnicity (i.e. Japanese writers have Japanese names), the grade level of the writer is not indicated, as this was not a focus of the description of the class. The gender and ethnicity of 
each writer, however, is alluded to in the texts I have collected, while their status as a graduate or undergraduate student is not.

I wish I could say I knew these students as I know Cleo, Phillip, and Bob. However, the amount of time I spent with the three of them greatly contributed to the extent to which I've come to know and understand their experience. Limited to only the writing samples I collected from the remaining students, I can present only a limited picture of the class as a whole.

\section{In the Beginning}

The first week of the term, students were asked to complete the freewrite in the Supplemental Writing Notebook (see Appendix C) about their cultural background. In this freewrite, the students generally responded, using a combination of three different strategies: considering their individual culture, problematizing the question, or comparing their culture to another culture.

Many students responded to the question by focusing on their individual culture, as did Mark, a graduate student, who wrote that "American (USA) culture is multi-faceted and complex" (PN 1). He continued, in his freewrite, to suggest that many factors play a role in his cultural background, including "ethnic group, geographical location, and economic/educational status" (PN 1). 
Many US-American students answered similarly to Mark: first, stating that they are American and then describing in some detail what that means for their own personal self. These writers often referred to their heritage cultures, as did Laura, who described herself as "a mixture of Swedish, Norwegian, English and Irish blood" (PN 1). Another writer who focused on her individual culture, Meg, focused on action, when she writes, "[m]y husband + sons keep me busy. Scouting, soccer, play practice, plus family time is a lot of my culture" (PN 1). Others wrote similarly of going to church or feeling themselves to be resistant consumers. In these cases, individualism was a focus, as Rachel, a US-American writer, explains:

My culture is becoming more diverse over time-culture seems to be an "individually defined" state, as I would define my culture differently than my sister based on her different life experiences and alliances. (PN 1)

For some US-American students, defining their cultural background focused on defining themselves as an individual within a greater context.

For other students, this initial question was problematic. One student, Kelly, attributed herself to belonging to American 
culture, then continued by questioning the political tenor of the country:

I belong to American culture. It has recently become disappointing to me that our society here in the USA is so politically correct and multi-cultural that we can no longer call Christmas, Christmas and we can't sing songs about Jesus in school as part of Christmas. This is just one example but I think it is a very important one. Ours is the only country that I know that does this. People from our country and others do not minimize the importance of cultural celebrations for others. There is also the point of these areas that have Spanish as an official language. I don't think I need to explain how language reflects culture and although I support speaking other languages and retaining ones own cultural customs, I truly believe that in order to have cultural cohesion in the USA we should all speak English at one level or another. At the very least English schools should be in English. I am an ESL teacher and I know the importance of knowing English for clear communication. ... (PN 1) 
After this focused political statement, Kelly does return to the problem at hand and defines American culture, focusing on independence, class differences, and valuing gender equality.

Other students, like Kelly, found this question challenging. Amy, a student who had traveled abroad and lived in many places, found the question difficult because she realized she defined her culture in context. She observes that when she was in Ecuador, for example, she defined her culture more broadly than she does in the United States. Similarly, Lisa, who spent three years living in Canada, is also unsure of how to define her culture, except to focus on "90's American culture."

Other students felt the question problematic because they did not see themselves belonging to one culture. Instead, they defined themselves as bicultural. Georgine is one student who defines herself biculturally:

The culture that I belong to is primarily American culture, however, I was raised with a wide range of cultural values and traditions. My mother is Filipino American. She came to the U.S. when she was a teenager. Her cultural reference point(s) have been both Filipino and American culture. Her experience in this country has influenced how I see myself as 
a second generation mestiza. The word "mestiza" means a mix of two cultures (usually Spanish culture with another)my father is white and my my mother is Filipino. So I am a mix of both cultures. It is interesting for me to reflect upon what culture I belong to because I feel that I belong to many cultures. (PN 1)

Other students who identified primarily as American described similar situations to that of Georgine's. For example, John wonders whether to call himself American because that is his country, or German because his family is German. He points out that he is not alone in this confusion, as "plenty of other Americans [are] in the same boat. To call oneself American doesn't really mean much" (PN 1).

Finally, another approach to this particular freewrite was to describe oneself in comparison to another culture. This approach was characteristic of Japanese students in the class, probably signifying their recognition that their cross-cultural experience has changed them. One student, Naoko, states that she belongs to two cultures, although her dominant culture is Japanese. Another student, Takae, observes that she is "familiar with Japanese culture" but she's not sure if she belongs to Japanese culture 
because she is not currently living there. On the other hand, she admits, "I don't think I belong to American culture because I'm still not quite sure what American culture is" (PN 1). For Takae, the difficulty comes down to defining culture.

In the beginning, all of these freewrites illustrate a degree of hesitance on the part of the writers in defining themselves in terms of their cultural background. Some writers resist placing themselves in a culture beyond themselves; others recognize the challenge because of their bicultural identity. Over the course of one quarter, however, these students' writing does shift during the process of completing the ethnography project. (To illustrate this shift, full transcripts of each person's first and final freewrite are included in Appendix E).

\section{The Ethnography Project}

The students had little trouble finding people who were willing to be interviewed for the ethnography project. They found volunteers among their colleagues in the culture learning class and in other classes. Others asked friends or acquaintances to be interviewed. In the sample of the class represented here, the cultures investigated varied greatly. While four students interviewed someone from Japan and two students interviewed a 
Finnish person, many other cultures, including Sri Lanka, China, the United States, India, Indonesia, Vietnam, Korea, and Tibet, were the focus of ethnographies.

For the most part, the students had little difficulty establishing rapport with their informants. Because the majority of the students met their informant through being classmate, they felt they already knew each other before they began the project. In other cases where the students met their informants through an acquaintance or through the International Student Office, they found that starting off slow and getting to know each other first helped facilitate rapport.

By the time the class did the freewrite asking them to consider Clifford Geertz's quote that "the culture of a people is an ensemble of texts, themselves ensembles, which the anthropologist strains to read over the shoulders to whom they properly belong" (p. 391) some students had encountered limitations in the information they were presented by their informants.

Some students found that their informant did not represent the culture-specific information they found in books. For example, Lisa writes, "I have found that there are times I will find something in a book about Japanese culture, and my informant will either 
contradict the information in our interviews or straight out tell me the information is false or outdated." Lisa handles this discord smoothly, however, as she explains, "I guess to some extent you can make generalizations about a certain culture, but without the input of the people who live that culture day-by-day how authentic can it be?" (Geertz freewrite). Lisa recognizes that her informant illustrates the individual variation within a culture.

Unlike Lisa, who felt that she was getting an accurate understanding of Japanese culture from one person's point of view, other students felt that their understanding was much less clear. Takae articulates her frustration, when she writes, "I'm still struggling to feel my informant's culture personally. I still feel like I'm only seeing the surface of the culture and being unable to reach the deeper context" (Geertz freewrite). Amy, too, communicates similar sentiments. Amy doesn't fault her Japanese informant for Amy's own inability to understand; instead, Amy suggests that she is unclear in her approach:

It's like I keep jumping up and down and moving around trying to see over their shoulder and my project is just all those bits and pieces I have seen. The problem is that I 
don't know how to move so I can see clearly, if that makes sense. (Geertz freewrite)

Amy sees that her limitation in processing the information lies with herself.

In contrast, Kelly, another student who reported limitations in understanding her Japanese informant's culture, felt that her informant told her primarily what he thought she wanted to hear. In addition, Kelly had difficulty understanding his indirect communication style. She explains,

My informant has provided me with many details about his personal. But as for putting together a cultural puzzle there are too many pieces that I do not have or cannot see. My informant does not tell me his personal opinion. He does not show strong emotions one way or another. I could interpret this as a cultural by-product, but I won't. (Geertz freewrite) Feeling frustrated by this lack of information, Kelly states that she is "without a mental picture of Japanese culture."

On the other hand, other students reported little difficulty taking in their informant's culture. Laura focused her ethnography on saunas in Finnish culture, and while she admits that she didn't get to actually experience the sauna for herself, she 
felt like she learned a great deal about Finnish culture from her informant. John also found little difficulty in understanding his informant's culture. He focuses on the idea of texts being open to interpretation, suggesting that the key to understanding is "to access the texts without rushing to settle on a particular interpretation too soon" (Geertz freewrite). After the project was complete, both Laura and John concluded that while the project was challenging, it was also "easy" and "inspiring" at the same time. They enjoyed the time they spent with their informants and hoped that they would continue to have a relationship with them in the future.

For the other students, the project was most definitely described as "challenging." Some were challenged by the amount of time required to do the ethnography; others thought the interviews were difficult at times. Either they did not feel comfortable structuring the interviews, or their informant did not want to talk about a particular topic the interviewer was hoping to discuss. Perhaps Hannah sums up the challenges of the ethnography when she writes,

I can surely say that this project has been challenging-not in a negative way, but I've been challenged in my interviews 
to come up with better and better questions, for example, \& it's been challenging to match J-'s commitment level on these huge issues. It's quite an enlightening experience to meet someone who is so completely committed to social change in this world. The connection itself has, however, been effortless. By this, I mean, I feel like $\mathrm{J}$ - is a friend. This new relationship is important to me and very demanding on some levels. Also, in an indirect way, it's been challenging for me-it's hard to put into words but I've had some pretty big issues in my own life going on at the same time, and J-'s steady faith \& his clear articulation of his beliefs in the face of great difficulties has translated often directly into my own personal experiences-- $\&$ it's taught me valuable lessons. This project definitely isn't typical, and most assuredly is inspiring. I've also been very moved that $\mathrm{J}$ - has begun, I think, to trust me on a deeper level. I can tell by the direction of our conversations, the incredible moment when he shared the fact that his marriage is ending. I felt really honored that he felt comfortable enough to share such personal information. More recently, I went to his classroom (this last Sunday), for 2 hours and watched him 
in action with his students. Little things, like the way I was introduced to his friends, and the way I was made to feel welcome in the classroom, made me feel that $J$ - doesn't consider me just to be a student doing a task. I feel very good about that, and have spent a lot of time sharing all this with my husband, who I hope will be able to meet $\mathrm{J}$ - at some point in the near future. It's amazing how you can initiate one action in your life that gives way to other actions and leads in totally new directions. It is my hope to continue to be a part of the Tibetan community and to help and volunteer my time when I can. As this project winds down, I feel that I am really only beginning to be in a position to begin to do the interview \& ethnography!

Finally, the biggest problem I've encountered is the definite conflict between doing something totally real, juxtaposed against an intense schedule with school and classes that allows me precious little time to fully commit myself to this remarkable project. (PN 9)

Hannah had a very positive experience with her Tibetan informant, and although she acknowledges challenges at all points during the process, she also alludes to the transformative nature of the 
ethnography: the new friendship she has in her informant has helped her understand her own experiences, as she writes above.

\section{After the Ethnography}

At the end of the term, the members of the class were asked again to describe their cultural backgrounds. Although the question doesn't directly relate to their ethnography projects, it does relate to their experiences in class. Furthermore, some students made the connection between the ethnography and their understanding of their cultural "self." One student who made such a connection, Mark, explains, "Learning about another culture (Finland) has helped me learn about my own. By looking at others closely, we can see ourselves in a different point of view, in a sense. It made me think of what I am \& what I come from" (PN 10).

Students' responses to this question were markedly different at the end of the term than they were at the beginning. Students who focused on their individual culture in the beginning now used language to describe themselves in terms of belonging to a bigger culture group. Students who looked on the question as problematic in the beginning were now able to answer the question in more clear terms. And, some students who described 
themselves as bicultural at first now focused on their belonging to one primary culture.

Mark, the student quoted above, reflects on the fact that focusing personal identity is, in fact, an American cultural pattern. Furthermore, he observes that "many Americans denounce any sense at all of a national culture" yet, he realizes that "individualism [and] critical thought" are part of his culture (final in-class freewrite). Another student, Rachel, adds to the list of "American" cultural values: "independence, education, Christian morality and collective responsibility" (final in-class freewrite). This language to describe their cultural values connects directly back to the culture learning class and its emphasis on bringing into the students' awareness the language of cultural difference. In almost all of the end-of-term freewrites, there is a greater use of intercultural terminology.

This increase in use of terms related to intercultural communication is particularly true for those who found the initial freewrite problematic. One of those students was Kelly. In the first freewrite, she focused on the politics of the U.S., almost ranting about the role of English in education. At the end of the term, she breaks free of the narrative structure of the freewrite. 
Instead, she writes a poem, one that emphasizes the language she learned in the class:

My culture. . .

values honesty

distrusts authority

believes itself to be self reliant

is motivated by pride and progress

discriminates against those who are

different but does not consciously

persecute them.

values media input and stimulus

is future oriented

does not like to accept blame

avoids finding fault with ones self

values fairness above all else

believes hard work can get you anything

lacks knowledge of the world around it

believes itself to be the leader of the

developing world(superiority complex)

wants everything as quickly as possible

"Time is money" $\rightarrow$ impatience 
Some people I would have to say value work over family

Fear death

Fear the unknown

values money, status, and prestige

(These observations do not describe everyone, including myself. They are generalizations.) (final in-class freewrite).

Not only does Kelly use the language describing cultural values such as "values media input and stimulus" and "is future oriented" but she also recognizes an important lesson learned from the ethnography when she points out that these kinds of words "do not describe everyone. . . They are generalizations." She has learned both the intercultural terminology as well as the context in which these terms are most effectively used.

Like Kelly, other students who found the initial freewrite problematic described more resolve in the final freewrite. Lisa, the student who described herself as being part of "90s American culture" now writes a little of her family's Polish background, but sums up that she is "all-in-all American" (final in-class freewrite). John, who initially wrote that he was not comfortable defining himself as "American" does not use that term to define himself at 
the end of class. Instead, he focuses on what he terms "European values": "nature is considered separate from man...emphasis on 'doing' rather than 'being'. . . importance of the individual... an obsession about time and efficiency" (final in-class freewrite). Here, John recognizes that these values have a tradition that goes beyond "American culture." John admits that these values have influenced him, even though he has "different notions of the ideal culture I would prefer to claim membership in" (final in-class freewrite). At the end of class, while John still resists labeling his cultural context, he acknowledges that he has one, and he defines the values of his culture.

Another student, Amy, found the initial freewrite difficult because she defined herself by context. In the end, she maintains that defining herself is difficult. Now, however, she says the difficulty lies in the fact that the individual may vary from the culture. Amy explains further, ... When you think of maybe the "typical" family or maybe the stereotype of a US family-ours may not match up-what comes to my head is a family who doesn't really get alongthe kids don't like the parents, cause trouble-the whole "teenage" thing, etc. So how do you describe "the culture 
you come from"-You could say life is fast paced, fast food, no home cooked meals, kids in daycare, both parents working + often divorced + remarried. This could be a way of describing my culture because it is what is around me-but so is the opposite-my friends + their families are more like mine than you may see, say on TV for example. So for me, describe "my culture" is hard unless it's more specific. Maybe-I don't know-maybe it's just me-I guess you just have to pick one and describe it + say what it is you are describing (final in-class freewrite).

Interspersed among her acknowledgement that individuals are different from their culture, Amy presents some of the values of the U.S. culture she considers herself a part of-importance of family, focus on time, valuing work, etc. While Amy may not agree with everything about US-American culture, in her final freewrite, she not only describes US-American culture, but she locates her own place within it.

Finally, the group of students who initially defined themselves in comparison to another cultural group had similar responses to the final freewrite about their cultural background. While these students, who were from Japan, wondered at first 
about being Japanese in the physical context of the United States, now they placed themselves more specifically as belonging to Japanese culture. Like the other groups of students, this group was also able to use more explicit terminology relating to cultural values.

Takae, an international student from Japan initially described herself primarily as Japanese, and unsure of American culture, describes herself as clearly Japanese at the end of the class. She uses intercultural terminology to explain her culture, saying that her culture "values harmony," "respects people who are older than us," and "makes a clear distinction between in-group and out-group" (final in-class freewrite) for example. Yuko, who wrote quite a bit about Japanese cultural values in the beginning of the class, responded similarly. She described some Japanese cultural values such as "solidarity" and "harmony," and concluded with a comment related to the class's position within a USAmerican context: "I found learning is enjoyable when people can discuss freely without worrying about keeping harmony all the time" (final in-class freewrite).

Another Japanese student, Naoko, who described herself initially as having two cultures, although admitting that Japanese 
was her "dominant culture," now writes of herself as different from the culture surrounding her. She writes,

I come from a culture that holds many different cultural norms from the culture in this culture. I was just working on my First Lang Acquisition paper, and there was a scholar (Pat Clancy in U of Santa Barbara) who talked about the cultural norms that Japanese mothers promote in motherchild interaction. According to Clancy, the ability to anticipate the speakers' intentions w/out being told them directly is one such cultural norm in Japanese communicative style. I think this holds true even for adultadult interactions in Japanese and those who cross cultures using different languages in a different culture would be problematic.

Culture of Japan has been discussed and promoted very ostentatiously everywhere nowadays-you can get so much info about the country and what's so called "Japanese culture"; however, I see it remain at very surface levelnamely informational side of culture: what people (esp. in language learning setting) need is more of behavioral culture, 
which concerns cultural norms in Japanese communication, for instance.

I see my culture I belong to from more $3^{\text {rd }}$ world perspective now; this was already taking place before this class, but enabled me to delineate what's going on! Thank you (final in-class freewrite).

While initially, Naoko saw herself as belonging to both Japanese and US-American cultures, she now clearly sees herself more from a Japanese perspective. Yet, as she acknowledges in the last line, the American context has given her a different position from which to understand herself. She is able to see herself from both inside and outside Japanese culture, as she has come to realize.

\section{Class Pictures}

While overall, the members of the class had different approaches to the initial and final freewrites, as well as the ethnography and other writings in-between, a pattern in their writing did emerge. Initially, the students used much less specific terminology in describing their cultural background. Whether they focused on their individual culture, compared themselves to another culture, or problematized the question, they did not use much, if any, specific intercultural terminology relating to cultural 
values. However, at the end of the term, all three groups of students showed a marked increase in the amount of interculturally-appropriate terminology they used.

This shift can be partially explained by the course's explicit focus on bringing such terminology into the awareness of the students. The class itself is rich in well-used opportunities to present these terms-readings, a film, and class discussion. In addition, both the midterm and the ethnography give the students opportunities to synthesize their understanding of these terms. However, the ethnography itself, I believe, plays the biggest role in creating the context for the shift in awareness to occur because the ethnography gives the students the chance to compare their culture to another person's culture. And, while the students in this class may have had previous experiences in another culture, this class provided them with intercultural contact and a focus on bringing terms to explain cultural difference into the students' awareness simultaneously. The ethnography project provides a context for the students to explore the cultural differences described in the readings, class lectures, and other classroom texts. These two things together-the ethnography and the focus on intercultural awareness - make the cognitive shift illustrated in 
the students' writings possible. As Mark says of the ethnography project, "Learning about another culture (Finland) has helped me learn about my own. By looking at others closely, we can see ourselves in a different point of view, in a sense. It made me think of what I am \& where I come from" (PN 10).

\section{Zooming In}

So far, what I have presented of the class can be thought of, in artistic terms, as a mural-big brush strokes covering a large area. While a few themes have emerged, the finer details are harder to notice. For that, zooming in is necessary.

In the next three chapters, I will present three portraits of individuals from the class. These portraits describe the experiences of Bob, Cleo, and Phillip as they were in the class. The portraits of each individual are shaped by more information that what was used to create a picture of the class as a whole. With Bob, Cleo, and Phillip, their writings are accompanied by many hours of interviews with me as well as the IDI profiles that they completed at the beginning and ending of the class. These additional tools have helped me shape my own understanding of their experience. 


\section{CHAPTER FIVE}

\section{A TOURIST IN THE CONTACT ZONE:}

\section{$\mathrm{BOB}$}

One of my initial research questions going into this project relates to how each student's experience with the ethnography project varies, depending on individual background. Would a person from an apparently more multicultural upbringing have a characteristically different experience interviewing someone from yet another culture? The Applied Linguistics program at Portland State University has a number of international students registered in both the MA-TESOL and certificate programs. How might their experience with the ethnography project be different from the experience of an American student completing the same project?

Two of the people I interviewed for this project consider themselves to be bicultural. One is Phillip, and his experience with the ethnography project will be discussed more fully in Chapter Seven. The other person who considers himself to be bicultural is Bob. While the purpose of these case studies is to describe each person's individual experience with the ethnography project, rather than compare experiences, I kept the above questions in mind as I began my interviews with Bob. 


\section{Meeting Bob}

Friday afternoons, the corridor where my office is located vacates early. By mid afternoon, I am the only one there, as I wait for Bob to arrive. Sitting at my desk in the windowless space I share with six other grad students who had long since gone for the day, I notice I am a little anxious for this first interview with Bob. I had never met Bob before our encounter in this class, and I was initially surprised that he agreed to be a part of my study. In the first few days of the class, he occasionally shared information with the rest of the class; yet, he often seemed reserved.

I had already interviewed the other people who agreed to be case studies. And, after interviewing them, I wondered what Bob would be like. A linguistics student myself, I was already acquainted with $\mathrm{Cleo}$, so we had established some rapport prior to our first interview. Although I had not met him before this class, Phillip surprised me with his initial openness-he admitted that he is a "people person" and likes to talk. I was curious to find out if Bob would be similar to Cleo and Phillip as I reflected on the ease of my other initial interviews; yet, I worried he might not share their openness. 
Lost in thought, I don't notice the light knock on the alreadyopen door.

"Hello," Bob says, softly, but cheerfully.

"Come in," I respond, smiling, but suddenly worrying if this context is going to feel too much like a teacher-student relationship. My office isn't exactly a neutral location, but confidentiality concerns have stifled my desire to meet with my informants over coffee.

Bob eases into the chair of my office-mate, and gently sets his backpack, bulky with books, down beside him. He smiles as he brushes his dark black hair away from his glasses. I can tell he's had a long day of classes, but his dark blue jeans and blue and white striped rugby shirt crisp and fresh.

After a few moments of small talk, we settle in to the interview. Later, after Bob leaves, I realize that my initial assumptions about him were not totally accurate. Bob has expressed several times his sincere interest in helping me with my project, and he has answered my questions with enthusiasm. It is an enthusiasm that is rarely evident outside of our interviews, however. Furthermore, following the writing teacher mantra "show, don't tell," I hear Bob telling me that he is excited about the 
project, but he is never very clear with me what that means. Instead of defining his excitement, Bob repeats that he is excited. Bob has been challenging for me, and one place where this has been most obvious has been in the interviews. Unlike Cleo and Phillip, who usually elaborated on my questions without prompting, Bob generally answered my questions directly, adding little extra detail. I've often found myself struggling to explain points to Bob that Cleo and Phillip understood more easily. Or, I've discovered myself talking too much in my own desperation to get Bob to talk a bit more, or to describe an instance more fully. Yet, Bob was not resistant. On the contrary, Bob was often smiling and occasionally telling jokes during our meetings. He came on time to the interviews, and seemed serious about the process (making sure that no one saw us interviewing or that the tape recorder was running, etc). Bob was cooperative, yet not able to respond easily to my questions.

Bob's style in the interviews seems consistent with his work in the course. As both the teaching assistant for the course, and as a researcher, I see Bob meeting the basic requirements for all assignments; yet, his work generally reflects a lack of engagement. He has met the requirements but little more, which may be 
indicative of his busy schedule. Bob told me that he was registered for eighteen undergraduate credits, and that he plans to take a full load of classes each term this year. Bob's heavy course load may explain his limited engagement with his coursework for the Culture Learning class. Yet, I suspect that Bob's course load is only one factor contributing to his approach to the ethnography project.

\section{Bob's Background}

Bob is a twenty-four-year-old male, undergraduate student. His major is Applied Linguistics, and he hopes to eventually become an elementary school teacher. When I first met with Bob, I knew only that he considers himself to be bicultural. In his first Progress Note, he writes that he is bicultural because he has lived in both Korea and the United States for an extended amount of time:

I consider my ethnicity to be Korean and my nationality to be American. Being bicultural, I feel very comfortable in both cultures without any worries about culture shock. That is not to say, however, that I like living in both countries. I would much prefer living in the states than in Korea, just due to the fact that I feel I lived in Korea long enough to get 
sick of living there. Immersion in one culture for too much time is not a good thing (PN 1).

After I met with Bob, I discovered that he was born in Eugene, Oregon, where his parents were attending school. While they lived there, Bob learned primarily English, which he considers to be his native language. When Bob was two, his parents returned to Korea; however, Bob continued to learn English because his parents continued to speak the language in their home. Furthermore, Bob attended an English-medium school.

Because Bob was socialized in two different cultural settings-Korean and American-I suspect that Bob is what Milton Bennett (1998) would describe as an "accidental bicultural" (p.29). Bennett suggests that an accidental bicultural is good at shifting between the two cultures he has been socialized in because those cultural frameworks are internalized; yet this type of person is not able to apply these adaptation skills to other settings (p.29). Bob's education and upbringing suggest that he has been socialized in both Korean and American culture; yet, I have observed very little evidence suggesting that Bob has been able to apply these skills in other settings. For example, Bob might apply his cross-cultural skills in his work as a tutor of an immigrant family from Kosovo. 
When he tells me about the family, however, he remains narrowly focused on their language issues. He mentions nothing about helping them adjust to the culture, although my first instinct was that Bob might be very good at helping someone in the U.S., since he is relatively new here himself.

Bob's thinking seems to be narrow, and at times, very dualistic. He operates either in American or Korean culture, and the boundaries between the two remain distinct.

Bob attended an international school that was run by Americans, although the student body was made up of students from all over the world. Even though his school was in Seoul, Korea, Bob says that it was conducted entirely in English, following an American curriculum. Bob explains that comparing his school to a Korean school is very difficult. He tries this a little for me:

Korean schools are much harder than Seoul International could ever be. I never went to a Korean school but my sister did and I know what went on through her. Koreans do not take education lightly...all of [Koreans'] coursework in junior high and high school is geared towards the major they want in college and most Korean students know what 
their majors are going to be....Another difference...is that opinions are not valued in Korean schools. The teachers and students stick with facts from the texts and independent formulations of opinions based on what it says in the texts are discouraged....[students] are supposed to listen and not talk back or disagree with the teacher. This may sound harsh but all the students are used to it because that is the way they were brought up in Korean society.

Bob says he doesn't know why his parents eventually sent his sister to a Korean school. He thinks they kept him in the international school, though, because they believed he wouldn't have been successful in a Korean school. As Bob tells me this, his voice is casual and lighthearted. I suspect Bob agrees with his parents on this issue.

Due to his experience with learning English, Bob considers English to be his native language and Korean to be his second language. Bob tells me that he didn't really learn Korean until his parents returned to Korea when he was a young child. Since his schooling was in English, he doesn't feel confident with written Korean and is currently taking Korean language classes to improve 
his command of the language. Bob points to his language experience as one example of not feeling totally comfortable in Korea. Bob says that when he lived in Korea, he felt more comfortable speaking in English than in Korean. He explains that when he and his friends were on the trains in Seoul, they would usually speak English, which often drew stares from the other Koreans around him. He suggests that other passengers were surprised to hear Bob speaking English so fluently because he looks Korean.

Not surprisingly, when Bob graduated from high school, he didn't apply to a Korean university. He says, "I knew that I wouldn't be able to take it. I probably would have flunked out really early, or something." Instead, Bob applied to a few schools in the U.S., including a university in Illinois that was recommended by a friend of his mother. He was accepted at that school and attended it for awhile. Bob had a hard time adjusting from the urban landscape of Seoul to the rural midwestern university town; he struggled academically and was put on probation. Eventually, he transferred here to the Pacific Northwest, and he reports he is doing much better, both socially and academically. 
After he is done with school, Bob plans to stay in the U.S. He doesn't want to go back to Korea. He says plainly, "I've lived there all my life and I really don't like the country...I would much prefer living in the States." Furthermore, Bob believes his parents expect him to stay in the U.S. because he's been, in his words, "Americanized." He says that he told his parents he doesn't like Korea and they understand. However, Bob reveals that his grandmother feels differently.

It's important to her for Bob to keep Korean tradition, and this includes marrying a Korean woman. This is in part to preserve the unique customs of Bob's family, as he explains, "If I married an American or a Japanese or a Chinese those customs wouldn't work as well because they wouldn't understand the culture. They never lived there and they never grew up around that type of culture and yeah, so my grandmother in particular would want me to marry a Korean." As for Bob, he says he doesn't really prefer a specific ethnicity but he does admit a certain allegiance to his grandmother when he adds, "if I went against my grandmother's wishes, what would she think?" Bob understands the importance of family and relationships for his grandmother, and this compounds this issue for him. Furthermore, Bob 
expresses some concern about how his family would accept his future spouse if she were from another culture; he also worries about how a future spouse would adapt to Korean culture. This is an example of the either/or thinking that Bob seems to be bound by. In considering a future spouse, Bob is acting in accordance with Korean culture, both in consideration of a Korean spouse as well as taking his family's wishes so seriously. Yet, Bob's reasons for thinking about marrying someone Korean seem to contradict Bob's earlier statement that he is too Americanized to live in Korea. Right now, however, Bob doesn't have a reason to come to terms with these contradictions-he isn't currently dating anyone.

Bob admits that he's never traveled to another country outside of the United States and Korea. Travel is one of his future aspirations, though. Bob is particularly interested in visiting England and Australia because he wants to learn more about the differences in English in these two countries and the United States. Again, Bob's lack of experience traveling to other cultures fits with the image of him as an accidental bicultural. Bob hasn't had many opportunities to expand his ability to shift cultural frames of reference. 
While Bob considers himself to be bicultural due to his experiences with both the United States and Korea, he considers his family differently. Bob does not consider his parents to be bicultural, as he explains to me:

I would consider them just to be Korean because they were just here for graduate school and they didn't really stay very long after that. They were sort of like foreign exchange students. I wouldn't consider them bicultural by any means just because they like living in Korea. They've lived there all their lives and they're just so used to being at home. And, they don't really have the chance to use English all that much. They have some friends who do speak English but they're real comfortable with Korean...it's their native language and so that's what they're used to.

Similarly, Bob isn't sure if his sister thinks of herself as bicultural even though she was also born in the United States. She attended the same international school as Bob, but when she was in fifth grade or so, Bob's parents transferred her to a Korean school. I am struck how Bob sees his sister so differently because of the years she spent going to a Korean school. Bob tells me that his sister was also raised speaking English, and that she currently lives in 
New York, where she's working as an actress. When I asked Bob more about his sister, he persists that he's not sure if she thinks of herself as bicultural, and that his parents must have considered her less Americanized to be willing to place her in a Korean school. He offers little more.

Bob says he wants to be a language teacher because he loves little kids and because he's developed patience over the years, which he thinks will help him with out of control kids. He's interested in languages and possibly teaching ESL, and he has an intuition that he'll be a good teacher. Bob thinks that his purpose in life is to teach kids, and as part of his strong religious commitment, he believes that God is calling him to be a teacher. In a quiet voice, he tells me that he first heard this call to become an elementary school teacher when he was in the airplane on the way to Portland. With growing enthusiasm, Bob describes this moment. His eyes sparkle. "I heard God telling me," he says quickly, while shaking his index finger at me twice, " you must teach kids for a living." There is a brief pause, then he adds a little more rapidly, "So I am." He seems settled, which I suspect is something he's gained since moving to Portland from Illinois, and ready to begin the graduate teacher education program. 
During the fall term, Bob was also taking the TESOL Methods I course. As part of the practicum requirement for this class, Bob was tutoring a Korean student and a family from Albania. I asked Bob to tell me a little about how he approaches including culture into the language teaching he's been doing. Initially, Bob focused his answer on language, explaining to me that he can use Korean when talking to the international student he tutors, which helps him to explain English slang expressions. With the Albanian family, Bob expresses more of a challenge because he doesn't know Albanian. Focusing more specifically on cultural aspects of this experience, Bob tells me:

I consider myself to be more culturally aware than other people because I've lived in two different cultures. And, that's not to say that I know everything about other cultures that are totally different from my own, but I try to learn about it.

He furthers this by telling me that he's learned some things about Albanian culture from this family. In working with this family, Bob sees culture as important because he tries not to offend the family. 
In this conversation, Bob describes how culture fits into how he sees himself as a teacher. He envisions himself as sensitive and accommodating:

I try to become more culturally aware by reading up about a culture I know nothing about. And just because I'm bicultural I think I would be more acute about what's going on in other cultures...I try to become more alert to other situations...I try to apply the perspective of the two cultures I'm from. I would try to accommodate.

In this particular instance, Bob seems to be focusing on the cognitive aspect of culture learning in that he tells me that he would try to learn more by reading about the culture. Although he is trying to use language that also attends to the behavioral aspect of culture learning by using such words as "acute" and "alert," which imply that he is trying to increase his perceptual acuity, he doesn't give any examples of how he might accommodate people with his behavior. "Applying the perspective..." remains in the cognitive domain; furthermore, Bob says that he would apply the perspective of the two cultures he's from, but he doesn't mention anything about trying to take on the perspective of a third culture. 
Later, I ask Bob to tell me if he considers himself as a cultural informant. Thinking about how Bob has lived in both the United States and Korea, I assumed that Bob would be a great mentor to someone just beginning to adjust to life in the United States. Yet, Bob tells me that in both of his roles as a tutor, he hasn't focused on culture. In the case of the Korean student, Bob has been "accommodating" him by helping him study for the TOEFL. The Albanian family Bob has been working with doesn't know any English, so Bob isn't sure about when he'll teach culture, although he thinks it will be easier to teach once the family is a little more proficient. In either case, Bob thinks the culture part will come eventually.

\section{Bob's Network Analysis}

As part of my interviews with Bob, I asked him to complete a network analysis. I asked him to think of all the people and places he has contact with in an average week. Bob thought for a minute, and said, "church and PSU." He drew one box for himself, and a line down to two other boxes labeled "church" and "PSU." When I initially questioned these two categories, Bob adamantly assured me that his time is spent divided between time at school and time 
at church. Eventually we were able to expand these two categories, and the result is shown in Figure 5.1 below.

Bob's initial categories-church and school-remain the primary categories for his analysis. Bob explains that when he isn't at school, he's usually at church. His friends are either friends from school or friends from church. There is only minor overlap in these two categories. Bob is involved with a student church organization at PSU. In drawing his network analysis, Bob labored over these categories, drawing and erasing several times before he was satisfied with the result.

After Bob and I listed each of his contacts-people, classes, and organizations, I asked him to write the cultural background of each contact next to it. These cultural distinctions are also shown in Figure 5.1. Interestingly, Bob's contacts are fairly evenly split between American, nineteen contacts; and Korean, eighteen contacts. This does not include contacts from other cultures or contacts that Bob determined to be multicultural. Furthermore, Bob's contacts with Americans and Koreans are primarily segregated. For instance, Bob attends a Korean church, and he lists no Americans as contacts there. Similarly, Bob denotes no other Koreans involved in the PSU campus church organization, 


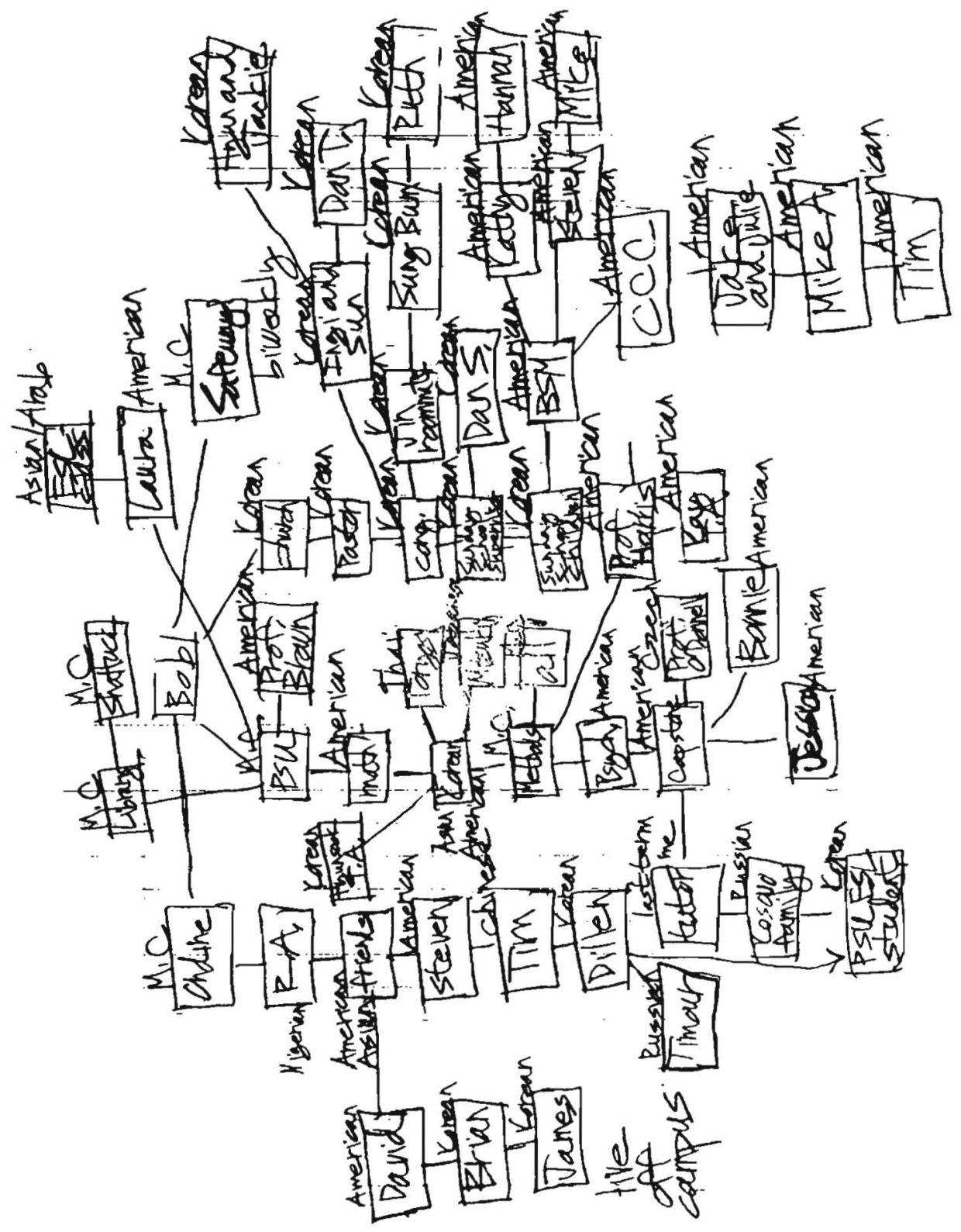

Figure 5.1 Bob's Network Analysis 
which has only American contacts. While Bob is taking Korean at PSU, Bob associates no American students with it; in addition, he associates no Korean students with any of his other PSU classes. The only real place where Bob lists both Koreans and Americans is his friends, both on- and off-campus. Bob's network analysis supports his dualistic view of his own biculturalism. Bob is either Korean or American depending on the context.

\section{Bob's Initial IDI Profile}

Bob's initial IDI profile supports the dualistic thinking that characterizes most of my interactions with him. Although he has experience in two cultures, Bob has doesn't have a clear understanding of biculturalism. Furthermore, he has never articulated to me times that he's been aware of shifting frames or behaviors. Bob's initial IDI profile (see Figure 5.2) indicates similarly.

Bob first took the IDI during the first week of class. The results presented here show only the means for each of the six scales. Although the data for the individual questions is not presented here, Bob generally did not answer with either extremes, such as Strongly Agree (7) or Strongly Disagree (1). 


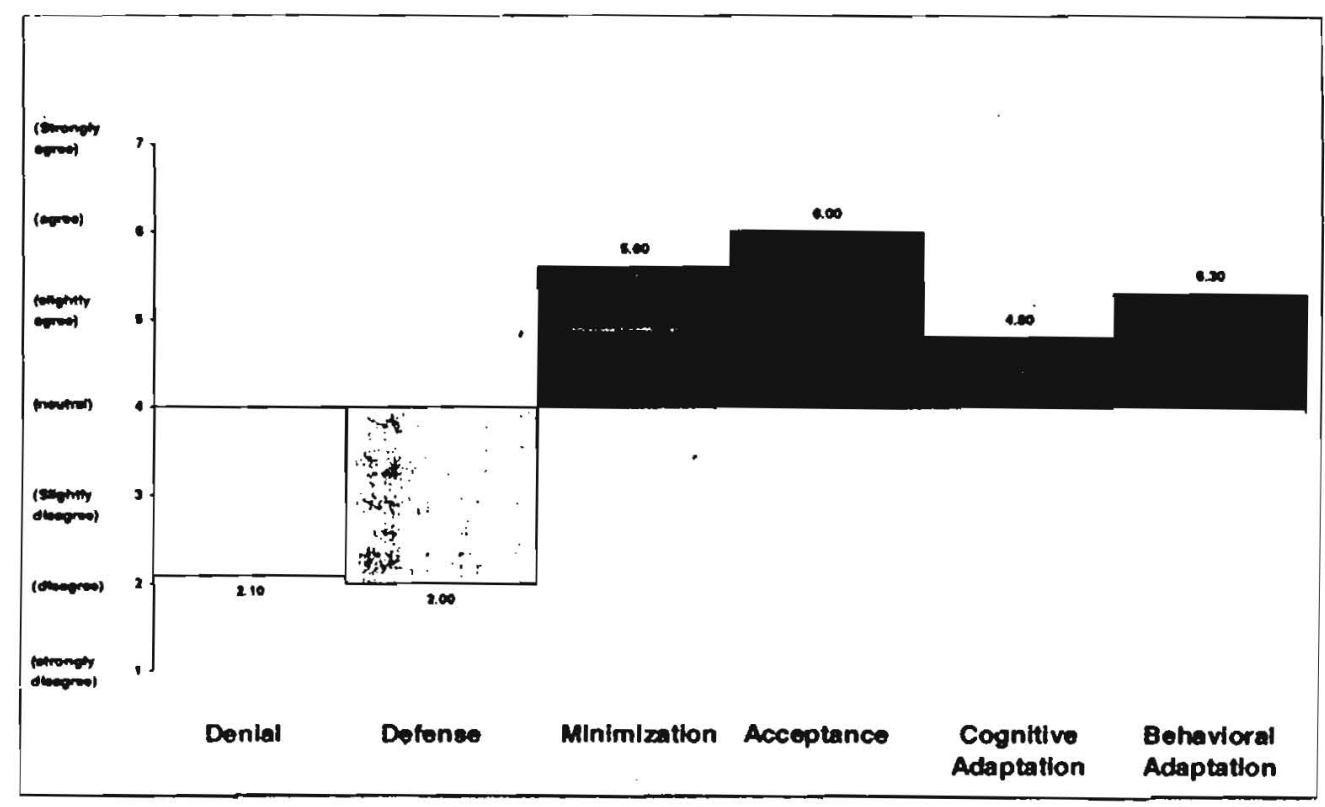

Figure 5.2 Bob's Initial IDI Profile

On the first of the ethnocentric scales, Bob's Denial score is 2.10, which means that Bob confidently rejects the worldview of Denial. This means that Bob notices cultural differences and does not avoid them. Furthermore, Bob's score for the Defense stage is 2.00, which indicates that Bob also rejects this stage as well. This suggests that Bob also respects cultural differences-he does not think that his culture is better, for instance.

Bob's Minimization score is 5.60 . This score is partially explained by Bob's religious affiliation, as one element of 
Minimization is the belief in the transcendent universalism of religion. However, this high score in Minimization suggests that Bob's strategy for dealing with the cultural difference in his own life is to emphasize the similarity of cultures rather than the differences. This follows with Bob telling me that he doesn't experience culture shock going back and forth from the United States to Korea, for instance, and overall, fits with the picture of Bob as an accidental bicultural.

On the first of the ethnorelative scales, Bob's Acceptance score is 6.00. This suggests that Bob accepts and is interested in cultural differences. Bob's strong curiosity about other languages would be one example of how Bob enjoys learning about other cultures, for instance.

While the Minimization and Acceptance scales are most significant to Bob's IDI profile, it is worth mentioning his scores on the other two ethnorelative scales. Bob's Cognitive Adaptation score is 4.80 , and this is, in part, due to his answering Neutral (4) on several of the questions. This score suggests that Bob is still learning the language to explain his biculturalism, and he is not always able to make shifts in his perspective. Bob's Behavioral Adaptation score is slightly higher at 5.30, which indicates that he 
is able to shift his behavior, although he may not always understand why. Again, these two scores support the notion of Bob as an accidental bicultural because they show Bob still learning how to transfer his skills in Korean and American culture to other cultures as well.

Considering Bob's background, an appropriate developmental activity to move Bob from Minimization to Acceptance would be for Bob to have a significant intercultural experience. Although I didn't actually look at Bob's IDI before he began the ethnography project, in retrospect, I assert that Bob could have a transformative experience with the ethnography project due to the culture-contact aspect of the project. Will the ethnography project be a significant cultural experience for Bob? With this question in mind, I will now turn to Bob's ethnography project.

\section{Bob's Ethnography}

Bob expressed initial enthusiasm in the ethnography project. He was attracted to the ethnography project in part, because of its purpose of learning about another culture, but also because of its authentic, experiential focus. He relates these aspects to me, 
I think it's a great thing to do because we are in a culture class and learning about other cultures is the whole point. During this project we'll be finding out for ourselves, we'll be doing all the work. . I consider this to be a hands on project because everyone in the class will be doing all the work...instead of it being dictated to us. ... The information will stick with us better.

In this description, Bob demonstrates his understanding of how this project attends to different learning styles in that it is "hands on." While he makes this connection to learning styles, he doesn't suggest any connection between learning styles and culture, or how this project may enhance his own understanding of a different culture.

Furthermore, in addition to applying the project to his interest in education and learning styles, another advantage Bob looks forward to about the ethnography project is its relationship with language. Considering learning about culture an extension of learning about language, Bob was excited about the possibility of learning more about another culture. He explained his comparison of languages and cultures to me, "not only am I into languages, I'm really into...since I'm bicultural as I mentioned before, I'm sort of 
interested in how the other cultures work and live and everything." These comments reveal that Bob had very general expectations of the ethnography project. While I think that Bob started his ethnography project not knowing what he would find, his comments here reveal an interest in trying to make sense of his own cultural perspective in that he links his own identification with being bicultural to his interest in the project itself.

For his ethnography, Bob chose to interview another student from the class. He chose "Sergei" because they were already friends prior to the course and because Bob "wanted to get to know both the culture and the person." In Progress Note 3, Bob shares his limited knowledge of Russia and Russian culture. Bob writes:

The culture I have chosen to write about is Russia. All I knew and know about Russia is that it used to be called the Soviet Unions before all the states separated, Boris Yeltsin is President, the capital is Moscow, and the Kremlin is located there. What I hope to learn is how the people survive with all the problems they have, what they do for entertainment, and how they live in general. I'm also hoping to get to know my informant better by trading cultures with him for my ethnography. (PN 3) 
In our interviews, Bob added to his list of what he wanted to learn about Russia-food, what people do for fun, the arts (and theater, specifically), and more about the political system. Bob admitted this was something of a wish list, and he knew he wouldn't get to it all. While some of Bob's topics include more surface-level cultural aspects (Foods, Flags, Festivals), he does express interest in the values, attitudes and beliefs of the Russian culture. Interestingly, Bob's final ethnography focuses primarily on education, something not on his list. And, while his final ethnography at times appears to only adequately address the assignment, Bob's discussion of education in Russia is rather thorough.

Bob explains his interest in choosing the Russian culture, and his informant in particular, in Progress Note 2:

My informant is from Russia. He is also Mongolian among many other cultures due to the ancestry of his grandparents and parents. My informant doesn't exactly [know] which culture he is from because he has such a diverse background due to his ancestors. He will probably stick with Russia, however.

I chose my informant because Russia and Mongolia 
are countries I know nothing about that I would like to learn. I've become more interested in Russian culture ever since my sister sent me a postcard from St. Petersburg when she was visiting.

I think this ethnography will be quite useful for me since I will have a written record of someone from a culture totally different from my own that I can look back on and reflect on in the future. (PN 2)

Bob doesn't directly express many reasons why he chose to study Russia beyond the fact that it is "totally different" from his own, which may explain why he didn't interview someone from another East Asian country, and that his sister visited Russia. However, in this respect, Bob is like most students doing the ethnography project. He chose his informant based on a vague interest and the availability of someone to interview.

I asked Bob, based on this description of his informant in Progress Note 2, if he thought his informant was bicultural. Considering what Bob says about Sergei here-that he is "Mongolian among many other cultures"-as well as the fact that Sergei graduated from high school in California and has lived here ever since (as I've learned in an interview with Bob), I think of 
Sergei as bicultural, at least. While Bob wasn't sure if his informant is bicultural, his initial answer suggested that he considers Sergei to be primarily Russian. Bob thinks for a minute, and then says slowly:

I think he considers himself more Russian than anything just because Mongolia or the province he's from was recently part of Mongolia but there was this revolution or something and Russia took it over. His province where he's from separated from Mongolia and then became a part of Russia after that so I think he considers himself more Russian than Mongolian although he identifies with both still.

Here, Bob focuses primarily on the geographical reality of the region where Sergei is from in making his determination that Sergei must be Russian. Because Sergei is from a region now governed by Russia, Sergei is Russian, according to Bob, and although Bob briefly mentions that Sergei continues to identify himself as Mongolian (and Russian), Bob never mentions how Sergei's years in the United States may have shaped his cultural identity.

Bob and Sergei actually interviewed each other for the ethnography project, and Bob told me that they felt comfortable 
talking to each other about cultural issues because, having already had a few classes together in the past, they had become friends. However, they agreed not to tape record these interviews. Similarly, Bob suggests that their comfort level was more general, as he told me in our first interview,

it's to a point where we're both comfortable talking about general stuff about my culture, but I'm not sure if it's to a point where I could get really personal with him....And vice versa. If I wanted to focus more specifically on him I would have to get personal. And now it'll just depend on the questions I end up asking because there's probably some questions he wouldn't want me to touch on or anything.

Bob thinks that his friendship with Sergei would facilitate the success of both students' ethnography projects. Bob expressed some hesitance about interviewing someone whom he didn't know, and this makes sense to me because in my own interviews with Bob, I had some difficulty in establishing rapport with him. We were able to talk informally even from the beginning; before and after our interview sessions, Bob and I often talked casually about matters relating to school or upcoming plans. Yet, during the 
interviews themselves, we remained at a fairly high level of politeness. Bob was often careful in his speech, often times asking me to turn the tape recorder off for a few minutes while he composed his answer in his head. In the last few interviews, Bob was more open with me, but even then, he maintained an acute awareness of the tape recorder. Reflecting on my interviews with Bob, I wondered what his interviews with his informant were like.

Bob admitted to me that he and Sergei had difficulty finding time in their busy schedules to interview each other. They chose to interview each other simultaneously, bouncing questions back and forth, each person taking notes (they both resisted tape recording). In spite of scheduling difficulties, Bob anticipated getting to know Sergei a little bit better. However, Bob was also cautious initially, as he tells me:

We don't really know each other THAT well yet but we do know each other to the point where we're comfortable talking about our cultures and general overview type of situation. . . It'll turn out better than if I interviewed a complete stranger but. . he may just not want to talk about certain things so we'll see. 
Hearing Bob's comments, I reflected again on my own musings before beginning my interviews with Bob. Not only did he seem to be reserved in his interviews with me, but also in his interviews with his informant. I suspect that Bob's concern about interviewing a "complete stranger" was related to a worry about establishing a new relationship with someone rather than to a concern about the type of information he would gather. I have the sense that Bob was trying to maintain a polite distance in both his interviews with me as well as with his informant.

Bob's initial concern about the level of trust he and Sergei had established was surprisingly intuitive. And, while Bob wasn't certain at first what topics might be off-limits in his interviews with Sergei, he soon found out. He first alludes to this in Progress Note 5, where he writes:

This ethnograhy project has helped me realize how many different cultures there are in one region or country. Russia is relatively large and there are many different cultures within Russia that I could write about. I have also learned that every culture has its own customs and traditions that will help me better understand my informant. 
I believe that the environment a person was raised in helps him/her become the person he/she is today.

I haven't really encountered challenges yet. I had already established a rapport with my informant before this project and this class even started. The only problem I may run into is getting a little too personal as I continue my interviews. My informant and I are at a comfort level where we could talk about anything but some subjects may still be off-limits. (PN 5)

It's interesting that Bob writes that he hasn't had any challenges with the ethnography project, because in our second interview, I asked him about what he meant when he wrote, "some subjects may be off-limits."

Bob told me that he had asked Sergei a question about his relationship with his American girlfriend. Bob was interested in knowing about cultural issues that may have arisen for the two of them, but Sergei apparently was uncomfortable with the topic. "I don't want to talk about it," Bob recalled Sergei saying, so Bob dropped the subject. When Bob and I talked about this incident, Bob thought he might be able to try bringing the question up again if he framed it differently. However, he never did ask Sergei such a 
personal question again. In thinking about this incident, I am reminded of the places in Bob's final ethnography that are lacking in depth. I can't help but wonder if this incident contributed to some shyness in asking deep questions, or if Sergei himself avoided answering on a deeper level.

While working on the final ethnography, Bob stayed fairly general for the first two parts. In his first draft, he wrote about Sergei's background. He described Sergei's childhood, growing up near Lake Baikal. In his second draft, Bob was encouraged to write more "thick, rich description," and he responded by including more detail about Sergie as a child:

If you had met my informant, Sergei, when he was a child, you might have seen him hanging out with a lot of cousins from the various relatives he has. As he matured into adolescence, you might have seen him playing a lot of sports, in particular, soccer and table tennis. You might have heard the ball whiz past your head as Sergei kicked the ball into the goal. You could have smelled the mud and sweat mixed into his clothes as he walk past you or you could have been close enough to touch his hair just to feel how coarse it was 
due to all the perspiration. (Russia: A Look Through One Man's Perspective, p. 2)

Bob's use of sensory description here builds upon his initial draft in which he introduced Sergei's childhood. However, even in this second draft, Bob was not entirely sure what he would focus on for his final ethnography.

In Progress Note 6, Bob writes about his focus for the MiniTour, the second paper. During the writing process, Bob reveals his aspirations of possibly including some of the cultural models discussed in class, yet he remains open to where Sergei wants to take him. Bob writes:

My focus for the Mini-Tour is more about my informant's life and finding out about his attitudes and beliefs about culture. I will quite possibly use the models from Kohl's article as a starting point. I will also go into more detail about my informant's life that wasn't present in my first paper. The themes haven't emerged yet because I haven't actually interviewed him yet since we are both very busy. It's hard to set up a time. I will get it done however. This project depends primarily on the interviews. (PN 6) 
As this progress note suggests, Bob changed his direction after meeting again with Sergei. The theme that emerged from Bob's interview was that of education, which is the primary focus for both the Mini-Tour and Bob's final ethnography.

Bob indicated that the theme of education was emerging when he completed a freewrite about the Clifford Geertz (1996) essay, "Deep Play: Notes on a Balinese Cockfight." In this freewrite, when asked how he is a reader of Sergei's culture, Bob details how he sees himself in relation to his project:

I am a reader in the sense that I try to find out as much as possible through my interviews and through written sources about the culture. I am approaching it as if I am a tourist in my informant's country visiting for the first time. My ethnography is focusing on the education system in Russia. I've been in school for quite awhile and through all the courses I've taken, I've become interested in what education systems in other countries are like. (Geertz freewrite) Again, Bob focuses on the importance of this topic in relation to himself. Bob and I have discussed the theme of education extensively as well, as Bob is working hard to complete a Bachelor's degree and move on to a master's program in education. 
Bob's final ethnography project includes significant portions of both his Grand Tour and his Mini-Tour as well as some of his Progress Notes, such as the one in which he describes how he established rapport with Sergei. Bob's final ethnography is a combination of these three papers, several facts about Russia, two maps, and several pictures of Lake Baikal.

The bulk of his final ethnography focuses on the education system and how it is both similar to and different from the system in the United States. Bob explains that his rationale for this is that he has been "a student for quite a while now and being involved with this class has gotten me more interested in this aspect." In addition to the immediacy of this topic, Bob was also interested in education because of the topic's importance to his background, as he explains, "Being raised in another culture also figures into my reasoning because when I had younger, I had an idea that education systems were the same all over the world. As I grew older, through the course of my schooling, I found out that this was not the case and I wanted to find out how they were different." Education has been an important issue for Bob, and interviewing Sergei about the education system in Russia appears to be important for Bob. 
In looking at the differences in the American and Russian education systems, Bob focuses primarily on similiarities. One example of a similarity Bob found is that Sergei was educated in Russian, and children in the U.S. are educated in English. Bob further expands on this language issue by pointing out some of the similarities between the two languages. He points out that there are cognates, such as "milk" and "moloko," and "apple" and "yabloko" (Russia: A Look Through One Man's Perspective, p. 9) and that there are words that Russia has borrowed from western languages, although he doesn't give any examples of these. Other similarities between the two educational systems that Bob mentions are that the grade levels are similar, and that education defines its students. Bob writes that he agrees with this statement, and he certainly has backed this up in our interviews when he points out that he has been "Americanized" through his schooling in Korea.

As for differences between the two systems, Bob writes that they are "significant." He then points out that in Russia, students apply directly to the department of the university that they wish to attend, and if they are not accepted they must wait to apply again the next year. Interestingly, while this is a difference between 
Russia and the United States, this is quite similar to what Bob has told me separately about Korea, although he himself has never drawn this parallel. Bob concludes this section on differences by transitioning to talk about educational reform in Russia.

Finally, Bob rather abruptly concludes his ethnography by including pictures of Lake Baikal. Bob provides no captions for the pictures, nor a detailed explanation of them. He provides a brief introduction to the pictures, stating that he wanted to include them because the lake is part of Sergei's neighborhood.

Bob concludes his ethnography with a sudden paragraph, wrapping up the entire project. In this final paragraph, Bob writes that he has found learning more about Russia to be "fascinating...because of the Communist rule before the Soviet Union fell apart” (Russia: A Look Through One Man's Perspective, p. 15). Furthermore, he reminds the reader of his limited knowledge of Russia prior to beginning this project, and thanks his informant for his help, saying, "With Sergei's help, I think I have now a better understanding of Russia although this ethnography did not focus on all aspects of the country, just on one. With all the problems Russia is currently having politically and economically, it will be interesting to see how it will cope with their 
problems in the new millenium" (Russia: A Look Through One Man's Perspective, p. 15).

Again, while Bob doesn't mention it in his ethnography, his final freewrite for the class matches his conclusion about Russia, to some degree. When asked one final time to write about his cultural background, this time, Bob wrote about Korea:

Korea is a homogenous monolingual society. Koreans value family tradition, history, and the arts in particular crafts such as paintings and pottery. Koreans consider history to be very important as evidenced by the many historical docudramas that come on every new television season representing the different dynastic periods of the country. They also value honoring their ancestors every New Year's Day and all families do this whenever Jan.1 comes around. The economic and political systems have gone up and down recently including our own presidential scandal. Unlike Clinton, however, it had nothing to do with sex. Korea elected a new president two years ago and he is hoping to stabilize the economic and political system when the country went bankrupt. Many Korean students in the States had to go back home because most of them were relying on their 
parents for financing. Some, however, stayed and found jobs in the U.S. because they had to start supporting themselves. The conclusion here reminds me of Bob's conclusion to his ethnography project, in that he mentions political and economic issues for Russia in his ethnography and the same for Korea here. Perhaps Bob was trying to maintain a certain level of formality with his ethnography project; thus he kept his own voice out of the pages of the ethnography paper. However, Bob did not draw this parallel when I asked him about this final freewrite, either. Instead, Bob said that he wasn't sure why he wrote about Korea. He said that we asked him to write about his cultural background, the culture he belonged to, and he just started writing. He did admit, however, that the strong negative feelings he had about Korea at the beginning of the term had lessened. Bob explained these conflicted feelings to me: . . just because I've lived here awhile. It's been seven years now. I kind of miss it...miss Korea, but not really. I mean, it's like hard to explain because on the one hand I miss certain aspects of it, but on the other hand, I do not. Whereas at the beginning, I was just sick of Korea just because we have so many problems. 
Over the course of the term, Bob appears to have developed a more complicated understanding of his own relation to Korea and the U.S., particularly in that he now feels comfortable saying that he misses Korea. However, in discussing Korean and American culture with me, Bob never used any of the terminology that was discussed in class, such as cross-cultural communication patterns (e.g. high/low context) or even Kohls' models, which he had considered using with Sergei, although Bob has described for me the differences between the American and Korean educational systems (included above).

\section{Bob's Final IDI Profile}

I did not observe much change in Bob beyond his increased comfort with his Korean ethnicity, and Bob's final IDI score reveals similar information. The means of each scale of the IDI are presented in Figure 5.3 below. Furthermore, Table 5.4 illustrates the numerical comparison between Bob's course initial and course final IDI results. Bob's final IDI results indicate no change in the initial two ethnocentric scales, Denial and Defense. However, changes occurred in the next two stages, Minimization and Acceptance. From the course initial IDI to the course final inventory, Bob's Minimization score increased by .60 and his 
Writing in the Contact Zone 161

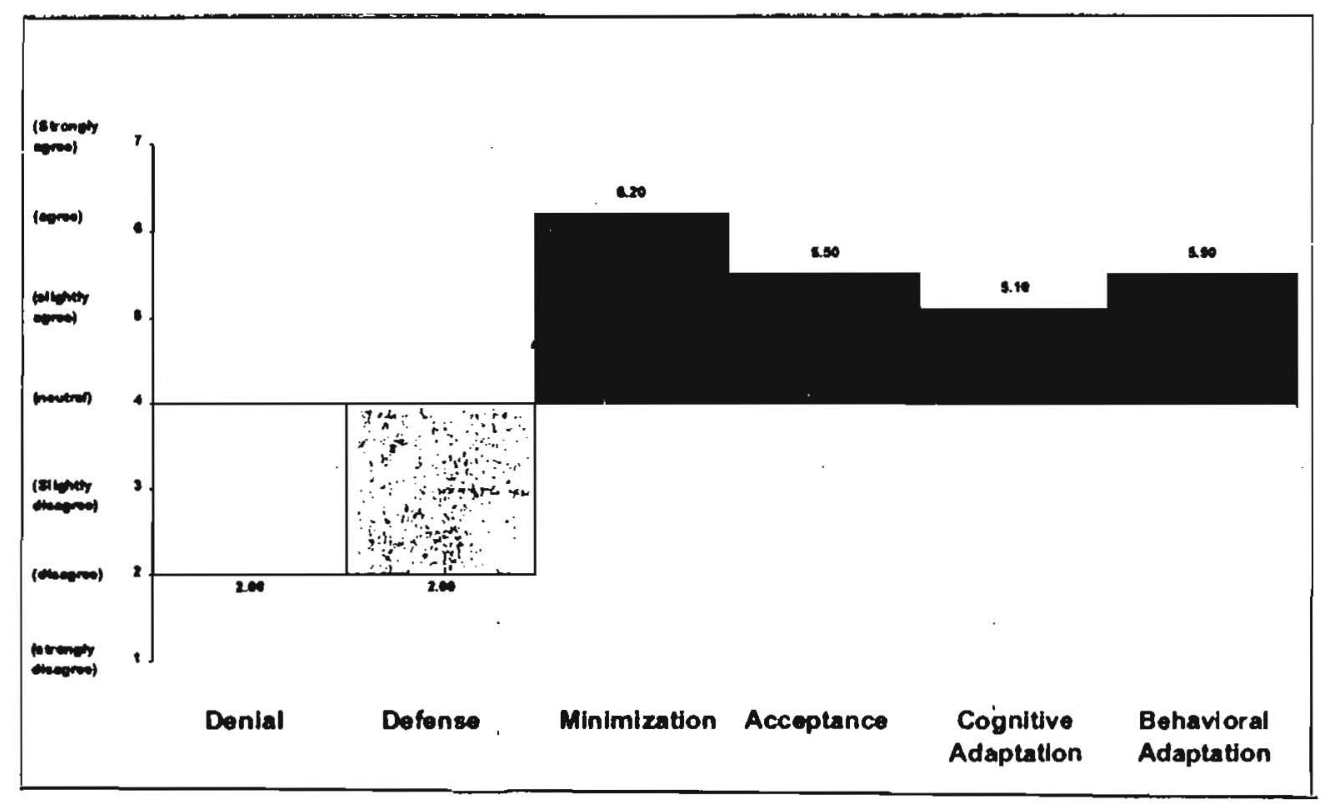

Figure 5.3 Bob's Final IDI Profile

\begin{tabular}{ccccccc}
\hline & Denial & Defense & Minimization & Acceptance & $\begin{array}{c}\text { Cognitive } \\
\text { Adaptation }\end{array}$ & $\begin{array}{c}\text { Behavioral } \\
\text { Adaptation }\end{array}$ \\
\hline Initial & 2.10 & 2.00 & 5.60 & 6.00 & 4.80 & 5.30 \\
Final & 2.00 & 2.00 & 6.20 & 5.50 & 5.10 & 5.50 \\
\hline
\end{tabular}

Table 5.4 Bob's course initial and course final IDI results 
Acceptance score decreased by .50. In part, the increase in Bob's Minimization score is related to his willingness to answer the more extreme answer "Strongly Disagree" (7), which he didn't use at all the first time.

On the other two ethnorelative stages, Bob showed a slight increase in both scores. On the Cognitive Adaptation scale, Bob had initially answered several questions with the "Neutral" (4) choice; however, in the final administering of the IDI, Bob chose to answer only one question on this scale with "Neutral;" instead, he answered with "Slightly Agree" (5). Perhaps this is a slight indicator of a growing confidence in his ability to make frame shifts.

In our final meeting, I asked Bob to talk a bit about his IDI results. He had previously told me that he had spoken with Kim about his results, and he relayed parts of that discussion to me. I told Bob I could show him copies of his IDI results if he wanted; however, he talked to me without them. It was clear to me that his results had made a strong impression on him.

He began by pointing out the changes in his Minimization and Acceptance scores. He spoke in a quick, confident tone as he told me about this change, ". . my Minimization skyrocketed, to me. When I saw it I thought, 'Whoa! Is that a good thing or a bad 
thing?' I wasn't sure." He said that when he talked to Kim about it, he realized that "I was just recycling stuff from the class even now."

Bob described to me that he sees now how he moves from Acceptance back to Minimization because of the comfort of the latter one. I asked him why he thinks he's more comfortable in Minimization, and he replied:

Oh, just because I haven't really had situations that were. . . (he pauses for a moment to think)..uh, challenged me. I would rather be in my comfort zone that step out of it. I don't really feel comfortable stepping out of it, out of the culture zone I'm in. I really think that I should do that in order to, you know, evolve into Acceptance and Cognitive Adaptation. But I haven't done that yet, and I haven't really had situations where I would be able to do that.

Thinking about Bob's questioning his informant about his girlfriend, as well as Bob's experience tutoring the Albanian family (which, at the time of this interview, he tells me he's no longer doing), I am surprised that Bob says he hasn't had any truly challenging cultural experiences. So, I ask him what he thinks might be challenging. 
Somewhat predictably, due to Bob's love of languages, his answer is translation. He tells me that due to the subtle nuances, he thinks that translation would be a truly challenging cultural and linguistic experience. Furthering this topic, I ask him if he is seeking ways to create such a challenge, and his response is no. He tells me:

I'm not actively seeking it out on a conscious level because first off, I don't really have time right now, and so, yeah, I would love to do that at some point. Just not right now. . .

I would love to do that at some time, just to see where I end up. To see if I move beyond Minimization.

For now, though, Bob views Minimization as a viable strategy as he focuses primarily on finishing his education.

\section{Reflection on Transformation}

Earlier, in one of Bob's freewrites, he describes himself as a tourist, taking in the information about Sergei's culture. In many ways, this metaphor fits Bob, because as a tourist, Bob has gone through the process of the ethnography project. However, Bob is a tourist because his level of experience with the project, at least as he describes it now, has not been transformative, as it could have been, considering Bob's initial IDI profile. However, for Bob, this 
project has not been a significant cross-cultural encounter. Bob's experience with the ethnography project has been primarily that of a course assignment. Having completed the project, Bob has remained relatively the same as when he began the project.

I began this case study on Bob wondering how an individual's background might influence her/his experience with this ethnography project. In the case of Bob, his upbringing as an accidental bicultural has had a significant influence on his experience with the project. Bob has perhaps made some changes in his understanding of the two cultures that he considers a part of him, but he has not yet been able to shift those skills to other cultures. In one of our final interviews, I asked Bob what influence he thought our interviews had on his experience with the ethnography project. Bob thought for a moment and responded, "It's helped make me more conscious." A sign of reflection, but not quite the reflexivity Donna Qualley describes as a potential outcome of both the writing process and a cross-cultural encounter. 


\section{CHAPTER SIX \\ LIVING IN THE CONTACT ZONE:}

\section{CLEO}

One of the limitations on transformation, according to Mezirow, is age. He suggests that a person must have a wellestablished perspective before it can be transformed, and both the process of perspective-building and setting up the conditions to create the cognitive dissonance necessary for perspective transformation take time. Mezirow points to the third decade of a person's life as a time of transformation. Although he doesn't give hard evidence for why he believes transformation doesn't happen before then, he does add that his own observations and those of his colleagues have at least anecdotally supported this hypothesis.

Reflexivity, on the other hand, is not a phenomenon bounded by age. Certainly Anchee Min (1994), in The Fall of Autumn Leaves, experiences reflexivity when, as a child, she forced herself to denounce her favorite teacher as a spy. And, while in Anchee Min's case, her reflexive experience probably led to transformation because it altered her relationship with her family and her favorite teacher forever, reflexivity does not always lead to transformation. Just because we have exposed our assumptions through the 
dialogue with an other does not mean we want to change what we believe. Transformation, on the other hand, is change.

I keep these questions in mind as I approach Cleo, a European-American female graduate student who agreed to be interviewed. One of the questions I hoped my study would answer is, do graduate students have a different experience with the ethnography project than do undergraduates? Naturally, I suspect the answer is yes. Again, observation (this time my own and that of my graduate student colleagues) suggests that graduate school is an intense experience of both reflexivity and transformation. We often talk about "the learning curve," which seems to take hold the second year, and my teachers have certainly corroborated this observation. As graduate students, our learning curve spills over to our own life, causing us to become transformed more than merely intellectually. Classmates of mine have gotten married, come out, divorced, and/or quit school because they found their passion. In my own experience, I can say that graduate school pushed me to travel abroad for the first time and to have a baby, truly a transformative experience. In contrast to Mezirow's observations, these transformations have happened to graduate students still in their twenties (myself included). Mezirow does not 
write of graduate school in his description of adult learning, but I can't help but wonder if graduate school serves as a catalyst for the transformative process?

As I described in the Introduction, my own transformation began, or at least became conscious to me, through the process of doing my own ethnography with Su-ho. Now, some years later, I can still recall my conversation with Dr. Brown (and I can say without hesitation that I'm sure she can too) when I told her of the profound effect the ethnography experience had on me in spite of the fact that I had not yet reached my thirties. Considering that I wanted to see if my experience could be replicated in other individuals, I was glad when Cleo (coincidentally, aged twentynine) agreed to be part of my study. Although I realized that her encounter with the project would most likely be vastly different from mine, her participation offered me the chance to step into the experience of another graduate student.

\section{Getting to Know Cleo}

I first met Cleo in an Applied Linguistics class we took together. She and I talked, and we were friendly to each other, but the demands of our own schedules kept us from spending much, if any time, outside of class together. As her colleague, I thought of 
her as very bright, articulate, and very goal-focused, and although I liked her, I hesitate to admit that her direct manner and work ethic intimidated me at first.

The day I described my study to the class and invited them to participate, Cleo sought me out. It was an hour or so after class, and she found me in the English Department office. She handed me her consent forms and said, "Here, I didn't give this to you earlier. And, I want to be one of the people you interview." She told me she knew that it's hard to find willing participants, so she wanted to help out. I had anticipated that she would be too busy, but I was glad she wanted to be interviewed, and I looked forward to learning more about her.

I met with Cleo in my office, usually on Saturday mornings. She came to her interviews with me looking as professional as she did on days that she was teaching. When we met, I often felt like we were on equal footing because we were colleagues together in the MA program. We spent a great deal of time talking "off tape" and we discussed different classes, professors, and issues related to writing a thesis. As our interviews continued, we both became more personal, disclosing more about ourselves, and at times, Cleo referred to our time together as therapy sessions. I know that I 
looked forward to our time together, and now, I miss having such regular contact with her.

When we first met, she had already written Progress Note 1, so I knew a little about her background. In that freewrite, she described herself as follows:

It's so hard to say "I belong to X culture." My culture seems to be so much a part of me that I have difficulty narrowing it down and explaining it in explicit terms. I come from a background of explorers. My most distant relatives explored, moved around, and were willing to take chances. My immediate family is like that too. I belong to many places and don't call any one place my "hometown." My parents, in their struggle to become financially-able-toprovide have moved from place to place, only stopping long enough in two places to get me and my brother through our schooling without too much difficulty.

I've often felt on the outside of things, although my appearances as a main stream young woman might tell some otherwise. My parents are products of 60's culture. They were young when I was born and inexperienced as parents. I loved my parents and they were all I knew. We had no 
money. I had few things. I didn't do ballet, learn how to play an instrument, or become a part of any extracurricular group. I soon learned that my "ticket out" was education. It was the only thing I did regularly. My parents supported me in all my school activities. There was much in the beginning that I didn't understand. There is much I don't understand now.

I don't strive for "things." My goal is not to acquire lots of money or other materialistic items. I don't shun these things either. My culture seems to value "things." I suppose that's the nature of capitalism. I question my society and culture, but I realize I am a part of it. Sometimes I'm proud of my culture, sometimes I'm ashamed. Regardless, I am who I am and I cannot so much change that, but I can try to be a positive, healthy, contribution to my existence [underlined with a line to "Individualism?"] and growth [underlined with a line to "focus on future?"]. (PN 1)

In this initial freewrite, Cleo presents a complex portrait of herself. On the one hand, she describes herself as a cultural marginal, feeling on the outside, not having one single place to call home. She says that she can't place herself in one specific culture. On 
the other hand, she gives hints of belonging to American culture. She observes that she appears to be a mainstream young woman, and she also describes herself vis-a-vis American capitalism, in that she doesn't "strive for 'things" but she sees how that desire fits in capitalism. Furthermore, she wonders about how individualism and future orientation, American cultural values, relate to her self.

In our first meeting, I asked Cleo to expand on the ideas in her first freewrite. She talked a little about the tension between feeling a part of mainstream middle-class culture and feeling outside of that culture. Although she is clearly aware of her working-class roots, she also says, "I suppose I'm more typical of American culture than I probably like to think I am."

Settling into the grey vinyl chair of my office-mate, Cleo continues, in our first interview, to describe her childhood in Colorado, where her parents chopped wood to heat their A-frame house, not being able to afford to fully fill their propane tank. She describes her family as working class, but not poverty level. As part of her definition, as in her writing above, she focuses on her early education and other activities. She tells me,

I was never read to, you know...just struggled in my youth, 
in school....[I] was always deemed bright in classes and stuff, but felt inadequate because of my family background. My parents were supportive of me, but I didn't go to ballet class. I wasn't in Girl Scouts. I didn't have a lot of friends.

The one thing Cleo did have, though, was the realization that college was the way to go. Although her parents didn't go to college themselves, she credits her mother for whispering "college" in her ear when she was only two years old.

When Cleo was in sixth grade, her family moved to Alaska, and she stayed there through her first year of college. She then transferred to the University of Oregon, where she majored in Japanese Language and Literature. After she graduated, she spent three years in Japan working for the JET program before returning to the United States and eventually beginning the MA-TESOL program here.

After this initial interview with Cleo, I feel a strong connection with her and I laugh at myself for once feeling intimidated by her before this meeting. Cleo has put me at ease with her willingness to share so much of herself. In my research journal, I remarked that I was relieved to have interviewed her first, because by answering my questions so straightforwardly, she 
gave me the confidence to do the other interviews. Furthermore, I can relate to Cleo's working class background, and I share her dilemma of defining the boundaries between working-class and middle-class life. I, too, had "college" whispered in my ear early on; so much so that at times I've wondered what I'm doing in college. Interviewing Cleo was definitely a reflexive experience for me in that our conversations left me feeling exposed much of the time (I suspect it may have been for her, too, particularly because she described our meetings as therapy sessions). I was aware of this during the process of the interviews, and I recognize that Cleo's effect on me has shaped my understanding of her.

\section{Cleo's IDI Profile}

The results of Cleo's initial IDI profile are characterized primarily with issues in Acceptance and some unresolved issues in Minimization. Her initial IDI profile appears in Figure 6.1. Not surprisingly, her Denial and Defense scores are low-1.70 and 1.10 respectively-and this suggests that Cleo is aware of other cultures and does not isolate herself from them or see other cultures as less complex than her own. This fits fully with both Cleo's experiences in Japan as well as her interest in English language teaching. 
Cleo's Minimization score is 3.70 . While this score is low, it does suggest that Cleo has some unresolved issues in this area. The Minimization subscale reveals that Cleo agreed with the majority of the superficial difference items, or those items suggesting that cultural differences are subordinate to humanity.

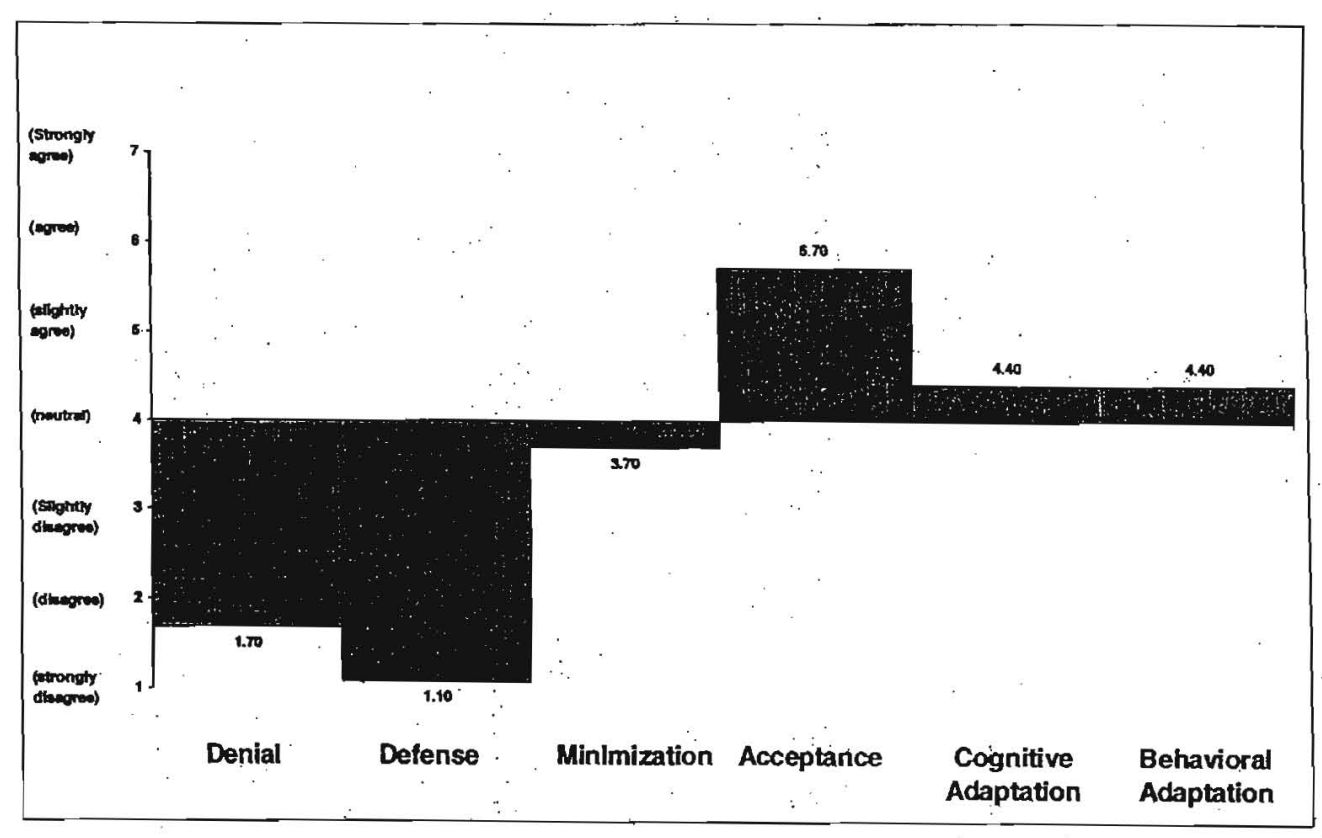

Figure 6.1 Cleo's initial IDI profile

She also showed some uncertainty in the other two subscales, human similarity and universal values. On the Acceptance scale, her score is 5.70 , just still within the range of uncertainty. In 
looking at the subscales, the issue Cleo seems to be resolving is value relativity (i.e. the notion that good and bad differs among cultures).

Both her Cognitive Adaptation and Behavioral Adaptation scores are 4.40. Overall, these results suggest that Cleo is doing both of these things, but not always feeling successful. In spite of her enjoyment teaching survival English, Cleo does not describe herself as a cultural bridge person, according to her IDI results.

To a large degree, Cleo's results fit with her description of herself above. Although in my interviews with Cleo, I did not find any evidence of Minimization, Cleo did describe herself as a cultural marginal. And, at times, Cleo seems to be uneasy with that definition. She states that she doesn't feel as though she belongs, or that she doesn't think her outward appearance matches who she is on the inside. Cleo did not, in her writing or her interviews, make direct statements minimizing human difference. Instead, I suspect that Cleo's description of herself as a marginal connects back to her minimization score. Considering Cleo's IDI profile, the ethnography project, as well as the strong cognitive dimension of the class as a whole, would be an appropriate opportunity for Cleo to put her the intercultural skills 
she's already developed into practice, while at the same time developing a bigger vocabulary for understanding intercultural experience.

\section{Cleo's Ethnography}

Cleo was prepared to do the ethnography long before she registered for the class. In fact, she had planned to take the class the year before, but she decided that she was unsure what culture she wanted to study, and she wanted to really learn something from the project. She told me she took care in choosing her informant so that she would have good results. I asked her to describe what she meant, and she told me, "I want to really have this be interesting, and informative, and fun. I am so excited about this project, I think it's really cool. . . . I'm definitely not approaching it as, 'Oh, it's something that's required, and I have to do it." Rather, she tells me that she hopes that it will give her information and inspiration to travel to Vietnam, the culture she's chosen to study. When asked why she selected this particular culture, Cleo informs me that she's always been drawn to Southeast Asia, but she's not sure why.

Cleo chose to interview Long, a Vietnamese man in the survival English class she's been teaching twice a week. She 
describes Long as "a sturdy man in his 30's" and one of the strongest students in her class. She feels like she's already established rapport with him because he was in her six-week summer course as well. He readily agreed to be interviewed for her project, and they met every week at McDonalds for an hour before going to the survival English class. In Progress Note 2, she describes Long a little more:

... I don't think anyone could push him over, and even if they could, I imagine that he'd bounce back up even more determined and steadfast than before. That's no wonder because Long comes from Vietnam and as you can imagine, has been pushed over many times. He and his family weren't one of the "bad guys." No, they were the good guys, fighting alongside of U.S. troops. Of course, that is assuming that you even think there were "good guys" and "bad guys" in the Vietnamese war. Long thinks there were. He is grateful to the American for saving his familyparticularly his father who was a lieutenant with the VRC, who subsequently spent 6 long years in prison, and who came to the U.S. as a political refugee. "Thank you" Long 
said to me in one of our interviews. A feeble "You're welcome" was all I could muster.

How I came to meet Long isn't a great story. What's important is that we know each other and have a good rapport. (PN 2)

Cleo tells me that she knew very little about Vietnamese culture before she began interviewing Long. She says she knew about the food, "cause I like Vietnamese food," she says with enthusiasm. She then continues, describing her surface knowledge of the religion, politics, and economics of Vietnam. However, even after only a few interviews with Long, Cleo feels as though she has learned a great deal.

Cleo began her interviews with Long by asking him to talk about where he was born. In the process of answering that question, Long detailed much of the recent history of Vietnam, placing himself in the context of the Vietnam war that divided his life between pre-1975 and post-1975. In writing about the significance of that date for Long, Cleo inserts herself as well: Almost every event in Long's life has somehow been affected by the date 1975 . Long knows the date well and he and many others refer to the month of April, 1975 as "Black 
April." It's hard for me to imagine April 30th, 1975 as a black day. I can't remember the specifics of that day in any tangible shape or form. In April 1975, I imagine that I remember myself as a little, pigtailed, blonde-haired girl, full of emotions and going off to my first year of kindergarten. Long remembers it as a horrible day, one that does truly mark the end of one life and the beginning of another. It is the day that following a major Communist offensive, Saigon fell. (Grand Tour, p. 5)

In her ethnography, Cleo describes how Long's family went from living a comfortable life in the city to being driven to the country, where they were basically given nothing but a knife to survive. They had to create a hut out of whatever natural materials they could find. In the remainder of the project, Cleo explores Long's family in detail and she describes his experience coming to the United States.

In the passage quoted above, Cleo demonstrates a great deal of self-awareness in portraying herself in contrast to Long. Cleo included the above section in her final draft, along with small sections of dialogue between herself and Long. In small ways, she 
brought her own experience into the final ethnography while maintaining the focus on Long and his culture.

Cleo was aware that the teacher-student dynamic played a part in her relationship with Long during the project. Cleo said that she was aware that teachers are respected in Vietnamese culture, and she attended to this aspect of her relationship with Long during the time that they met for interviews. Cleo also told me that Long initiated most of the topics during their time together, particularly through bringing photo albums and other realia to their meetings. She says that the theme of family emerged as a central focus for her ethnography because "he was always talking about his family and ... how they stayed together. . . I heard all about family, so I just kind of took it and went with it." In her final ethnography, Cleo recounts a conversation with Long about his family. Long brought a snapshot of his father to one of their meetings, and said, "[Cleo], I interviewed my father and wrote up his military history and training for your information" (Call It Saigon, p.11). Cleo describes the write-up Long gave her with the snapshot as "detailed." In addition to this topic initiated by her informant, Cleo also told me that Long brought her videos to watch and was generally very willing to talk about Vietnam with her. She 
reveals that she didn't feel like she was interviewing Long, but just having a conversation with him.

Cleo found the interview process to be very conversational, and she doesn't describe any difficulty in eliciting information. She and Long had known each other before she began the project, and she felt confident that they had established rapport. Furthermore, Long's willingness to talk about his culture facilitated the process, and Cleo felt the interviews were very open. Cleo not only suggests that the interviews were very open, or "freestyle" but that the ethnography project was not in the forefront of their meeting. She tells me that the pictures he brought would naturally pique her curiosity, and then, "Forget the project, you know, forget the project. I wanted to know, 'What's this food on this plate here, in the wedding ceremony? Really, what does this mean?" She describes being genuinely interested in the pictures Long brought to their meetings, and in her conversations with me, she talks with enthusiasm about meeting with him and sharing his culture. She continues to stress this fact, when she tells me, "Regardless of the impetus for us being there was that I'm doing the ethnography project, but once I got in, it wasn't about the ethnography project, really, to me. It didn't feel like it was about that. It was just, okay, 
finding about him and his deal and him sharing and me sharing, and there we were."

While Cleo and Long talked about the fall of Saigon, a time Cleo characterizes for Long's family as a time when his "family fell or rather were sent plummeting to depths so low and painful that I am glad I only have to imagine what happened, because to have lived it may have been too unbearable" (Call it Saigon, p. 9), Cleo also tells me that they didn't get "really touchy-feely with it." Instead, she describes their relationship much more professionally. In addition to the teacher-student dynamics, Cleo believes that gender may be professionally constraining their relationship. And, Cleo says that she's not personally involved, or in the relationship for a "life-long friendship." This holds to be true. Toward the middle of the term, Cleo feels like she and Long have exhausted their topics for conversation. She tells me matter-of-factly, It's not super touch-feely. . . he's [not] like "My life story is being told! And I'm going, "I'm the one telling your life story!" We're not doing that. It's. . . he's telling me what he's telling me, and I'm interested, and we're having nice conversations, and I think he feels. . . of course, I don't know exactly how he feels because that's how he feels, but I think he feels 
happy to talk about his culture and that people are interested.

What definitely comes across in Cleo's ethnography is that she is interested in Vietnam. The detailed portrait she creates of Long and his family is woven together with colorful descriptions and Long's own words. After reading her final project, I feel like I have met Long, even though I have not. I reflect on Cleo's observation at the beginning of the project that what was important was that they had already established rapport. This fact shines through in her ethnography.

\section{Cleo's Writing Process}

Over the course of our interviews, Cleo and I talked about her writing process, and how she was going to take the wealth of information Long had given her during their interviews and turn it into her final ethnography project. Cleo described her process as organic, definitely not limited to a specific format. While she admits she wrote an outline for her midterm, she shuns an outline for the ethnography. Instead, she looked for the emerging theme of family, and then looked through her transcriptions of the interviews to find supporting quotes. While the process of gathering the information from Long was relaxed for Cleo, around 
the time she turned in the Grand Tour, the first draft of the ethnography, she was still unsure of how it was all going to come together. Progress Note 5 asked her to consider her process so far, and what she had learned. She responded,

What have I learned? What a silly question! Of course what I have learned is a tremendous amount of information and not easily relayed in a quick $10 \mathrm{~min}$. free write. I certainly haven't learned how to be reflective, that's a concept with which I'm already painfully familiar. I have learned that culture learning through ethnography is fun, if not a little trying at times. I've learned that a willing, reciprocal informant is a must to create an environment of mutual exchange. Naturally, a willing and reciprocal interviewer is also a must. I've learned that people like talking about themselves and their culture provided they are in a safe environment. Equal status and reciprocity are not easily achieved, but worth the challenge.

The major challenge I've come across is how to make it all come together. How can I tell another's story and still do it justice. How can I talk about an entire culture in 15 typed pages? (PN 5) 
In our conversations together, Cleo made reference to the fact that the ethnography format is different from other forms of writing. She observed that the structure was more dependent on the information, although she also noted that some students followed the Progress Notes as a structure for putting together the ethnography. Cleo also commented that she was glad the class had been given the chance to see sample ethnographies because some used formats she hadn't even considered.

Toward the end of the term, she concluded that she would synthesize the three drafts, taking out extraneous information from the first draft. Feeling somewhat stressed at the end of the term, Cleo tells me,

I'm not going to knock myself out, and put in all kinds of new, new, new, new, new stuff in the last one. We'll see how much time I have. Unfortunately, it's unfortunate that it has to come down to that instead of just trying to. . . do it justice, and the whole project justice. . . [G]iven the limited amount of time, uh, just do the best I can with what I, with what I'm able to get. And hopefully that will still be nice. In addition to being limited by time, Cleo also acknowledges other limitations on her portrayal of Long. In fact, in the 
introduction to her ethnography, she writes that Geertz's guiding principle that "societies, like lives, contain their own interpretations. One has only to learn how to gain access to them" (p. 254) is the principle that shapes her experience with Long. Similarly, she recognizes that Long is only one person, and that he can only represent his understanding of Vietnam. Cleo describes her understanding of her limitations further, when she freewrites about Geertz:

Geertz's quote ["the culture of a people is an ensemble of texts, themselves ensembles, which the anthropologist strains to read over the shoulders of those to whom they properly belong"] eloquently states the feeling that I've had about my ethnographic project. I, however, have not attempted to put my feelings into words. My ethnographic project is a representation of a part of one person, from one culture, set in a limited span of time. The fact that this project is not autobiographical, but biographical also adds the element of the writer's/interviewer's own subjectivity. How I "read" an individual from another culture has got to be different from how that person reads his own culture. What I have chosen to focus on in my ethnographic project may or 
may not be what my informant would have chosen. My ethnographic project represents only a miniscule portion of what my informant is made of-oh, well. I just hope that what portion I am able to represent, I represent accurately and sensitively. (Geertz freewrite)

In this freewrite, Cleo seems to observe the limitations of the ethnography. She recognizes that our understanding of our selves and our own culture are characteristically different from our understanding of another culture. Cleo not only acknowledges her own lens but also her responsibility as the author of the ethnography. While she choose what information to include, she also took care to portray Long "accurately and sensitively." I don't know if Cleo shared her final ethnography with Long, although I'm sure she would have been comfortable doing so.

In addition to acknowledging the cultural limitations of ethnographies, in Progress Note 9, she writes about other factors that contributed to the complexity of the project for her:

I'd say that for me this project has been more challenging than effortless. The whole process of ethnographic work was unknown to me before this class. I had to learn the techniques of effective interviewing in order 
to successfully get at the underlying aspects of my informant's culture. I needed to find many outside sources and read up in order to make hypothesis and then search to see if they were correct. The sheer amount of time involved made this project atypical. Would I call it inspiring? I don't know. I guess not at this point. Maybe three weeks from now I'll feel differently.

I feel that in some ways I've experienced my informant's culture. Just meeting with him weekly and talking about culture was enough for me to feel as if I experienced his culture. My informant also brought many visual materials such as pictures, holiday items, and even incense that created a visual picture of his world. He even brought me a video that he checked out of the...library. Of course, I don't feel like I experienced the full depth and breath of Vietnam through this project, but I'm a little closer than I was before. This project has made me realize all the more my desire to visit Vietnam and see the country for myself. (PN 9)

Cleo clearly describes herself as still being within the process. She wrote this progress note shortly after having finished her final 
draft, but the process was still fresh for her, and she is aware that she cannot fully comprehend the effect the ethnography will have on her. So, while she returns to her original interest in Vietnam (i.e. she would like to travel there), she presents it more complexly. Her informant has increased her interest in traveling there, in part, because she now realizes how little she knows about Vietnam.

\section{"What have I learned? What do you mean by that!?"}

After finishing the ethnography, I asked Cleo to both write and talk to me about what she had learned from the project. Her writing, in the form of Progress Note 10 characterizes her impatience with my question. Aware that her perceptions of what she had learned was still an abstraction, she wrote the following: It's hard for me to say what I learned from this assignment. It's hard for me to pick things apart in a way that I can say I learned _ $\mathrm{X}_{-}$from $\_\mathrm{Y}_{-}$. All of my experiences contribute to my learning. I suppose I did learn some skills like the different ways to ask questions in interviewing. I learned about how one man from Vietnam perceives my culture and in turn how he perceives me. I learned more about the culture and history of Vietnam than I knew before. I'm sure that I don't fully understand the extent of what I've learned 
at this time. It's possible that what I've learned will manifest itself at some time in the future, and I'll say "oh-I get thisIt's like the ethnography project-or I learned this in Kim's culture class." Who knows. I do know though that I have learned I'm different now than I was when I started this project. (PN 10)

Cleo recognizes that she can't necessarily put words to what she learned, at least not at this point in the process. Even more important, she observes that interviewing Long has changed her, even if she isn't sure how.

Naturally, I asked her about this when we met. I was especially curious about Cleo's experience because she had written, in Progress Note 10 (above) that she "learned about how one man from Vietnam perceives my culture and in turn how he perceives me." Here, perhaps, was some self-scrutiny resulting from her experience with Long. While this may be the case on some small level, Cleo does not characterize her experience, or how she changed as a result of her experience with Long, that way. Although Cleo feels changed by the project, she reports that she didn't feel like her encounter with Long resulted in any "heavy duty self-reflection." I then asked her if she felt like she had 
experienced reflexivity. We talked for awhile about the term and its definition, and she then told me, "no, that did not happen with me in my ethnographic project." She continued, telling me that she feels confident that it didn't happen during the ethnography because she has experienced reflexivity before: "when I was living in Japan, and practically my whole existence."

I asked her to speculate about the reasons why she may not have experienced reflexivity. Cleo suggested that neither she nor her informant "were willing to go quite that far." She says that she stayed within her "comfort zone" the entire time, and she points out that in her relationship with Long, her student, she had many advantages. "[B]eing in my own country, in familiar surroundings, in my language environment, when I meet my informant, I was not the one coming to the table with the lesser of the information or the comfort zone." As for her informant, she considers the fact that he works with many Americans in his job, along with his numerous years in the United States as reasons for his relative ease with the interviews. Cleo does admit that he was nervous initially, and when we discuss this, she realizes that she had not attended to his safety. She recalls Long's hands shaking during the first interview, and she tells me that it probably wasn't safe for 
him at first. In spite of this initial issue, however, Cleo and her informant had good rapport, and she doesn't think either of them were far enough outside of their comfort zone to experience reflexivity. Cleo says of the ethnography, "It wasn't a knock-mysocks-off-blow-me-over-wowie-hair-standing-up-on-end kind of thing."

Still searching for how Cleo has changed, I asked her to return to a topic we had discussed earlier in the term. Before the midterm, I had asked Cleo how she might be considering the concept of culture teaching and learning differently. Back then, she had told me that she was beginning to think of it more holistically. When we returned to the topic at the end of the term, she told me that culture learning is definitely within her level of awareness. Cleo continues, telling me,

The whole concept of culture learning is more in my level of awareness than it ever was before. And, I also like thinking of it in those terms, "culture learning" not "culture teaching." This is a distinction that I am making in my mind right now, that I don't like "culture teaching." In rejecting "culture teaching," Cleo has defined culture in more process terms. Whereas in the past, she fell back on "culture 
teaching," especially giving “textbook explanations of culture, for lack of any information or another way to approach that" now, she feels confident that she has strategies for "culture learning" that she can share with her students.

In the end, Cleo and I discussed how the culture learning class was different from other Applied Linguistics classes. She commented that other linguistics classes were more theoretically focused and didn't emphasize cultural dimensions of language learning. She told me that the class changed her understanding of culture learning and that she was "definitely not looking at it the same way as I have looked at it before. I like the culture of this class, and I think it's cool." She continued, saying that the class is "right up there as one of the best classes I've taken." In discussing how this class was different, Cleo talked about the challenge of doing an ethnography project, and she told me that she had never done this type of project before. She described the project as recursive, saying that the project

was a lot of going back and forth and trying to be thoughtful about that. . . All the interviewing, and listening back over tapes, and reformulating questions, and coming up with hypotheses, and re-testing them, and ... the cyclical nature 
of it makes it much different from other classes, at least for me.

She says that other classes feel much more linear to her, giving information that she thinks can be extracted from beliefs. The culture learning class is different, though. To describe it, she draws a spiral in the air with her finger. We both laugh.

\section{Cleo's Final IDI}

At the end of the term, Cleo, along with the rest of the class, took the IDI again. While at the beginning of the term, Cleo's results were characterized by Acceptance with just a little unresolved in Minimization, her end of the term results illustrate the change that Cleo has articulated above. Cleo's final IDI results indicate strong Acceptance, moving into Cognitive Adaptation. Furthermore, her Minimization issues are resolved.

Cleo's final IDI profile appears in Figure 6.2. As expected, Cleo's Denial score is 1.40 and her Defense score is 1.00 , both indicating that she has no issues in these areas. Her Minimization score is now 2.00 , suggesting that whatever issues Cleo had in this area are now resolved. Moving into the ethnorelative sections of the IDI, Cleo's Acceptance score is high, at 6.20. This is 0.5 higher than Cleo's initial IDI score. This positive change probably 


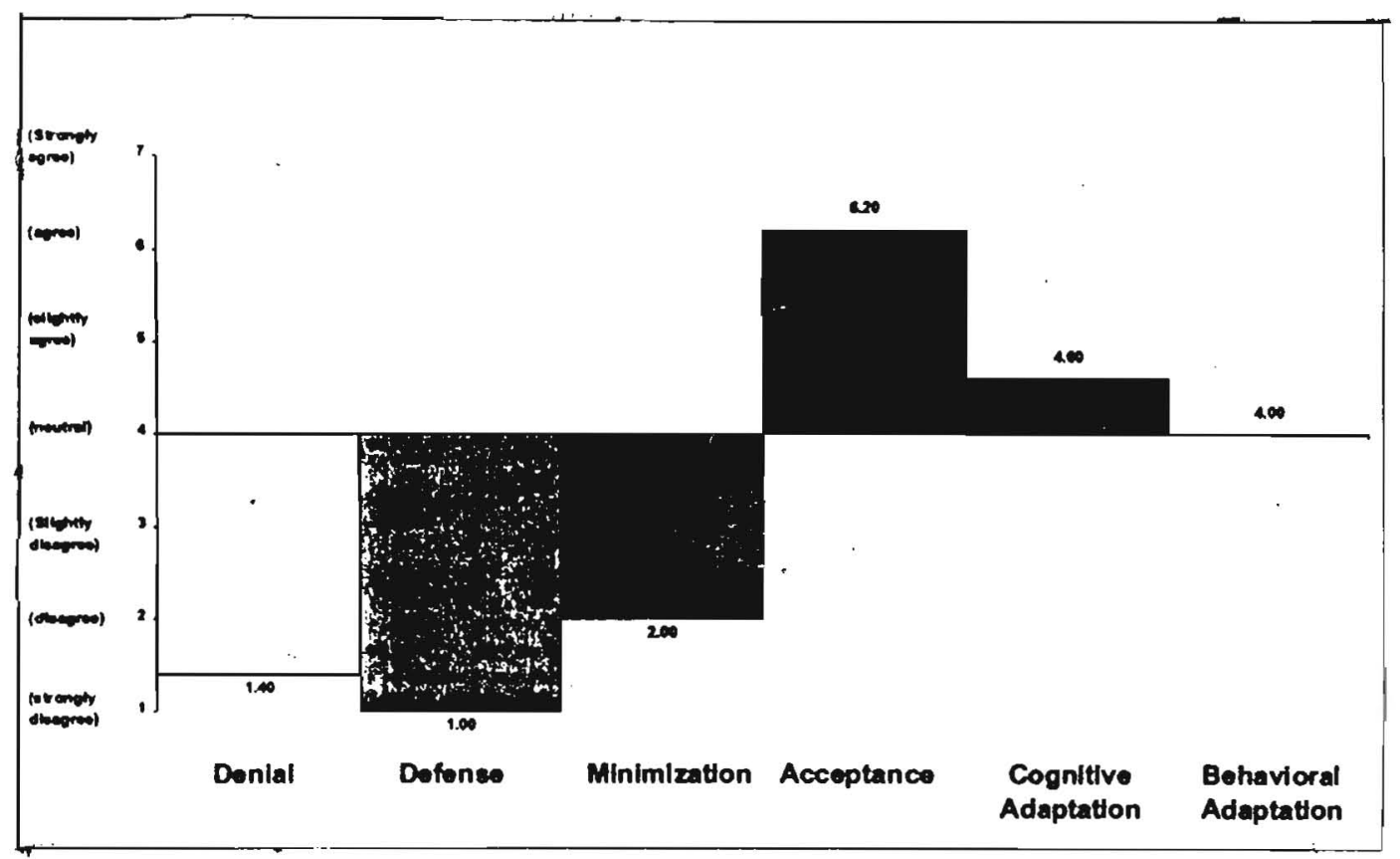

Figure 6.2 Cleo's Final IDI profile

indicates that Cleo has become even more comfortable in her understanding and acceptance of cultural difference. Additionally, Cleo's Cognitive Adaptation score increased from 4.40 to 4.60 . The subscales of Cognitive Adaptation indicate that Cleo feels comfortable analyzing situations from multiple perspectives, and that she has grown in her awareness of her role and ability as a cultural bridge. Yet, her score on the IDI suggests that she doesn't always think she evaluates situations using different cultural 
perspectives or helping other people understand cultural differences. Similarly, her Behavioral Adaptation score decreased from October's 4.40, now 4.0. This change reflects more strongly negative answers to questions relating to feeling comfortable in other cultures. In reflecting on Cleo, a successful ESL teacher, and her answers on these last two scales, I wonder if she has underestimated her ability? I imagine Cleo responding that she doesn't think she attends to these issues with her students; that she could do so much more. I think back to her saying that she didn't want to get "touchy-feely" with her informant, and I wonder if she feels similarly with her students?

Overall, Cleo's results indicate positive change, as is indicated by the comparison of her pre- and post-class IDI scores, which appear in Table 6.3. The shift in her Minimization score, from 3.70 to 2.00 , indicates that she has clearly resolved any issues in that area. While her first IDI could be characterized by some ethnocentrism, her final IDI results suggest a much more ethnorelative world view. This change is clearly 


\begin{tabular}{lcccccc}
\hline & Denial & Defense & Minimization & Acceptance & $\begin{array}{l}\text { Cognitive } \\
\text { Adaptation }\end{array}$ & $\begin{array}{c}\text { Behavioral } \\
\text { Adaptation }\end{array}$ \\
\hline Initial & 1.70 & 1.10 & 3.70 & 5.70 & 4.40 & 4.40 \\
Final & 1.40 & 1.00 & 2.00 & 6.20 & 4.60 & 4.00 \\
\hline
\end{tabular}

Table 6.3 Cleo's course initial and course final IDI results

reflected in her freewrite, written in the class on the last day. When asked to describe her cultural background, Cleo responds, Being in an academic environment I feel surrounded by white-middle class culture. I feel that I only partly come from this type of culture-although I blend well. I realize that white-middle-class culture is a blanket term and that there are many different aspects of culture than can be contained in it. But-I'm using it anyway. Coming from a working class family I'm often surprised by the things I encounter in my academic life here at PSU. I often find myself uncomfortable, not with where I came from, but with the fact that others think I'm like them. In one class I remember a graduate student talking about how those of us who are in graduate school are the academic elite. I cringed inside. I'm not an academic elitist. I simply have not come from that background. I resent that because of where I am- 
I'm interpreted as coming from a certain place. I'm not willing to "advertise" (dress, look, act) differently than I do now. I just would like it if we all would slow down a little and learn about each others' uniqueness. We are not all the same and because of that we all have an interesting story to tell. (freewrite, last day of class)

In this freewrite, Cleo clearly rejects a Minimization worldview. In focusing on others' uniqueness in the last lines of her freewrite, she communicates her acceptance of cultural difference. She describes irritation at other people assuming she is just like them. And, even more strongly rejecting of Minimization, she concludes with, "We are not all the same and because of that we all have an interesting story to tell."

This final freewrite also supports Cleo's change in terms of Cognitive Adaptation. In this freewrite, she uses language that demonstrates her own awareness of her cultural context. She uses terms like "white middle-class culture" and "academic environment," while at the same time describing herself as coming from a working class background. She acknowledges her own ability to shift cultures, operating in a primarily middle-class, academic culture. Furthermore, while Cleo did not experience 
reflexivity in relation to her informant, she most definitely describes reflexivity above when she says that a classmate referred to graduate students as academic elite. Cleo's cringing at the thought that she could be perceived that way caused her to reconsider who she is and how she defines herself and is defined by others.

This final freewrite illustrates a much more confident Cleo than at the beginning of the term. Her initial freewrite about her culture was met with hesitation ("It's hard to say 'I belong to X culture.'). She focused on specifics of her own experience, while in this final freewrite, she elaborated on specific differences between herself and others who are characteristic of "white, middle-class academic" culture. In her own words, Cleo has grown in her awareness of culture learning.

Cleo's experience in the culture learning class illustrates that transformation may not always be "a knock-my-socks-off-blow-meover-wowie-hair-standing-up-on-end kind of thing." Cleo's positive change in her IDI score suggests some kind of transformation occurred; in fact, Milton Bennett argues that in order to move out of Minimization, a "paradigmatic leap" must occur. I don't think such a leap happened as a result of her ethnography project. 
However, I do think that the format of the class, being focused more on the abstract and less on the linear, provided a certain amount of positive cognitive dissonance for Cleo. In addition, she spoke with energy about having the concept of culture learning in her awareness. This, too, may likely have contributed to the transformation illustrated by both her IDI and her final freewrite. As for why her transformation doesn't seem profound, Cleo says it best when she states that she went through many such transformations in her time in Japan as well as in her whole life. Cleo is good at experiencing reflexivity and self-reflection, and she takes it as it comes.

\section{Cleo Confronting Mezirow}

As described by Cleo's final IDI results and supported with her final freewrites and interviews with me, Cleo was transformed in terms of her level of intercultural sensitivity. Cleo may describe it without much fanfare, but the change is clear. Yet, Mezirow's work would suggest that $\mathrm{Cleo}$, at age twenty-nine, is somewhat too young for true perspective transformation to occur. As I argued in the introduction to my portrayal of Cleo, graduate school may be a factor that overrides age in terms of transformation. Now, as I put the finishing touches on my portrait of Cleo, I can't help but 
wonder how class and experience abroad also influence transformation.

Cleo is acutely aware of class, and its place in higher education. She is savvy, and she knows that higher education is primarily the property of white, middle-class America. In our time together, Cleo recalled more than just one class-related incident in her education. I can definitely empathize with her because I, too, have had my fair share of class-related misunderstandings in my university education. I wonder if this "extra cognitive dissonance" we've experienced has facilitated our ability to undergo perspective transformation. I suspect this question may be one for my future research.

Further, how does experience abroad shape transformation? Cleo points out that her time in Japan was full of reflexivity and self-reflection. In our time together, she recounted times that were both cross-culturally difficult as well as enjoyable. In all, though, her time in Japan was intense and transforming. Yet, time abroad does not mandate transformation, as stated best by Milton Bennett when he notes, "Being merely in the vicinity of events when they occur does not necessarily mean you've experienced that event." 
Cleo could have been in Japan and resisted having a truly Japanese experience, but she didn't.

Perhaps that is why the fact that Cleo is young (according to Mezirow) doesn't seem to matter in terms of her transformation. Cleo has opened herself up to many experiences_-traveling around as a child, studying Japanese and living in Japan, navigating class differences, interviewing Long, teaching English to immigrants and refugees, and meeting with me to discuss her ethnography project, culture learning, and reflexivity. Through these, and other experiences, Cleo has become good at shifting between cultures, Japanese and US-American culture, academic and working class, and others. Her ability to weave in and out of these different cultures has created for her a critical space-a contact zone-she's comfortable in. Cleo's familiarity with the contact zone is the reason why her transformation in the culture learning class is understated. 


\section{CHAPTER SEVEN}

\section{"WHOSE EYES ARE YOU LOOKING THROUGH:"}

\section{PHILLIP}

Reflexivity, as I have defined the term throughout this thesis, is the process of self-scrutiny that results from an encounter with an "other" (Qualley, p. 11). As I turn to Phillip, I realize that something about reflexivity that I had not considered was that it can be a two-way street. That is, reflexivity may be happening to me, but it may also be something the other person experiences, too. Cross-cultural exchange can result in positive or negative changes for all people involved. In the classroom, with the ethnography project, though, we only see the students. Since we have access to their informants only through the ethnography itself, we don't know what happens to them.

In my own case, I know that Su-ho, my informant, experienced positive change. Although he still found the United States a difficult place to live, and he returned to Korea soon after I finished my ethnography, he told me that he understood American culture more than he had previously. He also told me that he wouldn't feel so angry about his experience in the U.S., because I had helped him understand it better. In addition, the friendship we 
established, largely as a result of the ethnography, gave him a positive impression of one American, and he told me he would take that feeling back to Korea as well.

In my experience as the writing assistant for the culture learning class, I have not found this aspect of my experience replicated often. Not that it doesn't happen, however. Generally, the ethnographies are more focused on specifics about the particular culture the writer investigated, not the transitional process of the informant. In fact, in my own ethnography I wrote very little, if anything, on the topic of my informant's adjustment. Furthermore, I only briefly mentioned my feeling of reflexivity in the paper. I left this information out because it didn't seem to fit the rhetorical purpose of the paper.

When I began this study, I wanted to know how pre-service teachers experience this ethnography project. Would they have a reflexive experience? I honestly had not considered the experience of their informants-I have access to their informants only through the writers' words. I do not know who they are; I only know their pseudonym, their cultural backgrounds, and, in the case of my case study participants, the information that has been shared with 
me through interviews. So, the only way I can know if reflexivity is a shared experience is through second-hand information.

Yet, the case of Phillip suggests that second-hand information is trustworthy. Phillip brought to his ethnography project a wealth of his own cross-cultural experience. He shared that with his informant, a Japanese woman, and he believes they were both changed, although he would characterize her change to be much more profound than his. The portrait of Phillip illustrates a mentoring cross-cultural relationship.

\section{Meeting Phillip}

As with Bob, I had never met Phillip prior to this class. In fact, Phillip didn't really stand out to me among the members in the class until he agreed to be part of my study. The beginning of the term was hectic, and with over thirty total students in the class, I was busy trying to learn everyone's names and keep track of their information. By the time I was asking for volunteers for my study, Phillip had barely surfaced on my radar screen. Looking back, I feel fortunate that Phillip volunteered to take part in my study. I have enjoyed getting to know him, and I have learned a great deal about life and crossing cultures from him. 
Due to our schedules, Phillip and I did not meet in my office, as I did with Cleo and Bob. Instead, Phillip and I often met in the rather large conference room of the same building our class was held in. Although it was a friendly room, decorated in cultural artifacts, we sat across from each other at a long conference table. Even though I worried that my office might have created an unequal power dimension with Bob and Cleo, my office was also intimate in that it was a smaller room with reasonably comfortable chairs. The conference room Phillip and I met in, however, was more business-like. Yet, this room served as a good neutral space to meet. If anything, Phillip, with his experience and ease at crossing cultures had advantage. In our interviews, I often felt like he was always a step ahead of me. Yet, Phillip himself was disarming. He is patient, soft-spoken, although strong in his convictions. I could tell that he feels comfortable meeting people where they are at, while knowing also how to push them to take the next step. In his interactions with me, for example, Phillip put me at ease enough to find out that I was planning a trip overseas; in every meeting thereafter, he asked about my trip, and he was especially encouraging before I was completely committed to go. I 
suspect he knew that although I might have been hesitant, traveling abroad was important to my development.

When I first met with Phillip, I knew very little about him. I had his initial Progress Note, in which he defined his cultural background. Because Phillip's terminology for describing himself shifts during the course of the term, I think it's important to begin to understand Phillip on his own, initial terms:

I cannot say I belong to one culture because I belong to two cultures. I have often been asked to choose the culture I believe I belong to "most." I would tell that person that I could not choose one over the other. I would say that I am so much of both cultures that if you took one away it would kill the person who I am. It is like two trees that grow together at some point they become so entwined that if you were to attempt to separate them it would kill both (trees) of them. I feel truly bicultural even though I do not feel wholly bilingual. I know my English is better than my Spanish. If I want I can still think in Spanish. I don't have to translate my thoughts. My Spanish would be better if I had the opportunity to speak it in school and study the grammar there. I felt, as a child that I had to "give up" my Spanish to learn English. I did not 
know then that I could have kept both. There was a time in High School where I choose not to speak Spanish so that I would not be associated with the "kids," other high school students, that wore the bandanas over their foreheads, had the chains from their waist to their pockets and drove the low rider cars. I did it because they tended to keep Spanish and that would give me one more thing to make me not like them. My loss. My mistake. (PN 1)

In our first meeting, Phillip expands on what he has written, telling me that he considers himself Mexican-American, although he often uses the term Hispanic to refer to himself. He informs me that both of his parents were born in the United States, although his father returned to Mexico when he was an infant. His mother stayed in the U.S. until she was six, so Phillip says that she is more Americanized. He says both of his parents are bilingual, although his father speaks more Spanish than English.

As for Phillip, he tells me that he grew up in southern California, where "it seemed like most of my life [was] centered around the three block area where I went to." He attended parochial schools, and even though his world at the time didn't seem very big, he characterizes it as multicultural. He tells me that 
his school was very diverse, and that among the students he went to school with were other Hispanics, African Americans, and very rich kids. In addition, during his childhood, Phillip and his family remained very close to his Mexican heritage. On weekends and in the summer, they would visit his grandmother in Mexico, less than a two-hour drive away.

These days, Phillip is in his mid-thirties and full of experiences. He tells me of adventures traveling on a bicycle through Europe. He tells me about his daughters, and his eyes sparkle with love for them. He shares with me how his mother always told him he was going to be a teacher, and he realized that was true when he consistently found himself helping other people navigate through the bureaucracies of stolen IDs, buying a house, and helping their kids through school. One thing led to another, he tells me: "I was a teacher, assistant teacher, for a Head Start program for four-year-olds and five-year-olds for two, three years. And then, that, it just seems like I've always gone back to that. It's something I've always done, so I figured that I might as well get paid better for it." Now, he is working on his teaching degree, and he's in the culture learning class as part of his bilingual endorsement. 


\section{Phillip's Initial IDI}

Phillip's initial IDI profile reflects his comfort with other cultures. Included in Figure 7.1 below, Phillip's initial IDI profile shows a general rejection of ethnocentrism, and a strong acceptance of ethnorelativism, with reasonably high scores on the three ethnorelative scales.

Not surprisingly, Phillip has very low scores on both the Denial and Defense scales, which are 1.10 and 1.00 respectively. These scores indicate that Phillip is not uninterested in other cultures nor does he think his own culture superior. In fact, Phillip is keenly interested in other cultures, which is supported by his choice of a Japanese informant, since he admits he knows little, if anything, about Japanese culture.

Phillip's Minimization score, at 3.80, suggests that he does have some unresolved issues on this scale. The Minimization subscale for "Superficial Differences" illustrates a pattern of agreement for several of the items relating to the notion that people are the same in spite of cultural differences. In addition, Phillip agreed to the idea that it is "best to just be yourself." Because Phillip and I did not discuss his IDI (initially, due to my research protocol, and finally, due to Phillip's choice), I don't have a clear understanding of 
Phillip's answers here, as nothing in our interviews or his writing necessarily support this section of his IDI. Bennett suggests that some people who are from non-dominant cultures use Minimization as a way to cope with their minority experience; this may be one explanation for Phillip's answers. Whatever the case, Phillip's score suggests that he has some unresolved issues on the Minimization scale.

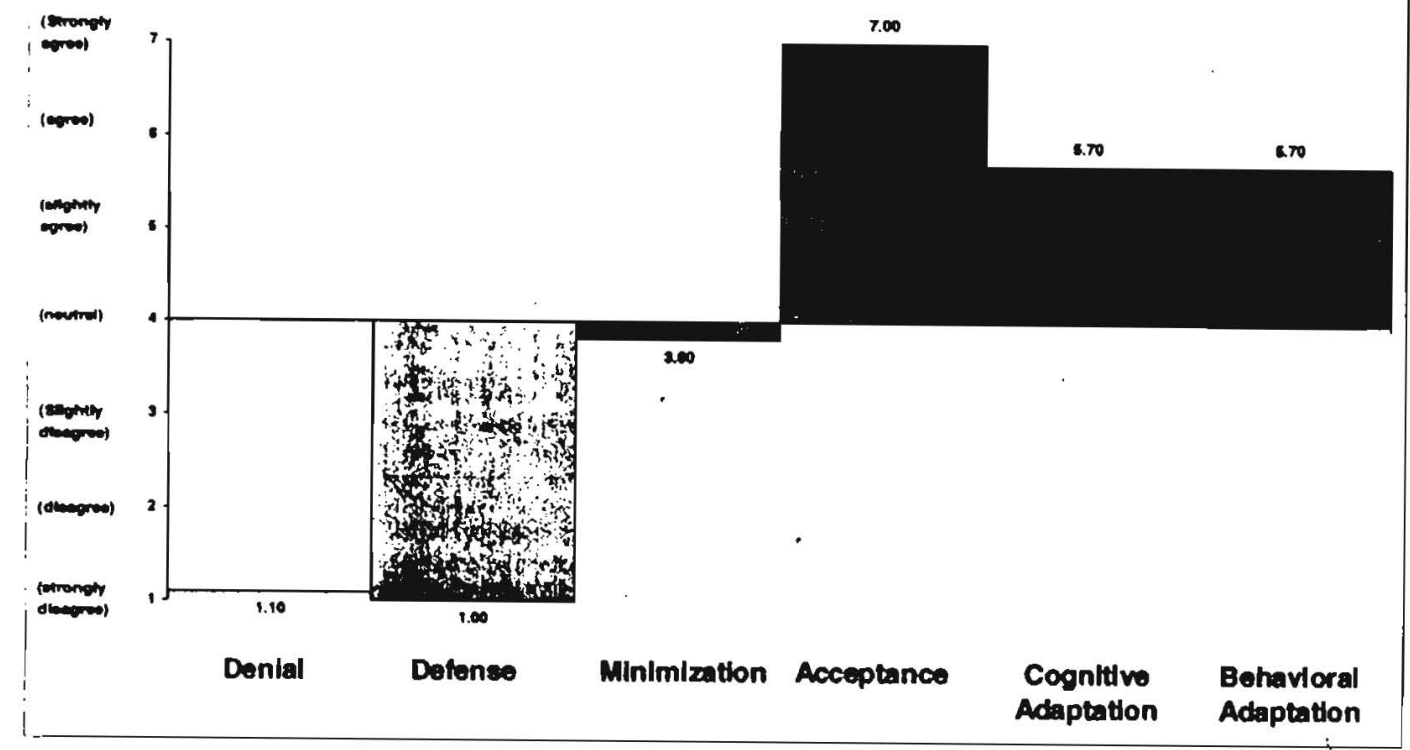

Figure 7.1 Phillip's Course Initial IDI Profile 
Turning to the ethnorelative scales, we can see that Phillip is very comfortable with other cultures. His Acceptance score is very high at 7.00 , indicating that Phillip strongly agreed with all of the items. His Cognitive Adaptation and Behavioral Adaptation scores are also high at 5.70 , suggesting that Phillip is generally comfortable using different cultural frameworks, both in solving problems, for example, and in his actions. The fact that Phillip describes himself as a cultural bridge supports his scores on these areas.

Someone who is as multicultural and as ethnorelative as Phillip has likely had numerous opportunities to interact with people from other cultures. Therefore, the ethnography project may not be as novel for him as it might be for some, and Phillip did voice this issue to me, suggesting that both the project and the class seemed geared for people with much less experience crossing cultures. Yet, the project still offers Phillip a chance to work with the language of interculturalism in the context of a cross-cultural experience. And, as we shall soon see, Phillip's maturity as a cultural bridge plays an important role in how both he and his informant experience the ethnography project. 


\section{Phillip's Ethnography}

Phillip chose to interview Himiko, a young Japanese woman in the TESOL Master's program. He and Himiko were taking classes together, although she was not in the Culture Learning class that term, and she had been interested in why Phillip speaks English without an accent. They struck up a conversation, and Phillip decided to ask her to be his informant for his ethnography project. Learning more about Japan was a good choice, Phillip says, because he previously knew nothing about it. In Progress Note 3, Phillip said more about his limited understanding of Japan. He writes,

I know very little about Japanese culture. All of the information I have of that country is from television and movies. I know it is an industrialized country that values education and group cohesion. Independence is not something they value. It is also a country that utilizes new technology as much as they can. I also believe it is a country that is male dominated, where most positions of power are occupied by men and women have specific roles they are supposed to fulfill. I hope to learn as much as I can bout 
Japanese culture and the values that my informant has learned through her culture. (PN 3)

Phillip also tells me that he's had some interest in Japan, but never really the chance to follow up on this interest. Although he's clear that he doesn't have the time to learn another language, he is hoping to learn a few Japanese words and phrases to help him better understand the culture. Overall, he's interested in beginning the project.

Early on, Phillip really enjoys the time spent with his informant, and he connects with her, in part, because of what he sees as their shared experience of being bicultural. He writes, I like my informant because she can express herself well in English and she feels she is BicuItural which I feel I am as well. I think we have may things in common with our points of views about being bicultural and some of the advantages and disadvantages that brings. I am looking forward to this assignment because of what I can learn about Japan and its culture and what I learn about that affects my views and beliefs. (PN 2)

Phillip used his connection to Himiko's biculturalism as part of his establishing rapport. Thanks to this connection, and Phillip's 
natural ability to get to know people and put them at ease, he and Himiko quickly found themselves becoming friends.

Although Phillip acknowledged their shared biculturalism early on, his initial interviews with Himiko did not focus so much on that topic as on other aspects of Japanese culture. Rather, they talked in some detail about bathing customs in Japan. The Grand Tour, his first draft of the ethnography, included almost two pages on Japanese baths. In addition, Phillip told me that he and Himiko also talked about Japanese families to some degree. He found out that Japanese people do not display physical affection, such as kissing, with their children. Phillip told me, and he also wrote about, how this would be something he would have difficulty with, as he enjoys being able to kiss his girls goodnight.

Phillip and I talked a great deal about his ethnography and its contents. He tells me that although he and Himiko have talked about certain aspects of Japanese culture, the interviews have really shifted to talking about her biculturalism. Initially, Phillip tells me this because he believes that what Himiko tells him is "edited." That is, "English isn't her first language, and she knows I don't know Japanese culture at all. . . . There's subtle things I'm allowed because I'm ignorant," he explains to me, suggesting that 
he doesn't get to know the intricacies of Japan because he knows nothing of the culture. He's only getting the big picture, with much of the detail left out. Furthermore, Phillip realizes that because Himiko has lived in the United States "at least three or four years" that she's "almost half-Japanese anymore." Phillip tells me that in one interview, he asked Himiko, "Whose eyes are you seeing through?" He states that he doesn't think she's seeing from Japanese eyes anymore.

In their discussion of being bicultural, Phillip thinks that he crossed the boundary of a strict informant/interviewer relationship. Instead, he finds that he's become friends with his informant. He relates this to me,

I think I crossed the line somewhere between informant and friendship. I think the way we talk...I'm really interested to see how she sees things. I think I have something to offer her in the sense that I can help her find the balance between being Japanese and her American influence because I've had to find the balance between the Mexican and American culture.

According to Phillip, Himiko is generally interested in trying to find the balance between Japanese and American cultures, even though 
at times she feels like she is more Japanese. Phillip says that he told her she isn't just Japanese anymore. Relating this conversation to me, he used a metaphor of a seed turning into a flower. He told her that when she was in Japan, she was a seed. Now, she's a flower, and he thinks she needs to let Japan know she's a flower, too. Phillip says that Himiko seems resistant to do such a thing, that she believes she can't reveal her true bicultural self when she is in Japan. He looks at me and says with a knowing smile, "I told her, 'You aren't just Japanese anymore."

While Phillip gently pushes Himiko to better understand her bicultural self, he shares with me that he does remember the time when he felt less comfortable about his own identity as well. In these connections Phillip is making with Himiko, and the mirroring of his own experience he shares with her, I begin to see a glimpse of reflexivity in Himiko. Phillip is offering Himiko a chance to see herself in a new way, even if this hadn't been her intention when she agreed to discuss Japanese culture with him.

I wonder if Phillip sees himself differently as well. Yet, just as Himiko found her own perspective transformation to be a surprising outcome of the interviews, Mezirow suggests that it is something that "neither learner nor educator is able to anticipate or 
evoke upon demand" (p. 202). I had to consider the possibility that Phillip might not value a new perspective offered by his exchange with Himiko. However, Phillip too, discovered himself through new eyes as a result of the project. Phillip told me, "Interviewing Himiko forced me to reflect on my own experience as a third culture person. My conversations with her brought me back to that point in my own life." His understanding of his cultural self shifted as a result of his interviews with Himiko.

In Phillip's conversations with Himiko, the notion of a Third Culture Kid/person came up. Here, Phillip was referring to a concept described by David C. Pollock and Ruth E. VanReken (1999) in their book The Third Culture Kid Experience: Growing Up Among Worlds. They explain the concept in terms of children who have grown up outside of their home culture-this can be in a number of different contexts. This concept really connected for Phillip, and he wrote his book review for the class on this particular book.

Phillip had never heard the term third culture person (he generally used the word "person" rather than Pollock and VanReken's "kid") before. Prior to reading this book, Phillip referred to himself as bicultural, but in making the connection with this 
book, Phillip realized that Third culture person was a better term. At one point Himiko told him she felt "neither" Japanese "nor" American, and Phillip connected this directly back to Pollock and VanRecken, as one section of their book uses that same terminology. For Phillip, he described almost feeling three cultures: Mexican, American, and Mexican-American. Therefore, the notion of Third Culture really described his experience.

Phillip shared his conversation with Himiko about being a Third culture person with me. He told me that she asked him what changed for him; how he knew that he could have both cultures. He said that after he lost his Spanish language, someone had told him that he didn't have to lose it. He realized, I could keep my culture and still be who I am. And it was at that point that I decided that I will be Hispanic and I will be American and I'll be both and I'll be proud of both. To deny it is to deny a part of myself. It's been a long time now, almost ten years, or longer. . . . I accept being a bridge. I'll always be a bridge.

In recognizing himself as a bridge, Phillip also recognizes himself as a Third culture person, and the conversations with Himiko have firmed this up for Phillip. He explains that talking to her about her 
experience has "taught me that I'm very comfortable in two cultures. . . and I think that the one thing that happens when you're a Third culture person is that you get to know yourself very well."

\section{Phillip's Final Ethnography}

These conversations about cultural identity were significant in terms of Phillip's final ethnography, as his project was ultimately focused solely on this issue. Phillip took out the information on bathing, for example, and focused primarily on the issue of being a Third culture person. It is worth noting, at this point, that Phillip refocused his ethnography based on written comments on his previous drafts by both Kimberley Brown and myself. In addition, in our interviews, I encouraged Phillip to write about the connections he had made in terms of the Third culture person concept. I'll discuss more about my role in my informants' writing in the following chapter.

In his final ethnography, Phillip describes a little bit of Himiko's background and how he's come to see her as a third culture person. Quoting Himiko, he suggests that her perspective is changing:

Himiko said, "Japan and my hometown used to be the whole 
world.I knew intellectually that there was more to the world but it had no meaning to me. Now I see Japan as only a small part of the world.

Here, in this quote from Himiko, Phillip is relating Himiko's own perspective transformation. Phillip has been a cultural other who has given Himiko an opportunity to experience reflexivity. Through her experience with Phillip, she has come to see herself in a new way-as a third culture person who is both Japanese and American.

In his ethnography, Phillip describes himself as having changed as well. His conversations about being bicultural, or a third culture person, brought consciously back to that space for himself, and Phillip shifted his level of awareness. In his ethnography, he recounts a moment in class where he became aware of his cultural identity:

The more I interviewed Himiko the more I found myself relating to her stories of not really fitting into one culture or the other. I guess a good recent example of this would be when the class showed the film "Fear and Learning at Hoover [Elementary]." I suddenly felt very Hispanic and looked around to see if there was someone else there of Latino 
descent. There wasn't. For the first time in a long time I felt as if I stood out like a sore thumb. I don't know if any of the other students noticed that I was the only Hispanic in the classroom at that time. (Ethnography p. 6)

Watching a film about a young El Salvadoran girl's experience in a poor section of Los Angeles was a different experience for Phillip than for the other members of the class. Phillip connected with the film on a very personal level, and in the process, he became aware of his positioning in the class as the only Hispanic person there.

The experience of feeling like he didn't belong to the American culture, as he described above, is somewhat unusual for Phillip. More common is that he feels like he doesn't belong to the Hispanic culture. He writes in his ethnography that this frequently happens around watching the Spanish channel on TV because the topics or language are sometimes unfamiliar to him. On the other hand, he also recognizes that his feelings of not belonging to one culture or another are "wrong" because of his proficiency in both cultures. He writes that he remembers his confidence "especially when I end up talking to someone in Spanish for ten or fifteen minutes non stop and don't have any difficulty finding a word or expressing myself. When this happens it makes me feel real confident in my abilities" 
(Ethnography p. 7). Similarly, Phillip recognizes his place in American culture, when he explains that "I also feel that I am very American when a Hispanic person asks me a question or to explain something that they are unfamiliar with" (Ethnography p. 7). Phillip has chosen to write about these moments of shifting culture, as well as times when he's felt less confident in Mexican and American cultures; his conversations with Himiko have created an opportunity for Phillip to revisit these topics for himself.

Furthermore, Phillip acknowledges in his ethnography that the project has changed him. He describes some of his own change in Progress Note 10, in which he writes,

Yes, I learned quite a bit about myself. I thought this project was to learn about another person not about myself. I learned that I am a Third Culture Person and that I have lots of things in common with my informant. She is Third Culture as well. I also had some of my views challenged about education and physical touching. What I expect is "normal" or acceptable is opposed to what is acceptable in Japan. I didn't know I liked my independence and individuality, something I would have a hard time with in 
Japan. I did not have any expectations because I did not know anyone from Japan prior to my informant. (PN 10) In interviewing his Japanese informant, Phillip believes he has just touched the surface of what it means to be Japanese. In addition, the project has "given me words to describe myself and other people who are or understand two cultures. ... I have had to reflect on how I act as a Mexican/American and realize that I am a bridge to both cultures to people who have questions concerning Mexican and American cultures" (Ethnography 8). Phillip, too, has experienced reflexivity because, through his interviews with Himiko, he has come to see himself differently. He has come to see himself as a third culture person. While this may be a subtle shift in language from his previous use of "bicultural," it is an important one because for Phillip it represents a more complex understanding of his experience in that he discovered he has three, rather than two, cultural frames through which he sees the world. In addition, he has had to take stock in his role as a cultural bridge and acknowledge it more consciously than he had before.

Phillip tells me how he sees his role as a cultural bridge as similar to being a teacher. He's come to terms with his role, and he feels like he never takes off that hat. He says sometimes he doesn't 
want to be a representative of his culture. "So I do a little bit less, but that's as low as I'll go. If someone asks, I'll always tell them about my culture." Phillip adds that, "You're going to communicate something one way or another, so you might as well communicate something positive." Similarly, he sees teaching as a role that never ends for him. He says that teachers are always part of the community, and they always have an opportunity to teach. The constancy of these roles, along with their responsibility, has become easier over time. Phillip shared this information with me, recalling how he had discussed it with Himiko. Yet, somehow, I felt like he was sharing it with me, too.

One additional outcome of the ethnography for Phillip was the strong friendship he cultivated with Himiko. Although he stated that he "crossed the line" between informant and friend, Phillip did not see a problem with the informality of their relationship. In fact, by the end of the project, or maybe even before, Phillip felt like the project almost got in the way of their friendship. In Progress Note 9, Phillip comments on this briefly along with making other comments on the process of the ethnography. He writes, 
Since I have never met anyone from Japanese culture before, I had very few preconceptions. What little I did know, or thought I knew was from TV but I know TV only gives a skewed perception of things. I think I have learned quite a bit from my informant but still have lots to learn! I found the ethnography inspiring because my informant became my friend. I think having your informant become your friend facilitates the process. The process was challenging in that I wanted to just hear the stories and not write them down. I wanted to get to know the person and not have to worry about "the project." (PN 9)

To a degree, his focus on getting to know Himiko rather than worrying about the project is illustrated by his final ethnography. In it, he discusses her own personal background and both of their experiences as a third culture person. Japanese cultural norms are mentioned only briefly, and only in the context of Himiko's experience.

\section{Phillip's Final IDI}

Phillip revealed that when he initially took the IDI, he had never heard of the IDI before. He approached the IDI curious, but "relatively unreflective." He had no context in which to understand 
it. At the end of the term, though, "topics from the class were swirling around in my head, and I considered them while I answered the questions." The class, then, created an opportunity for reflection.

Phillip's final IDI profile reflects not only an increase his understanding of himself as an interculturalist, but it also clearly illustrates the recursiveness of Phillip's reflections on himself and Himiko in terms of their cultural identity. Phillip's final IDI profile is illustrated in Figure 7.2 below. Table 7.3 indicates the mean

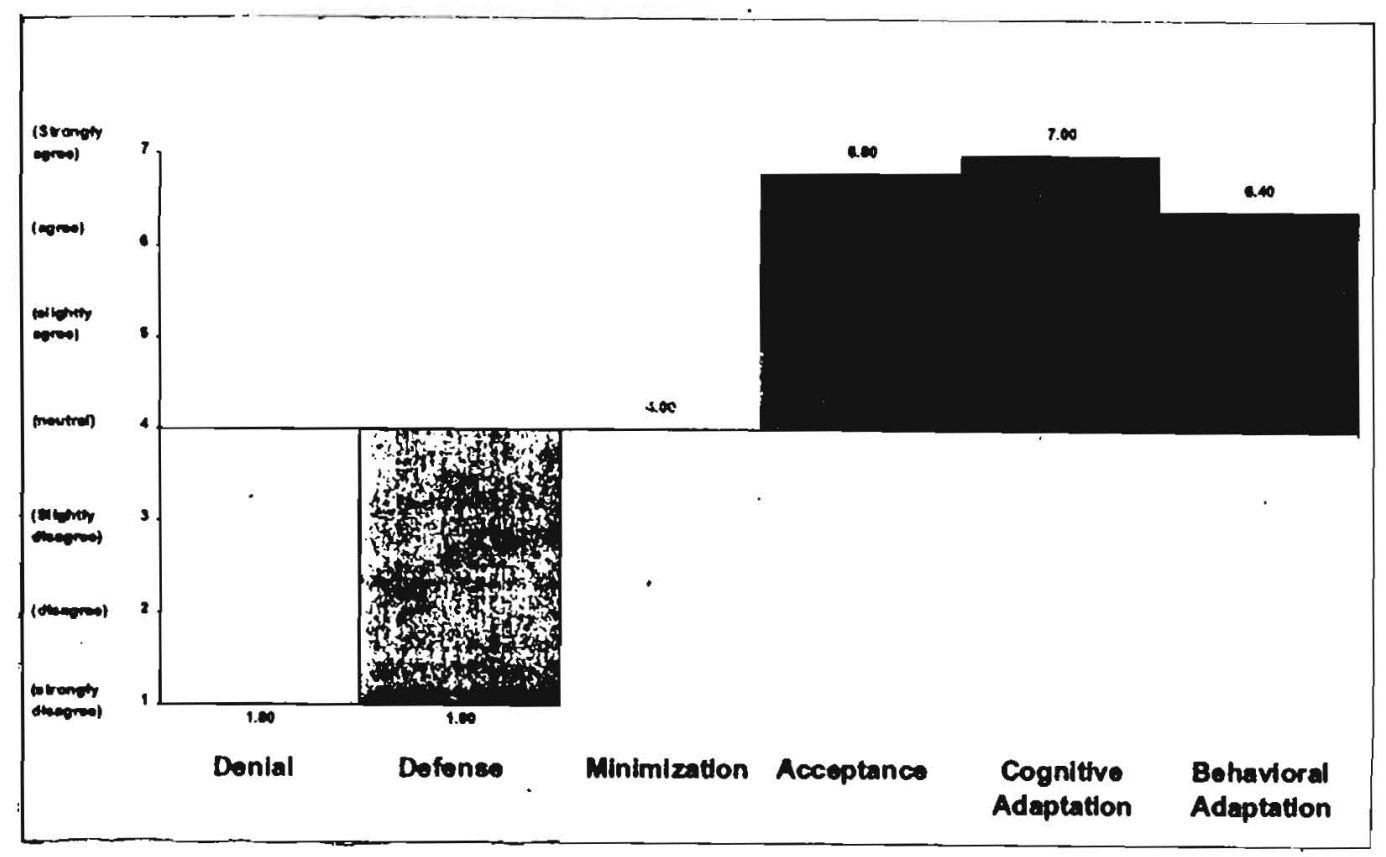

Figure 7.2 Phillip's Course Final IDI Profile 


\begin{tabular}{ccccccc}
\hline & Denial & Defense & Minimization & Acceptance & $\begin{array}{l}\text { Cognitive } \\
\text { Adaptation }\end{array}$ & $\begin{array}{c}\text { Behavioral } \\
\text { Adaptation }\end{array}$ \\
\hline Initial & 1.10 & 1.00 & 3.80 & 7.00 & 5.70 & 5.70 \\
Final & 1.00 & 1.00 & 4.00 & 6.80 & 7.00 & 6.40 \\
\hline
\end{tabular}

Table 7.3 Phillip's Course Initial and Course Final IDI Profiles scores for Phillip's Initial and Final IDI Profiles.

On the Ethnocentric scales, there is very little change. Phillip's Denial and Defense scores are both 1.00, the lowest possible score. Again, these indicate that he has no issues unresolved in these areas. His Minimization score is 4.00 , a slight increase from his earlier IDI. While the change in the Minimization score is not a large change numerically, the fact that it slightly increased, along with the increases in the Cognitive and Behavioral Adaptation dimensions of the IDI is worth investigating.

On the Minimization subscales, Phillip initially responded positively to some items in the Superficial Difference section, while he generally answered "Strongly Disagree" to questions relating to questions about universal values (i.e. that spirituality or other universal factors such as capitalism govern everyone, in spite of their cultural background). In the course final IDI, Phillip's pattern of responses is much more varied, reflecting a "snaggletooth" 
pattern of agreement on some answers and disagreement to other answers. In both the Superficial Difference section and the Universal Values section, Phillip indicates both agreement and disagreement.

One question where Phillip indicates change toward ethnorelativism (i.e. he shifted from answering "Agree" to answering "Disagree") is a question that asks if it is "best to just be yourself." Initially, Phillip agreed with this question. In considering his answer, I reflected on the fact that Phillip is a multicultural individual and he may, in fact, feel like he is always his authentic self even when crossing cultures. However, Phillip and I talked at length about his awareness in shifting cultural frames during our interviews (although not in the context of the IDI), and at the end of the class, Phillip answered this same question "Disagree." The conversations Phillip and I had, along with his similar discussions with his informant, may have influenced his answer here.

On the other hand, two other questions in the Universal values section reflect movement toward a more ethnocentric worldview. (It should be noted here that these items are on the subscales, and therefore are useful in understanding Phillip's experience. Yet, his overall movement in terms of the pre and post- 
test IDI is, itself, ethnorelative.) On these two items about people sharing a common spiritual being, Phillip had initially disagreed. On his final IDI, he answered Agree Slightly to one, and Agree to the other. This was a bit surprising to me at first because I had no context to place this information. I might have expected this shift had I known that Phillip and Himiko talked about religion; to my knowledge, they had not. Yet, interestingly, in our final interview, Phillip and I talked about religion extensively.

It was near Christmas time, and Phillip and I met one last time, ostensibly to talk about his IDI. While we never really talked about the IDI, he casually mentioned something relating to religion. Realizing we had never talked about the subject, I asked him for more information, which led to a rather lengthy discussion of religion and spirituality. We, in fact, talked about world religions and their similarity. This, of course, fits with Phillip's final IDI profile, and it also fits with the recursive nature of the development of a more interculturally sensitive worldview. Milton Bennett suggests that as we develop intercultural competence, we recycle old issues, resulting in just the kind of slight increase Phillip's Minimization score indicates. 
The Ethnorelative scales illustrate the result of Phillip's reflexive experience with Himiko, his gently helping her understand herself in new ways, and his own new way of defining himself. The first of the Ethnorelative scales, Acceptance, shows a very slight decrease, from 7.00 to 6.80 . While this net change is 0.20 , the same as Phillip's change on the Minimization scale, this change is much less dramatic. Here, Phillip answered "Agree" to two items, rather than "Strongly Agree" as he had previously. Phillip has recently told me that this change in his Acceptance scores is the result of his reflection on the issue of female genital mutilation, which had come up in the class discussion that term. About this topic, he said, "I realized there are some cultural differences I will never be accepting of." Thus, the changes in Phillip's Acceptance score. Overall, however, Phillip is Accepting of cultural difference, and even when he disagrees with cultural practices, he does not denigrate the other culture. He is generally interested in other cultures and wants to know as much as he can about people from other places.

Phillip's Cognitive Adaptation and Behavioral Adaptation scores both indicate dramatic increases. His increase from 5.70 to 7.00 on the Cognitive Adaptation scale is both supported by the 
course goal of bringing the language of intercultural communication into the students' awareness, as well as by the conversations Phillip had with both me and Himiko in which he discussed being a cultural bridge and sharing his multicultural self. In asking Himiko, "whose eyes are you seeing through?" he in effect recognized that he, too, uses more than one set of lenses to evaluate situations. This is represented by his increase in the Cognitive Adaptation score. Similarly, his increase on the Behavioral Adaptation scale from 5.70 to 6.40 also represents the awareness he's gained of his actions as a cultural bridge. While Phillip, to be sure, was likely doing all of these things before the class started, the increase in his IDI score reflects his greater awareness, and language to describe that awareness, of what he has been doing.

\section{Final Thoughts on Reflexivity and Transformation}

For Phillip as well as his informant, the ethnography was transformative. I asked Phillip why he thought this was so. Phillip asserted that their experience with the ethnography was transformative because both he and Himiko were focused on the relationship more so than on the fact that he was doing an assignment. For Phillip, learning from Himiko was genuine inquiry 
through equal status contact. He was not an interviewer and she an informant. Rather, they were two friends, meeting to help each other understand their selves in the world.

Phillip's experience interviewing Himiko for his ethnography project revealed the exchange of reflexivity and transformation that can occur when people are able to be cultural others for each other. Both Himiko and Phillip experienced change that influenced how they saw themselves in cultural perspective as a result of the ethnography project.

For Himiko, the project was a clear catalyst for her own cultural disequilibrium; Phillip's gentle, but firm suggestion that she was not seeing through Japanese eyes forced her, at least from Phillip's perspective, to start to see herself becoming a multicultural, rather than monocultural, individual. Phillip, too, experienced cultural disequilibrium, although for the most part, he was more familiar with the feeling and it wasn't so shocking to him. He did, however, have a strong reaction when he realized that he was the only Hispanic person in the culture learning class. This was a moment of cultural disequilibrium for him, and it, along with his discovery of the term "third culture person" shaped his experience. Phillip's own reflexivity is indicated by his marked 
increase in his IDI scores on the Cognitive and Behavioral Adaptation scales as well as his growing confidence in describing his work as a cultural bridge during our interviews. Phillip has achieved "emancipatory education" according to Mezirow, who defines the term as

about more than becoming aware of one's awareness. Its goal is to help learners move from a simple awarenss of their experiences to an awareness of the conditions of their experiencing (how they are perceiving, thinking, judging, feeling, acting - a reflection on the process) and beyond this to an awareness of the reasons why they experience as they do and to action based on these insights. (Mezirow, p. 197) Phillip clearly bases his actions on the insights he's gained through his many cross-cultural experiences. Furthermore, Phillip has the ability to meet people where they are at. In this respect, Phillip states that he finds the theory of the DMIS useful, as he explains: ... . this is a great thing to know because it will allow me to treat someone in a way that they are ready for. A person who is not even aware that there is a difference can not be ready to accept another culture until they go through the proper steps. (PN 8) 
In his contact with Himiko, he was able to meet her at the point of being ready to explore her own cultural identity. In the time he spent with me, he encouraged me as I prepared for my first trip abroad, to Japan. I have no doubt that Phillip regularly acts on his own self-awareness to make the world a more culturally sensitive place. I'm sure that he will continue to nurture perspective transformation and reflexivity in all of the people he encounters. It's part of the hat that Phillip never takes off -the hat of a teacher. 


\section{CHAPTER EIGHT}

\section{RETURNING TO THE CONTACT ZONE: \\ DISCUSSION AND CONCLUSIONS}

In taking seriously the interpretive insights of the other...we can begin to develop our own. Our own understanding can become richer and more differentiated to the extent that we try to understand the point of other interpretations, come to understand our own in relation to them, try to accommodate within our own interpretations the insights we think those other interpretations may possess, and work to preserve our own interpretations from the lacunae we find in others.

--Georgia Warnke, Feminism and Hermeneutics

If anything I do, in the way of writing novels (or whatever I write) isn't about the village or the community or about you, then it is not anything. I am not interested in indulging myself in some private, closed exercise of my imagination that fulfills only the obligation of my personal dreams

-which is to say, yes, the work must be political. --Toni Morrison, "Rootedness"

In the Introduction, I suggested that this thesis celebrates contact zones, the places where cultures meet and collide. The pages of this thesis narrate the contacts several members of the class had with their informants, as they describe through the drafts of their ethnographies and the accompanying progress notes. Of the class members, the experiences of Bob, Cleo, and Phillip were presented in more detail, creating portraits of them and their contact with their informants. In addition, I have 
Writing in the Contact Zone 238

described my own experience in the contact zone during my encounters with Cleo, Phillip, and Bob. Each of these portraits has illustrated a response to the contact zone. In the case of Bob, culture contact resulted in retreat; for Cleo and Phillip, the contact zone created different opportunities for reflection and growth. Phillip's experience with the contact zone was not only transformative for him, but for his informant as well. Each person had an entirely different experience in the contact zone created by the ethnography project; these differences are illustrated by the individual nature of each person's portrait.

In making meaning from these different experiences, they need to be understood within a set of larger contexts. The first context returns me to the initial questions that brought me to this research. Understanding how the experiences of the class, as well as Cleo, Bob, and Phillip as I have described them throughout these pages, address my initial questions is necessary. In addition, the portraits created by this research can be understood in not only the framework of the culture learning class, but also in terms of the class's value as a part of the Applied Linguistics TESOL program. As part of my discussion, I address each of these contexts. In concluding this chapter, I consider also the 
implications for language teaching, the limitations of my study, and suggestions for future research.

\section{Returning to the Questions-the Role of Process Writing}

Two of my initial research questions related to the role of process writing in the ethnography project. I wondered,

1. How do pre-service teachers use process writing to make sense of cross-cultural encounters? and

2. How does the inclusion of process writing assignments influence the completion of the mini-ethnography project? Both of these questions were addressed by the creation of the Supplemental Writing Notebook for use during the completion of the ethnography project. Although I collected drafts of the ethnography project from all the students who participated in my study, the drafts themselves did not reveal as much about either the writing process or the process of the intercultural experience as the Progress Notes did.

As a whole, the volume of writing that I collected from the students was substantial. Each Progress Note alone represented approximately ten minutes of uninterrupted writing for each one. In addition to the ten Progress Notes were two additional tenminute freewrites on readings from the course packet. I also had 
two rough drafts of the ethnography from all of the students who participated in my study. These drafts were between five to seven pages on average. I also received copies of the final ethnography from all seventeen students in my research study; the final ethnographies ranged from nine pages to over forty pages! From Bob, Phillip, and Cleo, I also obtained copies of their midterms, which were another six to ten pages of writing. This volume of writing does not include the cultural artifact assignment, as I had difficulty collecting that informal writing due to the partnered nature of the assignment. All in all, the informal writings likely added time to the completion of the ethnography project; this vast volume of writing was useful to me in gaining an understanding of how the students experienced the process of the ethnography.

To begin with, I can say that the students used the process writing assignments well. They took them seriously, writing detailed responses to each prompt and turning them in regularly and on time. In addition, I observed that the students did use the process writing assignments to make sense of their experiences. It was in the Progress Notes that Bob described himself as a "tourist" in his informant's culture. Similarly, Phillip wrote in the Progress Notes that he wanted to be able to focus on the friendship with his 
informant, not the project. For Phillip, that connection was also included in his final ethnography; he referred to Himiko as his friend, and he wrote about how their friendship had developed through the interview process. However, I think that it was easier for Phillip to write about his friendship with Himiko in his final ethnography because he had also written about it in the Progress Notes.

In terms of the specific intercultural dimension of the ethnography project, the Progress Notes served as a forum to practice trying on the language of the class. For example, in Cleo's Progress Notes, she wonders about independence and future orientation in reflecting about herself. Her comments reflect one of the most common recurring elements in the class freewrites-the increased use of the language of interculturalism. Members of the class used this language to describe both themselves and their informants.

In addition, the Progress Notes gave students a space to explore their frustrations with the project. In early Progress Notes, students sometimes would write about trouble finding informants, or difficulty scheduling meetings with informants. In later Progress Notes, students such as Phillip wrote about how they 
realized that they were receiving "edited" cultural explanations. Much of this information was not included in the final ethnographies, but it was important for students to have a place to record their frustrations.

At the end of the ethnography project, the Progress Notes were a place for students to write about what they had learned from the project as well as to assess their experience with it. For many of the students, the ethnography project was a different kind of writing, a different genre. And, while some students, like Phillip, came to recognize that the ethnography was not just about the culture they were studying, but about themselves as well, most students chose not to write much about themselves in the ethnography. I can't help but wonder if the reason for this is the general belief among students that writing about personal issues and including the pronoun "I" is not allowed in good writing. Whatever the case, the informal writings gave students an opportunity to do some honest reflecting about how the project had influenced them.

My first research question of how the students in the class used the process writing assignments to make sense of the crosscultural experience of the ethnography project has been answered. 
Through the Progress Notes, students were able to take a very thoughtful approach to the ethnography project, which is illustrated by their responses to the prompts given in the Progress Notes.

As the writing instructor for the course, I found that the honesty of the freewrites was useful to me in that I could often easily address the concerns raised in the writing. I was able to give advice about getting a new informant, or suggesting ways to structure interviews, for example. In my earlier experience as the writing assistant for the summer course, I didn't feel as aware of students' concerns, and was therefore not able to address them as easily. This was definitely one way that the Progress Notes influenced the ethnography project.

Another influence the Progress Notes had on the ethnography project was that some students used them to structure the drafts of their ethnographies. That is, they followed the pattern of the freewrites in putting the ethnography together. First, the described their informant (Progress Note 2), mentioned what, if anything they knew about the culture (Progress Note 3), and described how they established rapport (Progress Note 4). Often, they would then discuss the theme that had emerged from 
Writing in the Contact Zone 244

their interviews (Progress Note 5). Not all students did this, but many students did use this format.

In our interviews, Cleo and I discussed this strategy for the ethnography project. She told me that many students she talked to were using this plan for their writing, although she didn't want to feel restricted by that format. On the other hand, Cleo told me she could understand why students felt attracted to using the Progress Notes to structure their project. This was because initially, there is very little direction provided by either the syllabus or the instructor on how to structure the ethnography. The reason for this is that to a large extent, the ethnography's structure should come out of the interview process. Rather than a student feeling limited by a certain structure or format, the ethnography should be open to possibilities. Therefore, there is no direct discussion of how to structure the ethnography until after students are well established in the process. The class did express some frustration at this ambiguity, and one way they coped with the ambiguity was to use the Progress Notes to structure their formal writing. This was a surprising outcome of the introduction of the Progress Notes to the course. 
My research question that addressed how the addition of the informal writings would influence the experience of the ethnography project has been answered by the data I gathered and my interpretation of it. The Progress Note facilitated communication between myself and the class about issues that came up during the writing process. Furthermore, the ethnography project was influenced by informal writings because students used them to structure their ethnographies.

The informal writings were useful in exposing the process of the ethnography, and thereby creating opportunities for reflection that had not previously been as present in the ethnography assignment. I maintain that the freewrites prompted reflection on the nature of the intercultural self as the process of the ethnography continued. Although this process may have existed before the freewrites were introduced into the course curriculum, the physical action of writing brought the process into not only the writer's awareness, but also my awareness as the writing assistant, and to Dr. Brown's awareness as the instructor for the course.

As for my research, the informal writings were invaluable. Without them, I would not have had insight into the students' process of completing the project. The Progress Notes not only 
reflected where the students were at in the process at the time they completed each one, but they also often reflected where they were going and what they hoped to achieve with the project. Through the informal writings, I could judge their own assessment of their success or failure with the ethnography irrespective of their success with the final product. Thus, the informal writings proved essential in uncovering the experience of the class as they processed the ethnography project.

\section{Demographics of Difference}

Another of my research questions focused on how the ethnography project might be experienced differently by graduate students and undergraduate students. I asked,

3. Is there a difference between graduate and undergraduate pre-service teachers' experience with the miniethnography project?

This question was crafted in relation to my own experience of a learning curve, a period of intense, connected learning, that characterized my graduate school experience. Because I have heard of similar experiences from my colleagues, this question seemed useful to me in understanding how different groups of students might experience the ethnography project. 
Overall, this question is difficult to answer. Of the three portraitures, only Cleo's represents a graduate student experience. Both Phillip and Cleo had transformative experiences with the ethnography, although Phillip is an undergraduate student. However, Phillip is an undergraduate student in his thirties, so he does not represent a typical undergraduate student. Bob, in his twenties, is more like a typical undergraduate, and Bob did not have a transformative experience with the ethnography. To a degree, then, these three portraits support my hypothesis that grade level, or age, may be a factor in the transformative nature of the ethnography project.

The distribution of the class data showed a fairly even number of undergraduates and graduate students in my sample, although I did not ask the class to provide me with information about their age. Of the class data, the majority reported a positive experience with the ethnography project, including statements that showed greater reflection about themselves and their cultural identity. This was true for both undergraduate and graduate students. However, only graduate students used language to suggest that the ethnography project caused them to see themselves differently. Of these, two graduate students who were 
in my research sample approached me at the end of the term to tell me, in their own words, that the ethnography project had been transformative. One was Hannah, who talked to me at length about how her experience with her Tibetan informant had really shifted her thinking on a number of issues, including her spirituality, politics relating to Tibet, and her interests in writing and teaching. The other graduate student who approached me was Marion. She had interviewed a priest from Sri Lanka, and she told me that her experience with him was "life-changing." After finishing the project, she felt inspired to pursue more information about intercultural communication, to learn Spanish, and to teach English classes to Spanish speakers at her church. For these two graduate students, the ethnography project was the catalyst for reflection on their own intercultural perspective. Furthermore, for both of them, these reflections translated to action because they both told me how the class inspired them to teach. Since these students were graduate students, their conversations with me, along with their final freewrites, seem to support my hypothesis that graduate student might be more likely to have a transformative experience. 
Writing in the Contact Zone 249

One limitation in considering how individual differences might play a role in the experience of the ethnography is the overall sample size. In total, I had only seventeen research participants, so making generalizations from such a small number is difficult, if not impossible. Furthermore, I was bounded by the characteristics of the people who were willing to participate in my study. I might have wanted to know if men and women have different encounters with the ethnography project; however, I had only four men agree to be in my study. Similarly, I cannot consider other factors, such as extended overseas sojourns because I did not ask for such information from my research participants. Anecdotally, however, I know that the vast majority of my research participants have spent more than three months in an overseas sojourn. Because I had little variability among my research participants in such characteristics such as gender, time abroad, etc., I am unable to draw any conclusions in these areas. Yet, the overall purpose of my research was to learn from the experience of the individuals, and this was successfully accomplished through the process of creating the portraits of Bob, Cleo, and Phillip. 


\section{The Role of the Intercultural Development Inventory}

The Intercultural Development Inventory (IDI) had only recently been introduced to the course curriculum at the time of my data collection. The purpose of the IDI in the class is primarily for individual reflection and growth. Because the IDI can be used as an assessment tool, it also serves to assess an individual's change in intercultural competence over the course of the term as well. In collecting both the initial and final IDIs from Cleo, Bob, and Phillip, I wondered how useful they would be as a triangulation instrument as I approached the other types of qualitative data I had gathered. More specifically, I asked,

4. How does the Intercultural Development Inventory (IDI) further illustrate pre-service teachers' experience with the mini-ethnography project, particularly in terms of intercultural competence?

In answer to this question, I assert that the IDI provides another theoretical lens (the DMIS) with which to understand the writer's experience with the ethnography. While I cannot attribute all of the growth that Bob, Cleo, and Phillip demonstrated on the IDI to the ethnography itself, due to my conversations with them, I know that the ethnography played a significant role in the kind of 
reflection they were doing around the issues described on the IDI. In discussing his IDIs, for example, Phillip told me that at the end of the term, he was "definitely reflecting" on issues raised in the class as well as the experience he had with Himiko. Similarly, in the case of Bob, the IDI helped me to understand his struggle with the ethnography project. Seeing his initial IDI profile, I recognized that the ethnography project was probably not the most useful intercultural intervention for Bob based on where he was in terms of his own development of intercultural competence.

The IDI was indispensable in shaping my understanding of Phillip, Bob, and Cleo's experiences. The IDI gave me snapshots of them in terms of their own assessment of intercultural competence at both the beginning and the end of the term. This was information I did not have access to, particularly in the beginning of the term because I had only begun to establish my relationship with them, and I did not know them well enough to make such a thorough assessment of their intercultural competence by using only the theoretical model of the DMIS. Although I limited the IDI to a triangulation instrument, it was invaluable in providing objective support to my own observations drawn from the interviews and analysis of writing samples. 
In addition, the discussions I had with $\mathrm{Cleo}, \mathrm{Bob}$, and Phillip about their IDI profiles provided another layer to understand their intercultural competence. The IDI framed the context of these discussions such that we could discuss their intercultural competence more directly than we had in other interviews, which helped me understand their reflective (and reflexive) processes in relation to the ethnography project. For example, it was in the context of discussing the IDI that Phillip told me that the content of the class had caused him to reflect on his own intercultural experience. His reflection helped him realize that he is, in fact, a cultural bridge. Although I may have asked him about this in previous interviews, the framework of actually looking at the IDI provided a context to directly address the issues raised by the IDI profile.

Considering the usefulness of the IDI in interpreting my data, I return to my research question: how does the Intercultural Development Inventory (IDI) further illustrate pre-service teachers' experience with the mini-ethnography project, particularly in terms of intercultural competence? The IDI has helped me create a "thick, rich description" (Geertz, 1973, p.3) of Bob, Cleo, and 
Phillip's experiences because it has provided me with an objective theoretical lens with which to compare my own observations.

\section{My Role in the Contact Zone}

My final research question relates to my own role in the contact zone; that is, the relationship I had with my informants was not neutral, nor should it be. I had an influence on their experience with the class, as well as the ethnography project. In considering this issue, I was curious to know,

5. What role does my research project play in the case study volunteers' experience with the mini-ethnography project?

Although the process of collected writing samples might have had an influence on the members of the class, I focused here on my relationships with my case study participants. Because my experience with each of them was as different as their portraits, I will consider this question in terms of my specific relationship with each of them.

Bob and I maintained a fairly professional relationship. I enjoyed meeting with Bob, but usually our conversations did not stray far from the topic at hand. I tried to encourage Bob to be conversational during the interviews, but these moments did not last long. Bob did not ask for much direction in completing his 
ethnography, and when we discussed his process of writing, I sensed determination in his voice. For example, he told me with confidence that he was going to write about education in Russia as well as language issues because these were topics that seemed interesting to him. At no time did I feel like he was looking for my advice about his writing.

Bob and I did discuss several issues relating to intercultural competence and his situation of having been raised as an accidental bicultural (although we did not use that term to discuss his situation). At times, I felt as though Bob were pushing himself to the edges of his comfort level to help me understand his experience. Looking back, I can't help but wonder how my conversations with Bob influenced him. Considering his shift back into Minimization at the end of the term, I know that a variety of factors from the class pushed him to a point that he wasn't quite ready to get to, and he retreated into Minimization, which was safer for him. I don't know how to characterize his contact with me. It's possible that our meetings influenced him negatively, thus aiding his retreat into Minimization. However, it's just as possible that the time spent with me prevented him from retreating further. 
Although it's possible, I don't think that my time spent with Bob was a completely neutral influence.

With Cleo, however, the answer is clearer. Cleo and I developed a friendship during our interviews, and we continue to enjoy sharing conversations today. As I stated in her portrait, she often referred to our interviews as "therapy sessions," thereby signifying the importance these meetings had for her.

I don't think the time I spent with Cleo greatly shaped how she wrote the ethnography project. Although we talked about the project at length, she often spoke confidently about what she was writing about. To me, she seemed to have a clear idea about what she was going to write about, although we did talk about how other students were approaching the project differently. These topics were of interest to her, but did not change her plan. Because Cleo felt limited by time, she was practical and somewhat resistant to making big revisions in her writing.

I do think that my interviews with Cleo influenced her reflective process about herself as a cultural being. We talked about how she brought culture into her teaching, and she referred to that conversation in subsequent conversations. Furthermore, in discussing her time in Japan, she seemed to be acknowledging the 
process she had gone through then; I suspect that she had not often talked about this time in her life in such a detailed way, and I think our conversations, especially in the context of the class, helped her put her intercultural experiences into perspective.

Finally, Cleo told me that she has reflected on her statement that the she might recognize the influence of the ethnography project "at some point in the future." In giving me feedback on her portrait, she admitted that she hasn't really reflected much on the project. This in turn, caused her to realize that she wants to try to be more "in the moment." She expressed to me a feeling of loss, that the ethnography project may have offered her more than she took from it at the time. She decided, from reading her portrait, to try not to miss such opportunities. For Cleo, participation in my research has given her additional occasions for reflection. For me, getting to know Cleo through my research has given me an unexpected friendship.

Phillip and I also got to know each other on the level of friendship. He was genuinely interested in me (and I, him), and he was very curious about an upcoming trip I was taking to Japan. We spent a great deal of time talking off the tape about my trip, his girls, and other personal topics. 
In Phillip's case, I know that one influence I had on him directly relates to his final ethnography project. In his final ethnography, he cut much of his earlier information about bathing customs in Japan. Instead, he focused almost exclusively on the notion of the third culture person and how his informant was becoming a third culture person. Phillip felt comfortable changing his final ethnography because of discussions we had in our interviews. Initially, he felt some resistance to focusing on this topic, especially because I had suggested that he include some of his own experience as a cultural bridge in his paper. He maintained, "The paper isn't supposed to be about me!" Yet, when I told him that his process would be interesting to the reader, he felt comfortable changing his topic, thereby cutting his previous information. This naturally made his ethnography slightly short, around nine pages. I shared with Phillip that I had meant his revision to be an additive process, but he said he thought that the bathing information would be too different from the other information, which was why he chose to cut it. In this way, I believe I had an influence on Phillip's ethnography project. As the writing assistant, I might have encouraged Phillip to pursue this theme for his final ethnography, but I'm not sure that he would 
have pursued it if he didn't have the convenience of discussing these changes with me as a part of our interviews.

I think the key to my influence on all three of my informants relates to the relationship I developed with them. With Bob, I had a more professional, distant relationship, and I'm therefore somewhat unsure how I might have influenced him. With Phillip and Cleo, I developed friendships, and as a result, our interactions positively influenced their experiences.

\section{Other Considerations}

Although I have addressed the issues raised by my initial research questions, other questions remain. While my research questions addressed the notion of process writing as it related to experiencing the ethnography project, my questions did not directly address the concepts of reflexivity or transformation, two fundamental concepts I've based my research on. Because these concepts are so central to my research, taking time to discuss them in the context of the portraits is necessary.

As Carter and Gradin have maintained, reflexivity is a concept central to writing. The process of writing itself can be the dialogic engagement necessary to trigger reflexivity; yet the Culture Learning class offers an additional layer-the opportunity for a 
direct encounter with a cultural other. Writing about a person from another culture promotes reflexivity because it forces the writer to make connections between their own personal culture and the culture of the person they are interviewing. Additionally, writing necessitates making one's thoughts, or reflections, explicit. Thus, reflexivity is an expected by-product of the ethnography assignment because it creates a context that facilitates seeing the self from the perspective of a cultural other.

Moreover, reflexivity is related to intercultural competence because reflexivity itself requires reflection on the experience of encountering an "other." To experience reflexivity means to reconsider one's thoughts or actions based on some experience with someone (or something) culturally different from oneself. Responses to reflexivity can take a variety of forms, as the portraits of Bob, Cleo, and Phillip have illustrated. Phillip, for example, said that the project caused him to reflect on himself as a cultural bridge. He had not previously considered that issue, but he recognized that interviewing Himiko required him to revisit his own experience with becoming a third culture person. For Bob, the reflective nature of the project was uncomfortable. As a result, Bob limited his connection with Sergei, instead choosing to remain 
a tourist in Sergei's culture. Cleo believed that she stayed in her comfort zone with her informant, Long, although she shifted in her understanding of herself. This was likely in part related to the ethnography project and other intercultural dimensions of the class, but also related to the conversations we had during the interviews.

Overall, I believe that reflexivity is a natural outcome of the ethnography project. The conditions of the ethnography projectextended interviews, getting to know someone from a different culture - create an opportunity for seeing oneself from a different culture's perspective. Even in the case of Bob, I think that reflexivity occurred; his response was what was less typical. Yet, I also believe that a student may be able to complete the ethnography without experiencing reflexivity. This might happen because of a failure to establish rapport, limited contact (i.e. not doing the required 5-6 hours of interviews), or a unreflective approach. The ethnography itself invites reflexivity; the student, however, must follow through.

Transformation, as has been described by both Mezirow and Taylor, is a likely result of reflexivity. Reflexivity itself may be the experience of disequilibrium needed to precipitate transformation. 
Again, the portraits of Bob, Cleo, and Phillip illustrate the possibilities. Bob was not ready to be transformed; in fact, he is most likely still in the process of developing his perspective. Therefore, when presented with the opportunity to transform, he resisted. Cleo had experienced greater transformations before, so for her, the ethnography project gave her the opportunity for subtle change, one in which she was able to see herself more clearly as interculturally competent. In Phillip's case, the ethnography project presented the chance for transformation on the part of his informant as well as change in his understanding of himself. Because Phillip is culturally self-aware, the ethnography project offered him transformation on a subtle level. This change, characterized by the incorporation of another cultural frame, was important to Phillip. However, Phillip maintained that his informant's transformation was obvious because, through his contact with her, she was learning to see herself as bicultural. Phillip (and his informant), Cleo, and Bob illustrate a wide range of transformative possibilities.

In considering transformation, Mezirow reminds us that every experience of disequilibrium does not result in transformation; as teachers, all we can do is create the 
opportunity. Again, the ethnography presents the conditions for perspective transformation; the students must seize the opportunity.

\section{Applications for Language Teaching}

As illustrated by the portraits of Bob, Cleo, and Phillip, ethnography can be a powerful tool, not only for cross-cultural exploration, but also for self-reflection and transformation.

Because ethnography represents an opportunity for authentic cultural exchange, it can be used effectively in a variety of contexts, including language teaching.

Reflecting back on my own inspiration for my research, I think about Su-ho, my informant for the ethnography. Due to his own transition issues as an international student, Su-ho was having difficulty understanding the cultural differences around him. He would have benefited from having the opportunity to learn about the target culture through the eyes of a cultural native; that is, Su-ho, an intermediate speaker of English, would have benefited from doing an ethnography himself.

Language teachers should incorporate ethnographic assignments into their curriculum because they can not only help students better understand the target culture, but also encourage 
the development of a variety of skills. Ethnography includes speaking and listening, through the interviews. It also includes reading, through the library research that is needed to support the information given by the informant. And, most obviously, ethnography includes writing. The level of detail necessary for the ethnography as assigned in the culture learning class is likely too difficult for many language learners; however, teachers could easily modify such an assignment to make it more suitable for the level of their learners. The cultural artifact assignment, although not discussed at much length in this research study, may be one smaller ethnographic-style assignment suitable for language classes.

Clearly, there are some situations where ethnographic assignments are not appropriate. In early level language classes, when students are focusing on basic fundamentals of language, an ethnography may be too advanced because it does require a variety of skills in the target language. Furthermore, ethnography is most appropriate when students are in the early stages of Acceptance, and may not be successful if the students' worldviews are characterized primarily by ethnocentrism, as the example of Bob suggests. Yet, ethnography, as demonstrated by the experiences of 
Cleo and Phillip, can be transformative in the right context, and should be utilized in language learning settings.

\section{Applications for TESOL}

Nelson (1998) asserts that "it is the responsibility of masters' programs in TESOL to 'raise [graduate students'] cultural consciousness' (Kumaravadivelu, 1994, p. 40), and to train teachers who are effective intercultural communicators" (p. 28). The explicit goal of the Culture Learning class is to develop increased intercultural competence.

The experiences of Bob, Cleo, and Phillip suggest that cultural consciousness raising is taking place. Even in the case of Bob, who had difficulty with the ethnography project, he states that the class, and the ethnography made him more aware of himself as a cultural being. For Phillip, both the class and the project gave him the opportunity to reflect on his own cultural identity, and in part, to recognize that other students are not so acutely aware of themselves as a cultural being. For her part, Cleo asserted that the class was one of her favorite classes in the TESOL program because she felt like the class had clear application to real-life teaching situations. While all three of them agree that the class raised their awareness of cultural issues, their 
portraits demonstrate the centrality of the ethnography project to their increased awareness. Without this intense writing assignment, the level of reflexivity and transformation they experienced would not have been as great.

\section{Limitations of the Study}

As with any research study, there are limitations as well as aspects that I would change if I were to conduct this research again. As stated earlier in this chapter, my research sample was small, and I was unable to make generalizations about the class. However, my research was intended to be purely qualitative in nature, so this limitation does not affect the focus of my research. On a similar note, I did not collect demographic information from the people who agreed to participate in my study as part of the class sample. This was clearly an oversight on my part, and the lack of this information limited my study having this information may have made my description more rich. However, as my study was qualitative, I would not have been able to make any generalizations based on this information, so the lack of this information was not necessarily a problem.

One difficult aspect of this study was that I had a large amount of data to process. I had approximately thirty hours of 
taped interviews with my informants along with copies of Progress Notes, other informal writings, midterm exams, and drafts of the ethnography project. While all of this information helped me create a rich picture of each student's experience, this data was very difficult to synthesize.

On the other hand, collecting a few more pieces of data may have helped my study. Having an overall IDI profile for all of the students who participated in my study would have given me the ability to present a more detailed understanding of their experience as a whole; instead, I had this information only for my three portraitures. Obtaining a profile only for the members of the class who were in my study would have been difficult, as the class IDI profile contained data for other students who were not participating in my study. Isolating the data for only my students may have been difficult under the human subjects parameters for my research.

I regret that I was unable to collect the cultural artifact assignment and the letter exchange assignment. These two assignments would have likely given me another lens through which to understand the ethnography project. However, the letter exchange was not actually completed as part of the class 
curriculum, and I was unable to collect the cultural artifact due to the way the students paired off for this assignment. I would not have been able to change their pairing without violating my human subjects protocol; therefore, while this is a limitation, there was nothing I could do to change this situation. Furthermore, since I already had an enormous volume of data, I'm not completely sure how limited I was by not being able to collect these assignments.

\section{Directions for Further Study}

As the portraits of Cleo, Bob, and Phillip illustrate, there is much to learn from the process of pre-service teachers as they experience cultural difference. In preparing my review of literature, I found little, if any research relating to this specific topic.

Because culture plays such a central role in language teaching, understanding how teachers develop intercultural competence is necessary, in part, to better assess what kinds of learning is useful in teacher preparation programs. Therefore, more research, both qualitative as well as quantitative, in this area would be useful.

One element I was not able to explore in detail through my research is the experience of international students who are in the Culture Learning class. Although Bob is, to some degree, an international student, his U.S. citizenship definitely created a 
unique situation for him. I would have liked to interview a student who came to the U.S. for the purpose of completing the TESOL program with the plan to return to his or her country of origin. This was not possible purely because no one with this background volunteered to participate as a case study portrait. A future portrait of a student sojourner would perhaps give insights into the transformations such as the one that occurred with Phillip's informant Himiko.

\section{Conclusion}

This thesis has been an exploration of writing in the contact zone. The ethnography project for the culture learning class creates an opportunity for students to have an authentic crosscultural encounter within the safe parameters of a course assignment. Due to the potential for reflexivity, the ethnography project can lead to transformation on the part of both the interviewer and the informant. As has been illustrated by the portraits of Bob, Cleo, and Phillip, one's own intercultural competence shapes how that person enters the contact zone of the ethnography. While each writer takes something different from the ethnography project, and the culture contact involved may or may 
Writing in the Contact Zone 269

not result in transformation, the ethnography itself is an invaluable tool for intercultural learning. 
BECOMING:

AN EPILOGUE

Education is not preparation for life; education is life itself. -John Dewey

We reach an understanding with our object and appropriate it into our own self-understanding when we have learned from it and taken account of its views in formulating and refining our position. This kind of consensus represents a "fusion of horizons" in a twofold sense: on the one hand, we understand the object from the point of view of our assumptions and situation; on the other, our final perspective reflects the education we have received through our encounter with the object.

--Georgia Warnke, Gadamer: Hermeneutics, Tradition, and Reason

At the end of my proposal meeting for my thesis, one of my committee members asked me to consider how I would experience reflexivity during the thesis process. If reflexivity is the process of self-scrutiny that results from contact with an other, then surely I might experience reflexivity during the process of this ethnography. What did I think my reflexivity would entail, my committee member wanted to know. At the time, the only answer I knew to give was that, yes, I would probably experience reflexivity. I made a note in my journal: what about my own reflexivity? But I don't think that reflexivity is something predictable. While I could guess I might have some kind of reflexive experience, and I had little doubt I 
would understand myself more deeply from the process of doing this thesis, I could not predict how I would be influenced by this project. I did not want to guess how finishing this thesis might change the way I see myself. Instead, I began this project satisfied that the note I jotted down in my thesis journal would be enough to keep this aspect fresh in my mind. And now, as I have reached the conclusion of my research, I return to this question from my proposal meeting. How have I changed? How have I experienced reflexivity?

The process of getting to know Bob, Cleo, and Phillip on such an intimate level has naturally caused self-reflection on my part. When I consider Bob's experience, I can't help but return to times in my own education and identity formation that were less comfortable. I have connected with Bob because, although I was not raised in a bicultural environment, I am still very much in touch with the awkward moments of my early twenties. With Cleo, the similarity of our backgrounds has given me an opportunity to consider the possibilities. I felt a bond with her, in large part due to our working-class backgrounds, and thanks to Cleo and her success in the university, I came to understand that I don't have to let my background and inexperience hold me back. Phillip, on the 
other hand, helped me realize how much more I need to know. At times, I feel diminished by his experience and his ability to be a cultural bridge to so many people, myself included. Yet I know that Phillip would not want me to feel that way, but rather, learn from him. Phillip has taught me about taking risks and making friends. Phillip has been a constant reminder of the multilayered nature of intercultural communication. He has taught me to ask, "whose eyes are you seeing through?"

Phillip, Cleo, and Bob have been only a part of the reflexivity that I have experienced since I began this thesis. While my thesis has been a great source of intellectual growth, I have had other, greater opportunities for development during the last few yearsthis has been the direct result of having a baby. Although I find it hard to believe sometimes, having a baby has been a project bigger than this thesis.

Before having Jürgen, I laughed at the idea of writing as a birth metaphor. Now, however, as I am about to finish my thesis at the same time as Jürgen is gearing up to celebrate his first birthday, I find myself reconsidering, revising if you will, my response to this metaphor. The writer Anne Lamott (1994) says that "having a baby is like suddenly getting the world's worst 
roommate, like having Janis Joplin with a bad hangover and PMS come to stay with you" (p. 188). I think writing a thesis fits her definition, too. A thesis takes hold of your life and won't let go until the process is finished; a baby feels much the same way. Writing a thesis, like having a baby, is a rollercoaster of highs and lows. Both involve sleepless nights, hard work, and plenty of feelings of accomplishment. The biggest difference is the equipment. A baby necessitates special furniture, booties and caps, onesies, tons of blankets, and piles and piles of diapers accompanied by a stink-proof pail. With writing, we deal with temperamental computers, misplaced files, good reviews, reams of paper, and miles of inkjet cartridges. One of the only differences between a baby and a thesis is that a thesis comes to a point of being finished. You can't really finish a baby.

I suppose the writer Donald Murray (1998) would argue that children, like writing, eventually come to a point of letting go. With kids, that would be the time they turn eighteen, move out of the house and become independent. At least that is our hope in this US-American culture. With a thesis, the letting go would be the point when I turn this in for the last time and it gets bound and put in the library. I just hope that Jürgen isn't leaving for college 
at the same time. And, while my thesis collects dust on my shelf as I move on to other things, I don't think I'll ever really be able to let Jürgen go like that. He'll probably hope I will, though.

I never really thought I would have a baby. I had always sort of focused on school, and whether it's good or bad, I considered kids a speed bump in the path of education. High school friends never made it to college because they started families first. Other friends got sidetracked by their kids and didn't make it to graduation. Since I'd always had "college" whispered in my ear, I sort of assumed that kids would come later.

But, as I was collecting the data for my thesis, I was starting to hear the echos of "baby" whispered in my ear, too. First, they came from Chris, my partner in life. He had always loved kids, and I knew that someday, he would want a child of his own, so I wasn't surprised to hear his gentle asking. Then, the whispers started coming from elsewhere, too. Kim, my advisor, began to ask me about my plans for life. Did I want a Ph.D.? Yes, I told her. Did I want children? Probably, I said. Well, then, she advised, I should get to work. She told me that if I waited too long, I might lose my chance to have kids. A Ph.D. would always be there. 
I took her advice seriously. After all, I believe I should be focused on the journey, not the destination. I don't want to someday have a Ph.D. and nothing else. Giving myself time to reflect on her advice, I realized that those whispers of "baby" were coming from my own voice, too.

It would be dishonest to say that I approached the possibility of motherhood without fear. The thought of being a mother both thrilled and terrified me, and I obsessed about every aspect of parenthood in the months before I found myself pregnant. With this news came a greater sense of immediacy for writing my thesis. "Finish it now, before the baby comes," people would tell me with a knowing smile. After all, I would be too busy once he (yes, we found out early on that the baby was a "he") got here.

Fate would not have it that way, however. I spent the first six months of my pregnancy sick with a bacterial infection. Between working and trying to take care of myself, I had precious little time and energy left to devote to anything else. When I finally recovered from being sick, I was too pregnant to want to do anything else. I tried to write a little, but I resigned myself to finding time to write after the baby was born. I imagined myself sneaking in a little writing here, a little there, while Jürgen slept or 
amused himself with a toy. I probably don't need to mention that, of course, I was wrong.

Jürgen made his grand entrance into the world at 4:35 a.m. on July $24^{\text {th }}, 2001$. I had a long labor that lasted several days, and he was stubborn and big-headed, not wanting to come out. So, we had a c-section. Jürgen didn't cry at first, but instead, he looked around, seeming to take everything in. Soon after he was born, we found out that Jürgen had a medical problem that would require surgery. He would have to go to another hospital, and Chris would go with him. My joy of becoming a mother was dimmed by the fact that I was alone in a hospital full of mothers with babies.

That day, I came to understand motherhood in a way I had not previously considered. In the most obvious, physical sense, I became a mother because I had birthed a child. But, even more, I recognized at the time my sense of motherhood in that I began seeing myself in a new way. I was a woman who had a child, but my child was not with me. I longed for him, talked of him, and when, at one point, Chris brought me a Polaroid of Jürgen, I showed it to anyone who would look. Over time, I advocated for Jürgen's needs, asserted myself where I previously would not have, and sought out information I would not have otherwise needed. 
Before I went to the hospital, I imagined the three of us-Chris, Jürgen, and me-snuggled together in soft lighting. I pictured us leaving the Family Birth Center happily, together as a family. Instead, Jürgen left there in an incubator, hooked up to a hear/lung monitor, wheeled out by a specialized neonatal transfer team while I stayed behind to heal from my surgery and contemplate my new role as a mother.

Needless to say, my fantasy of Jürgen sleeping quietly in his infant carrier while I worked diligently on my thesis was an image purely of my imagination. The first eight months of his life were filled with doctor visits I've lost count of, three surgeries, and lots of emotions. And, among those things, not many pages of thesis written. Now, as Jürgen approaches his one-year birthday, his medical issues are resolved, at least for now. He is almost talking and almost walking, and I'm more comfortable than I could ever have imagined seeing myself as a mother.

The truth is, I haven't ever really known what I've imagined myself as. For the vast majority of my life, I have been going to school. While I've been going to school on the pretense of training for some future career, to be whatever it is I'm going to be when I grow up, I haven't really known what that is. Until now. 
I have come to see myself as a teacher. I haven't thought of myself in this way for long, however. When I began the TESOL program, I definitely could not envision myself in the role of a teacher. In fact, I took classes in Applied Linguistics because I wanted to cultivate that part of me, but at the time I began the program, it was a part of me I considered undiscovered, even if my colleagues disagreed. I downplayed what experience I thought I did have, and I often remained quiet in conversations about teaching, not wanting to admit that I was in the process of gaining the experience I thought others around me had. Just as I resisted becoming a mother until I saw myself as one, so I resisted seeing myself as a teacher.

During the last few years, however, I have had to revise that understanding of myself. I have logged countless hours of tutoring with both international and domestic students. I have stood at the front of the classroom to teach a variety of subjects including reading, composition, and linguistics. I have worked with students as young as twelve and as old as in their mid-sixties. Through these experiences, I have become a teacher, and I have found the confidence to see myself in this role. 
What's more, my interest in teacher preparation has been developing. Because of my own keen interest in the process of becoming a teacher, I have found in myself a passion for understanding this process better. This thesis has been one opportunity for exploring this area, and I continue to be inspired by the potential for reflexivity and transformation that can occur through education. Yet, I take comfort in all of the years of seeing myself as a student, and as I am in the process seeing myself as a teacher and a researcher, I find myself resistant.

This ethnography project, though, has been a good opportunity to see myself through new eyes. By investigating the experience of other preservice teachers, I was able to position myself differently. Through writing about their process of experiencing cultural difference, I had the responsibility to shape their stories according to my own expertise. I had to become both a teacher and a researcher. I had to not only find my voice, but I had to use it.

Discovering myself as both a researcher and as a mother has been surprising. I realize that I like these labels as I apply them to myself. At the same time, both are new roles for me-as I am coming to the end of my first year of motherhood, I am also 
transitioning on to the other goal I discussed with Kim, a doctoral program. There, I will continue to nurture my professional side as I continue to develop as both a researcher and a professional educator.

The process of completing this thesis has been a long and difficult one, complicated by my own life-process of having a baby. I've definitely felt like I've been experiencing my own internal contact zone as the culture of academia collides with the culture of motherhood. But I wouldn't have it any other way. Both experiences have caused many moments of self-doubt and hesitation along with times of joy and feelings of success. The time I've taken to be in the moment, to linger in the process, has given me comfort in taking on these new ways of seeing myself as a researcher, educator and mother. The length of the process has given me time to understand the countless reflexive experiences I've had in these contexts and time to process my transformation. From my interwoven texts of motherhood, teaching and thesis research has emerged a new understanding of myself. I have become an educator, a researcher, and above all, a mother. 


\section{REFERENCES}

Atkinson, D. (1999). TESOL and culture. TESOL Quarterly, 33:4. pp.625-654.

Bartholomae, D. \& Petrosky, A. (1996). Ways of reading, 4th Edition. Boston: Bedford Books.

Bennett, J.M. (1993). Cultural marginality: identity issues in intercultural training. In Paige, R.M. Education for the intercultural experience. (pp. 109-136). Yarmouth, ME: Intercultural Press.

Bennett, J.M, Bennett, M.J., \& Allen, W. (1999). Developing intercultural competence in the language classroom. In Paige, R.M., Lange, D.L., \& Yershova, Y. (Eds). Culture as the core: integrating culture into the language curriculum. CARLA Working Paper Series \# 15. Minneapolis, MN: CARLA. Bennett, M.J. (1993). Towards ethnorelativism: a developmental model of intercultural sensitivity. In Paige, R.M. Education for the intercultural experience. (pp. 21-72). Yarmouth, ME: Intercultural Press.

Bennett, M.J. (1998). Intercultural communication: a current perspective. In Bennett, M.J. Basic concepts of intercultural education: selected readings. (pp. 1-34). Yarmouth, ME: 
Intercultural Press.

Bennett, M.J. \& Hammer, M. (1998). The intercultural

development inventory manual. Portland, OR: The Intercultural Communications Institute.

Berlin, J. (1996). Rhetorics, poetics, and cultures: refiguring college English Studies. New York: National Council of Teachers of English.

Bizzell, P. (1993). Academic discourse and critical consciousness. Pittsburgh: University of Pittsburgh Press.

Candy, P.C. (1989). Constructivism and the study of self-direction in adult learning. Studies in the education of adults, 21. Pp.95-116.

Carspecken, P.F. (1996). Critical ethnography in educational research: a theoretical and practical guide. New York: Routledge.

Carter, D. \& Gradin, G. (2001). Writing as reflective action: a reader. New York: Addison Wesley Longman. 
Chiseri-Strater, E. (1991). Academic literacies: the public and private discourse of university students. Portsmouth, $\mathrm{NH}$ : Boyton/ Cook Publishers.

Chiseri-Strater, E. \& Sunstein, B. (1997). FieldWorking: reading and writing research. Upper Saddle River, New Jersey: Prentice Hall.

Crapanzano, V. (1986). Hermes' dilemma: the masking of subversion in ethnographic description. In Clifford, J. \& Marcus, G. Writing culture:the poetics and politics of ethnography. (pp. 51-76) Berkley: University of California Press.

Dallmayr, F. (1996). Beyond orientalism: essays on cross-cultural encounter. Albany: SUNY Press.

Damen, L. (1987). Culture learning: the fifth dimension in the language classroom. Reading, MA: Addison-Wesley. Dewey, J. (1938). Experience and education. New York: Macmillan.

Diesing, P. (1971). Patterns of discovery in the social sciences. Chicago: Aldine.

Dobbert, M.L. (1982). Ethnographic research: theory and application for modern schools and societies. New York: 


\section{Praeger.}

Elbow, P. (1981). Writing with power. New York: Oxford UP.

Emig, J. (1971). The composing process of twelfth graders. NCTE Research Report No. 13. Urbana: NCTE.

Faigley, L. (1986). Competing theories of process: a critique and a proposal. College English, 48 . pp. 527-542.

Fielding, N.G., \& Fielding, J.L. (1986). Linking data. Beverly Hills, CA: SAGE Publications, Inc.

Firth, R. (1961). Elements of social organization. Boston: Beacon. Fishman, S. \& McCarthy, L. (1996). A text for many voices: representing diversity in reports of naturalistic research. In Moretensen, P. \& G. Kirsch. Ethics and representation in qualitative studies of literacy. (pp. 155-175). Urbana, IL: National Council of Teachers of English.

Fishman, S. \& McCarthy, L. (1998). John Dewey and the challenge of classroom practice. New York: National Council of Teachers of English.

Flower, L. \& Hayes, J.R. (1980). A cognitive process theory of writing. College Composition and Communication, 31. p. 365-87. 
Geertz, C. (1996). Deep play: notes on a Balinese cockfight. In D.Bartholomae \& A. Petrosky (Eds.), Ways of reading, 4th edition. (pp. 227-267). Boston: Bedford. (Original published 1973).

Geertz, C. (1973). The interpretation of cultures. New York: Basic Books.

Gould, R.L. (1990). The therapeutic learning program. In J. Mezirow and Associates (Eds). Fostering critical reflection in adulthood:a guide to transformative learning. San Fransisco, CA: Jossey-Bass.

Gradin, S. (1995). Romancing rhetorics: social expressivist perspectives on the teaching of writing. Portsmouth, $\mathrm{NH}$ : Boyton/Cook Heinemann.

Gudykunst, W., Guzley, R., \& Hammer, M. (1996). Designing intercultural training. In Landis, D. \& Bhagat, R. (Eds.). Handbook of intercultural training, $2^{\text {nd }}$ edition. (pp. 61-80). Thousand Oaks, CA: SAGE Publications, Inc.

Homer. (Reissued 1975). The Iliad. (R. Fitzgerald, Trans.) New York: Anchor Books.

Homer. (Reissued 1998). The Odyssey. (R.Fitzgerald, Trans.) New York: Noonday Books. 
Hoopes, D.S. \& Pusch, M.D. (1979) Chapter 1: definition of terms. In Pusch, M.D. (Ed.), Multicultural education: a crosscultural training approach. (pp. 2-9). Yarmouth, ME: Intercultural Press.

Hymes, D. (1971). Competence and performance in linguistic theory. In R. Hurley \& E. Ingram (Eds). Language acquisition: Models and methods. (pp. 3-28). London: Academic Press.

Jurasek, R. (1995). Using ethnography to bridge the gap between study abroad and the on-campus language and culture curriculum. In Kramsch, C. (Ed.). Redefining the boundaries of language study. Boston, MA: Heinle and Heinle, pp. 221249.

Kachru, B.B. (1988). The spread of English and the sacred linguistic cows. In P. Lowenberg (Ed.) Georgetown University round table on language and linguistics 1987: Language spread and language policy (pp.207-228). Washington, DC: Georgetown University.

Kachru, B.B., ed. (1992). The Other tongue : English across cultures, 2nd ed. Urbana: University of Illinois Press. 
Kleine, M. (1990). Beyond triangulation: ethnography, writing, and rhetoric. Journal of Advanced Composition, 10. pp. 117 125.

Koepping, K.P. (1998). Bodies in the field: sexual taboos, selfrevelation and the limits of reflexivity in anthropological fieldwork (and writing). Anthropological Journal on European Cultures,7. pp.7-26.

Kramsch, C. (1993). Context and culture in language teaching. New York: Oxford University Press.

Kumaravadivelu, B. (1994). The postmethod condition: (E)merging strategies for second/foreign language teachign. TESOL Quarterly,28. pp. 27-48.

Lamott, A. (1994). Bird by bird: some thoughts on writing and life. New York: Doublday.

Lee, M. \& Greene, G. (Winter 1999). A social constructivist framework for integrating cross-cultural issues in teaching clinical social work. Journal of Social Work Education, 35. Infotrack Search Bank. <http://web4.searchbank.com/itw/ session/700/355/305446596ww3/21!fullart_> Accessed 6/9/1999. pp. 1-8.

Lenclud, G. (February 1996). The factual and the normative in 
ethnography: do cultural differences derive from description. Anthropology Today, 12. pp. 7-11.

Liebman, J. (1988). Contrastive rhetoric: students as

ethnographers. Journal of Basic Writing, 7:2. pp.6-27.

Mehan, H. (1979). Learning lessons: Social organization in the

classroom. Cambridge, MA: Harvard University Press.

Mezirow, J. (1991). Transformative dimensions of adult learning.

San Francisco, CA: Jossey-Bass.

Min, A. (1994). The fall of autumn leaves. From Red azalea. Place:

Publisher. New York: Pantheon Books.

Morgan, J. (1987). Displaced homemaker programs: the transition

from homemaker to independent person. Unpublished doctoral dissertation, Teachers College, Columbia University.

Mortensen, P. \& Kirsch, G. (1996). Ethics and representation in

qualitative studies of Literacy. Urbana, IL: National Council of Teachers of English.

Mountford, R. (1996). Engendering ethnography: insights from the feminist critique of postmodern anthropology. In Moretensen, P. $\&$ G. Kirsch. Ethics and representation in qualitative studies of literacy. (pp. 205-227). Urbana, IL: National Council of Teachers of English. 
Murfin, R. \& Ray, S.M. (1997). The Bedford glossary of critical and literary terms. Boston: Bedford.

Murray, D. (1998) The craft of revision. Orlando, FL: Harcourt Brace \& Company.

Nelson, G. (1998). Intercultural communication and related courses taught in TESOL master's degree programs. International Journal of Intercultural Relations,22. pp.1733.

Nelson, G. (2000) Utilizing the Intercultural Development Inventory in research. Paper presented at the meeting of Teachers of English as a Second Language (TESOL), St. Louis, MO.

Neuleib, J. \& Scharton, M. (1994). Writing others, writing ourselves: ethnography and the writing center. In Mullin, J. and Wallace, R. (eds). Intersections: theory-practice in the writing center. Urbana, IL: National Council of Teachers of English, pp. 54-67.

Newkirk, T. (1992). The narrative roots of case study. In Kirsch, G. \& Sullivan, P. (Eds.) Methods and methodology in composition research. (pp. 130-152) Carbondale: Southern Illinois UP.

North, S. (1987). The making of knowledge in composition: portrait 
of an emerging field. Portsmouth, NH: Boyton/Heinemann.

Qualley, D. (1997). Turns of thought: teaching composition as

reflexive inquiry. Portsmouth, NH: Boynton/Cook Publishers.

Park, Y.K. (2001). A case study: the effect of formal attention to

culture in the language classroom on students' intercultural

competence. Unpublished master's thesis, Portland State

University, Portland, Oregon.

Peirce, B.N. (1995). The theory of methodology in qualitative

research.TESOL Quarterly, 29. pp. 569-576.

Pennycook, A. (1994). The cultural politics of English as an

international language. New York : Longman.

Pollock, D.C \& VanReken, R.E. (1999). The third culture kid

experience: growing up among worlds. Yarmouth, ME:

Intercultural Press.

Pratt, M.L. (1996). Arts of the contact zone. In D. Bartholomae \& A.

Petrosky (Eds.), Ways of reading, 4th edition. (pp. 528-548).

Boston: Bedford. (Original published 1991).

Robinson-Stuart, G. \& Nocon, H. (1996). Second culture

acquisition: ethnography in the foreign language classroom.

Modern Language Journal, 80. pp. 431-449. 
Sewell, L. (1997). On being researched and becoming a researcher: an essay on reflexivity in qualitative composition research. Composition Studies, 25. pp. 37-53.

Sullivan, P. (1996). Ethnography and the problem of the "other." In Moretensen, P. \& G. Kirsch. Ethics and representation in qualitative studies of literacy. (pp. 97-114). Urbana, IL: National Council of Teachers of English. Sunstein, B. (1996). Culture on the page: experience, rhetoric, and aesthetics in Ethnographic writing. In Moretensen, P. \& G. Kirsch. Ethics and representation in qualitative studies of Literacy. (pp. 177-201). Urbana, IL: National Council of Teachers of English.

Taylor, E. W. (1994). "Intercultural competency: a transformative learning process. Adult Education Quarterly, 44. pp. 154174.

Tice, T. (1998). Border crossings. The Education Digest, 64. 4346.

Turner, D.A. (1991). Assessing the intercultural sensitivity of American expatriates in Kuwait. Unpublished master's thesis, Portland State University, Portland, Oregon.

Turner, V. (1982). From ritual to theater: the human seriousness 
Writing in the Contact Zone 292

of play. New York: Performing Arts Journal Publications.

Watson-Gegeo, K.A. (1988). "Ethnography in ESL: Defining the essentials." TESOL Quarterly, 22. pp. 575-592.

Warnke, G. (1993). Feminism and hermeneutics. Hypatia, 8(1). pp. $81-97$.

Warnke, G. (1987). Gadamer: Hermeneutics, tradition, and reason. Stanford: Stanford University Press.

Williams, R. (1958). "Culture is Ordinary." In Gable, R.(1993).

Resources of hope: Culture, democracy, socialism. (pp. 3-18). London, Verso.

Yamamoto, S. (1994). A qualitative study of Japanese students'

Intercultural experiences in the U.S. in relation to the

developmental model of intercultural sensitivity.

Unpublished master's thesis, Portland State University, Portland, Oregon. 


\section{Appendix A}

\section{Applied Linguistics 471/571 Course Syllabus and Ethnography Assignment}

\section{Culture Learning in the Language Classroom LING 4/571 \\ Preparation for the Overseas Experience \\ INTL 397 \\ Fall, 1999 SAB 210}

Instructor: Kimberley Brown

TA: Laurene Christensen

This course focuses on intercultural learning. It is designed in particular for those individuals who intend to become professional language educators or those individuals who expect to spend significant amounts of time studying outside the U.S. It is also suitable for those with a broad interest in issues of culture learning. This course is a writing intensive course and will substitute for Writing 323 (if grade $\mathrm{C}$ - or better). It meets the diversity requirement.

Lab fee: There is a $\$ 10.00$ fee for the Intercultural Development Inventory, which will be administered twice in the course.

Course Goals:

- To become aware of the role that language, values, attitudes and learning styles play in teaching and learning a second or foreign language.

- To develop a framework for incorporating a culture learning dimension into the language course you teach.

- To develop an understanding of the problems likely to occur when teaching persons from different cultural backgrounds.

- To investigate and report on another cultural group by carrying out an ethnographic interview project.

- To form a definition of multicultural education that is compatible with the concept of language and cultural diversity as a resource. 
- To become familiar with techniques and materials that will enhance development of intercultural competence in ourselves and our language learners.

Required Texts:

1. All students: Course Packet available at Clean Copy.

2. LING 471/571: Cultural Awareness

3. GRAD ONLY: Context and Culture in Language Teaching

4. LING 471 and INTL 397: One text from list below or another OK'd by instructor.

Texts to Choose One From:

- American Ways

- Distant Mirrors: America as a Foreign Culture

- Discovering Culture in Education

- Third Culture Kids

- From Nyet to Da

- Understanding Arabs

- Understanding Vietnam

- Encountering the Chinese: A Guide for Americans

- Transcending Stereotypes: Discovering Japanese Culture and Education

- Global Winnes

- Good Neighbors

Course Requirements

A. Culture Learning Project (40\%)

Observe, interview, research, and write-up your investigation of a cultural group previously unfamiliar to you.

1) Grand Tour:

Typed, double-spaced report (4-5 pages) including your rationale for your choice of informant, selection of your informant, how you established rapport, general information about his/her country, biographical information.

DUE WED OCT 20 IN CLASS

2) Mini Tour: DUE WED NOV 10 IN CLASS

Typed, double-space report (4-5) pages on information gained from specific questions and observations, e.g., values, nonverbal behaviors, experiences with acculturation, etc. It is 
appropriate here to include on or two charts, figures, schemata here.

3)Final Paper: DUE WED DEC 1 IN CLASS; typed, doublespaced report (about 15 pages) summarizing what you have learned about your cultural group with a focus on one or two themes

B. Culture Teaching Activities (see attached descriptions)

1) UNDERGRAD (15\%)

Pair Demonstrations of a technique for teaching something about culture; work in pairs to present a $20 \mathrm{~min}$. Demo + handouts. Schedule attached.

The Ethnographic Essay Assignment

C. Applied Culture Texts

1) UNDERGRAD ONLY (40\%)

Book review of one text from Texts to Choose From list above-see assignment description that follows

2) 4 HOUR commitment to service learning project: Building Bridges or other community culture program

3) GRAD CREDIT ONLY (30\%) +6 hour project of your choice: can be service learning project or cultural curriculum project or culture research proposal

4) GRAD CREDIT ONLY (20\%)

Reaction Review to Kramsch + attendance at 3 discussion sessions with signature on summary log of discussion

D. Mid-term Exam + regular attendance + participation $(45 \%$ UNDERGRAD; 35\% GRAD) DUE FRI OCT 29 (IN CLASS) Exam question is attached. Length: 3-5 pages; typed 8 doublespaced with full references in text and back (APA style); pick up a copy of the APA handout in the Writing Center $(\mathrm{CH} 188 \mathrm{~F})$.

Week 1: $\quad$ Monday: Introduction to Course +IDI Homework: Packet \# 1 Leinster

Wednesday Icebreaker + Film: The Intercultural

Classroom

Homework: Packet \#2 Edwards

Friday: Film: The Intercultural Classroom Cont'd 
Homework: Packet \#3

Week 2: $\quad$ Monday: Pair Demo-Critical Incidents; Lecture: DMIS Homework: Packet \#4 Bohannen

Wednesday: Discuss Readings

Homework: Packet \#8 Damen, \#9 Spradley

Assignment

Friday: Pair Demo-D.I.E.; Intro-Ethnography

Homework: Find Informant; Packet \#5 Geertz

Week 3: Monday: Learning with the Culture Box

Hoopes

Homework: Packet \#6 Hoopes and Pusch, packet \#7

DISCUSSION\# 1-

Wednesday: Culture Box, cont'd; GRAD

Chapters 1, 2 Kramsch

Homework: Packet \#10 Pratt

Friday: Debrief Readings; Field Trip: Building Bridges

Homework: Packet \#11 Taylor

Week 4: Monday: Technology and Culture Sources

Homework: Packet \#12 Byram

Research

Wednesday: Intercultural Competence from a

Perspective

Pair Demo: Non-verbal Communication

Ethnography Grand Tour Due

Friday: Ethnography Debriefing

Pair Demo: Culture Learning for Non-literate Adults

Homework: Packet \#13 Kohls

Week 5: Monday: Stempleski and Tomalin Audio Conference

Wednesday: Stempleski and Tomalin Cont'd

Grad Discussion Kramsch Chpts. 3 \& 4

Friday: MID-TERM DUE

Discuss Ethnography

Week 6: Monday: Pair Demo: Activity Based in Community

Learning

Language and Culture Relationships 
Wednesday: MINI-TOUR DUE

Homework: Scarcella \# 14

Different

Friday: Pair Demo: Activity Appealing to Several

Learning Modalities

Demographics of Cultural Diversity in the U.S.

Homework: Packet \# 15 Nelson

Week 7: Monday: Pair Demo Activity for Pre-Departure Orientation

Cultural Differences in Learning Styles

Homework: Packet \#16 Furey

learners

Wednesday: Pair Demo: Activity to help young

learn about each other

Teaching Across Cultures

MID-TERM DUE

Homework: Packet \# 17 Lipka

Friday: Pair Demo: Activity Using Newspapers

Grad Discussion: Chpts. 5 \& 6 Kramsch

Homework: Road Game Instructions

Week 8: Monday: Road Game Simulation-wear comfortable clothes

Homework: Packet \# 18 Jin and Cortazzi

Wednesday: Road Game Debriefing

Friday: Catch UP

Week 9: $\quad$ Monday: Fear and Learning at Hoover Elementary Wednesday: Pair Demo: Activity Using Film or Video Grad Discussion: Chpts $7 \& 8$ Kramsch

Friday: NO CLASS Thanksgiving

Week 10: Monday: Pair Demo: Culture Learning Icebreaker for short-

term language program in the U.S.

Wednesday: Field Trip preparation-Vietnamese culture

overview

Friday: FINAL PAPER DUE IN CLASS 
Course Synthesis and Evaluation IDI \#2

Week 11: Final Exam Time: Meet at Than Luong The Interview Project

The purpose of this project is to allow you to step as fully as possible for a brief period of time into another culture via your informant. This is an ethnographic project-not a full ethnography. Thus it is our expectation that you will spend about five or six hours interviewing an individual. Anthropologist Clifford Geertz looks at the notion of "rich, thick description." It is this level of detail that you are striving for in this project.

In her book The Witch's Dream (1985), Florinda Donner draws upon ethnographic writing techniques. Carlos Castenada has this to say about the power of such writing:

The first is the rich detail of her descriptions and narrative. To me, that detail is ethnography. The minutiae of daily life, which is

commonplace in the cultural setting of the characters she describes, is something thoroughly unknown to us.

The second has to do with art. I would dare say that an ethnographer should also be a writer. In order to place us vicariously in the ethnographic horizon he or she describes, an ethnographer would have to be more than a social scientist;

an

ethnographer would have to be an artist.

In this assignment, you will be acting like a photographer, capturing images in a narrative. Your primary task is to capture your informant's words and mold them into a coherent narrative. Your informant's words are the bricks-you provide the mortar as you weave things together. The blueprint for the house comes mostly from your informant (70\%); the general plan for the assignment comes from the information you gather in the grand tour and the mini-tour. 
The first two papers will not be graded. You will draw from them for the final paper. It is possible that the final paper will contain ALL of the information from the first two papers; it is possible that you will introduce completely new themes in the last paper and use only half of your work from the first two papers.

Paper One: The first paper is a GRAND TOUR. It should be around 4-5 pages long, double-spaced (12-point font). Your task is to indicate how you met your informant, to provide basic text-based information about your informant's country, to include a map WITH A CITATION OF WHERE IT IS FROM. In this paper, you will provide rich descriptions of your informant and general aspects of information covered in your first few interviews. The title of this paper may be a quote that comes from one of your interviews, or it may simply be:

Grand Tour:

Consider one set of examples:

Paper One- "The Grand Tour"

Paper Two- "The Tea Industry of Iran: A Mini Tour"

Paper Three-“'Touring Gilan's Tea Country with Jalal"

Please do not use your informant's real name. Find a pseudonym or let your informant choose one.

Try to begin the paper with something that will encourage your reader to keep reading. For example:

This ethnography expresses the image of a country through the voice of one Romanian. Through his dialogue, we are presented with vivid images and details which tell about his life in Romania. Many of these are unique in that they are his, and not others' personal experiences. Much of the information that Karl presents provides a description of life in the pre-and post-revolutionary stages, and the hardships that he and his family face.

As a child, my ideas of communist countries were the results of my father's teaching. Essentially, he taught me that communist countries such as the former Soviet Union and Romania were the evil, cold, uncaring nations who were willing to 'push the button' at 
any given hour, initiating the beginning stages of World War III. As children tend to exaggerate and believe their parents, I lived in constant fear of the 'evil' nations.

Yet another example:

Jalal, my informant, is originally from Iran. He grew up in Lahidjan, which is in the northern province of Gilan. He says it is very green. Gilan has a temperate climate, with heavy rain during the fall and spring. In the winter there is snow. The summer is usually humid and warm, but it can be wet and cool as well. Jalal wryly describes summer weather:

It is interesting that there can be 20-0 days a year of rain. In summer there is a beautiful mist. One summer I remember waiting for the sun because we were going to go to the sea. We never went. It rained the whole summer.

As a child, Jalal was often sick, and he blames this on the damp, cool climate. He finds it ironic that he has settled in Portland, Oregon, which has a very similar climate.

I chose Jalal as my informant for a number of reasons....

Paper Two: This paper should also be 4-5 pages long. In it, you should focus on one or two themes that have emerged in your interviews. These may include things like education in the country, two or three compelling themes raised by your informant, and some type of framing on your part, i.e. why have you chosen these themes, how did they emerge in your conversations, what is it that made them compelling....You should use as many of your informant's words as possible, but you should not simply include a set of questions and answers. When possible, support what your informant has said with written sources.

For example:

Jalal says that tea is easier to grow than rice, and so when the government began to encourage farmers to grow tea, they were glad to do so. Jalal says that the area is good for growing tea, "because there is rain, enough of sunshine, cool nights and hot days in summer." Jalal grew up in and around tea farms and factories. 
Jalal left Iran in the early 1970s. We therefore focused our mini-tour on a period of approximately twenty years, from the early 1950 s to the early 1970s. During this time Jalal says there was rapid expansion and improvement in Iran's tea production. The attached chart by Sarkar (1972), demonstrates a significant increase in tea production in Iran during this time, particularly in the 1960 s.

Jalal began with the story of how tea came to Iran. According to Jalal, a man who was later called "Royal Explorer" (Jalal's translation) brought tea to Iran:

He goes to India and he has a cane. He drinks tea and he likes tea, and in Iran there was tea, but it would come from India or Russia or China..so he goes to India and he thinks that Iran should have tea.

So what he does, he smuggles tea in his cane to Iran, some tea seeds, which are as big as nuts.

Jalal couldn't remember when exactly this is said to have occurred...In any case, I could find no written source material on the introduction of tea plants to Iran....

We discussed the distinctive taste of tea from Lahidjan....

Jalal went on to describe both his father's early career and how the Iranian government sought to expand its tiny tea industry:

I remember when the tea industry started in Iran there were only two factories. One, my father used to work...there was one in Lahidjan, one in Lakhan....

Note the balance of direct quotes, reported information, and written sources. This is what to strive for in both the second and final papers.

\section{Final Paper}

The final paper should be around fifteen to twenty pages in length. You may draw verbatim from the first two papers or specifically introduce new material. Two sample outlines of final papers include: 
The Iran paper: 24 total pages

\section{Cover}

Page One-photo from Iran

Pages 2-6: establishing rapport with informant + specifics about Iran in general and the northern region in particular Pages 7-19: details of the tea industry +3 pages of illustrations Pages 20-22: conclusions

Knowing Jalal as I do, I was very struck by the seasonal nature of life in Gilan....

In addition to the rural character of Gilan and the importance of seasonal change there, a suspicion of 'the center' clearly exists. This seems a natural result of the experience of having been dominated by the center, and perhaps of limited contact with people from Tehran.

Torab retired from his government position when the new regime came to power....

I heard echoes of a feudal culture in Jalal's descriptions of farm and factory life in Gilan and it made some things about Jalal easier to understand....

His essential formality now makes more sense to me....

Although I expected this mini-ethnography to be an interesting and perhaps entertaining project, I hadn't realized how much cultural information we would turn up during the course of our "tea tour." On the other hand, when I started, I naively hoped to be able to develop a framework in which to fit the fragments of Iranian culture that I deal with on a regular basis. Going back over the material I have collected, there are so many intriguing paths, interesting bits of information, and areas to explore further...

Pages 23-24 Bibliography (13 Sources)

Example Two: Final Paper 15 pages (10-point font)

Page One-photo 
Pages 2-9 detailed descriptions of Karl (Romanian0 and his life in Romania before immigrating. Seven quotes from other written sources + five long quotes from Karl

Pages 10-11 Introduction of new theme of "politeness of Romanians"

Pages 11-12 Concluding reflections

For example: In the beginning of the ethnography, I mentioned how my impressions and ideas about Communism changed after the cold war ended from "fear to fascination." After speaking with Karl and reading accounts from other authors, I realize that my impression has changed again. Hearing and reading about Karl's experience makes me feel depressed and helpless. However, the point of this ethnography is to avoid making judgments or evaluations, and should be based on my readings and my. interviews with my informant. Honestly, I realize that I cannot fairly hold an opinion because I was not in Romania experiencing the cold, the revolution, and the post-revolutionary changes. Also, it is not fair to compare one culture based on the characteristics of a second culture.

I can however, say that I definitely have a better understanding of the history, political, and social circumstances than I did before. If my father ever allows me to travel on one of his business adventures (and I hope that he does), I will feel adequately informed to venture to Romania and see it for myself. 


\section{Appendix B}

\section{Informed Consent Form}

$$
\text { I, _ agree to take part in this }
$$

graduate thesis research project on how pre-service teachers use writing as they complete an ethnography project.

I understand that the study involves allowing Laurene Christensen to record interviews with me approximately one hour per week throughout the term about my experience with writing the ethnographic essay assignment for Applied Linguistics $471 / 571$, to interpret and refer to information from my Intercultural Development Inventory (IDI) profile, and to include samples of my writing, both formal and informal, from Applied Linguistics 471/571 in her research project. Laurene Christensen has agreed to meet with me and discuss my IDI profile with me.

I understand that there are not risks or hazards to this study, but the interviews will take some extra time. I may not receive any direct benefit from taking part in this study, but the study may help to increase knowledge that may help others in the future.

Laurene Christensen has told me that the purpose of this study is to look at how pre-service teachers (those pursuing an MA-TESOL or TESL certificate) use writing, both formal and informal, to make sense of the cross-cultural experience they encounter in the ethnographic essay assignment for this course. The results of the research will be presented in Laurene Christensen's graduate thesis.

Laurene Christensen has offered to answer any questions I may have about the study and what I am expected to do. She has also offered to allow me to read the results of her research.

Laurene Christensen has promised that all information I give will be kept confidential to the extent permitted by law, and that the names of all people in the study will be kept confidential. She has promised that all excerpts of my writing that are included in her thesis will be identified only by pseudonym. She has promised that she will not reveal my identity or my voluntary participation in this study to Dr. Kimberely Brown, the instructor for the course.

I understand that I do not have to take part in this study, and that this will not affect my course grade or my relationship 
with Portland State University. I understand that I may also withdraw from this study at any time without affecting my course grade or my relationship with Portland State University.

I have read and understand the above information and agree to take part in this study.

Date: Signature:

If you have concerns or problems about your participation in this study, please contact the Human Subjects Research Review Committee, Office of Research and Sponsored Projects, 111 Cramer Hall, Portland State University, (503) 725-8182, or Laurene Christensen at (503) 725-3556 


\section{Informed Consent Form}

I, agree to take part in this graduate thesis research project on how pre-service teachers use writing as they complete an ethnography project.

I understand that the study involves allowing Laurene Christensen to include samples of my writing, both formal and informal, from Applied Linguistics 471/571 in her research project.

I understand that there are not risks or hazards to this study, but the interviews will take some extra time. I may not receive any direct benefit from taking part in this study, but the study may help to increase knowledge that may help others in the future.

Laurene Christensen has told me that the purpose of this study is to look at how pre-service teachers (those pursuing an MA-TESOL or TESL certificate) use writing, both formal and informal, to make sense of the cross-cultural experience they encounter in the ethnographic essay assignment for this course. The results of the research will be presented in Laurene Christensen's graduate thesis.

Laurene Christensen has offered to answer any questions I may have about the study and what I am expected to do. She has also offered to allow me to read the results of her research.

Laurene Christensen has promised that all information I give will be kept confidential to the extent permitted by law, and that the names of all people in the study will be kept confidential. She has promised that all excerpts of my writing that are included in her thesis will be identified only by pseudonym. She has promised that she will not reveal my identity or my voluntary participation in this study to Dr. Kimberely Brown, the instructor for the course.

I understand that I do not have to take part in this study, and that this will not affect my course grade or my relationship with Portland State University. I understand that I may also 
withdraw from this study at any time without affecting my course grade or my relationship with Portland State University.

I have read and understand the above information and agree to take part in this study.

Date:

Signature:

If you have concerns or problems about your participation in this study, please contact the Human Subjects Research Review Committee, Office of Research and Sponsored Projects, 111 Cramer Hall, Portland State University, (503) 725-8182, or Laurene Christensen at (503) 725-3556 


\section{Writing in a Room Full of Mirrors": A Case Study of Cross-Cultural Transformation and Reflexivity Through Writing (tentative title)}

Dear Applied Linguistics 471/571 Student:

My name is Laurene Christensen, and I am a graduate student at Portland State University. I am beginning a study for my graduate thesis on how pre-service teachers use the writing process to complete an ethnography project, and I would like to invite you to participate.

You are being asked to take part in this study because you are pursuing either an MA-TESOL or TESL certificate through the Applied Linguistics Department at Portland State University and you are also enrolled in Applied Linguistics 471/571: Culture Learning in the Language Classroom. As part of the study, I am interested in learning more about how you use the writing done for this course to make sense of the experience you have with writing the ethnography assignment. I hope that the information I collect with help us to better understand the significance of both culture learning and ethnography as a part of Applied Linguistics curriculum. If you decide to participate, you will be asked to give me written, informed consent to use excerpts of your formal and informal writing completed for Applied Linguistics 471/571. Your writing will be identified only by a pseudonym in my graduate thesis project. Participation in this role will take no extra time on your part.

In addition, you are also invited to volunteer to be an informant for my case study. Along with being asked to give written, informed consent to use excerpts of your writing in my thesis project, in this role you will also be asked to meet with me approximately one hour per week throughout the term to discuss your writing process in more detail. If you decide to participate in this capacity, you will be also asked to give written permission to use interview data as well as information from your IDI profiles that you completed as part of the requirements for this course. Again, your writing, IDI profile information, and interview data will be identified only by a pseudonym in my project. 
There are no risks or hazards to this study. I assure you that your decision to participate or not participate in this study will not influence your grade in Applied Linguistics 471/571. You may not receive any direct benefit from taking part in this study, but the study may help to increase knowledge that may help others in the future.

Any information that is obtained in connection with this study and that can be linked to you or identify you will be kept confidential. Subject identities will be kept confidential by using pseudonyms.

Participation is entirely voluntary. Your decision to participate or not will not affect your relationship with the researcher, with Dr. Kimberely Brown, or with Portland State University. If you decide to take part in the study, you may choose to withdraw at any time without penalty. Please keep a copy of this letter for your records.

If you have concerns or problems about your participation in this study or your rights as a research subject, please contact the Human Subjects Research Review Committee, Office of Research and Sponsored Projects, 111 Cramer Hall, Portland State University, (503) 725-8182. If you have questions about the study itself, contact Laurene Christensen at (503) 725-3556.

Sincerely,

Laurene L. Christensen

Portland State University 


\section{Writing in a Room Full of Mirrors":}

A Case Study of Cross-Cultural Transformation and Reflexivity Through Writing(tentative title)

\section{Research Project Interest Questionnaire}

I am registered for Applied Linguistics:

471 571

I am pursuing an:

MA-TESOL TESL certificate other

I am interested in being an informant for this study (which involves interviews periodically throughout the term as well as including information from my IDI profile in Laurene Christensen's written thesis, as explained in the invitation letter):

yes

maybe, tell me more

no

Participation in this study is entirely voluntary. Your decision to participate or not will not affect your relationship with the researcher, with Dr. Kimberley Brown, or with Portland State University. If you decide to take part in the study, you may choose to withdraw at any time without penalty.

If you checked "yes" or "maybe," please include the best way to get in touch with you outside of class (phone number, email, etc.):

Please include your name here: 
Your identity as well as the information contained on this form will be kept confidential to the extent permitted by law.

If you have concerns or problems about your participation in this study or your rights as a research subject, please contact the Human Subjects Research Review Committee, Office of Research and Sponsored Projects, 111 Cramer Hall, Portland State University, (503) 725-8182. If you have questions about the study itself, contact Laurene Christensen at (503) 725-3556. 


\section{Appendix C}

\section{Supplemental Writing Notebook}

Writing is a process of discovery that includes a variety of forms. The writing process involves generating ideas through brainstorming and/or freewriting, drafting, revising, and drafting and revising again. University level writing is often formal-final drafts turned in for a grade. Culture Learning in the Language Classroom is a Writing Intensive Course, and this means that you will be doing a substantial amount of writing over the course of the term. This packet contains the majority of informal writing assignments; however, other formal writings may be assigned.

Most of the informal writing assignments included in this packet - the Progress Notes - can be thought of as similar to freewriting. Freewriting is writing whatever comes to mind about a topic, not worrying about punctuation and grammar. Freewriting is done to help you get starting thinking and processing an ideayou don't have to have all the answers. Oftentimes, freewrites are written only for the writer; however, for this class, you will be turning in these informal assignments to be ready by the teaching assistant, who may offer suggestions or comments (although not about your grammar or punctuation, etc). Although these assignments will not be graded, your completion of these assignments is expected as part of the requirements for this course and will be recorded. The purpose of these assignments is to encourage you to not only reflect on your experience as you complete the ethnography project but also to help you become more aware of your own process of crossing cultures.

This packet contains several different informal writing assignments. There are ten Progress Notes, which will be assigned individually throughout the term. The Cultural Artifact Interview Project will be completed over the course of a few class sessions at the beginning of the term. The Letter Exchange assignment will be completed around the same time as you turn in your Mini-Tour paper.

Please keep this notebook in either a 3-ring binder or a folder so that you can keep all of your completed writings together. The final Progress Note asks you to reflect on your process of writing the ethnography project, and to do so, you will need to refer 
back to your earlier Progress Notes and other informal writings. Although you will turn in each assignment once during the term, you will be required to turn in your folder/binder containing all of the completed informal writing assignments during Finals Week.If you have any questions about these informal writing assignments, please ask Laurene Christensen. 


\section{Letter Exchange}

Write a 1-2 page letter to a classmate in which you reflect on your project so far. Describe what has been challenging as well as what has seemed easy or natural about the project. In addition, ask your classmate one or two questions about the process of writing the ethnography (e.g. how to categorize information, how to manage quotations, what information to include or leave out, etc). You might also want to raise a question or two about the culture you're studying. Bring two typed copies of the letter to class. Turn one copy in to the instructor, and give the other copy to your classmate.

Then, after you've exchanged letters, respond to your classmate. Write a letter in reply to your classmate to answer the questions he or she poses. In writing this letter, think about the kind of feedback that would be helpful for you. You aren't being asked to evaluate your classmate's writing, but rather, to share information to help with the ethnography project. Again, bring one copy for your classmate and one copy to turn in to the instructor. 


\section{Cultural Artifact Exchange}

This exercise mirrors the process of conducting interviews over time with an informant. It emphasizes working with the informant's perspective, making extensive and accurate observations, speculating and theorizing, confirming and discovering ideas, writing up notes, listening well, sharing ideas collaboratively, and reflecting on your data.

Choose a partner from among your colleagues. You will act as both interviewer and informant. Select an interesting artifact that your partner has brought. If either of you has forgotten to bring an artifact, focus on something that your partner is wearing or carrying: a key chain, a piece of jewelry, a passport, an item of clothing. Both partners should be sure the artifact is one the owner feels comfortable talking about. If, for example the interviewers says, "Tell me about that pin you are wearing," but the informant knows that her watch has more meaning or her bookbag holds a story, the interviewer should follow her lead. Once you've each chosen an artifact, try the following process. Please read the directions for the entire process before you start. Save your responses to each stage as you go, and turn in the entire project once you've finished it. Begin by writing observational and personal notes as a form of background research before interviewing. 


\section{Name}

\section{Cultural Artifact Interview: Part 1}

Take observation notes. Take quiet time in class to inspect, describe, and take notes on your informant's artifact. Pay attention to its form, and speculate about its function. Where do you think it comes from? What is it used for?

Take personal notes. Start your notes in class, but feel free to add to them later. What does it remind you of? What do you already know about things similar to it? How does it connect to your own experiences? What are your hunches about the artifact? In other words, what assumptions do you have about it? (For example, you may be taking notes on someone's ring and find yourself speculating about how much it costs and whether the owner of the artifact is wealthy.) It is important here to identify your assumptions and not mask them. 


\section{Name}

\section{Cultural Artifact Interview: Part 2}

Interview the informant. In class, ask questions and take notes on the story behind the artifact. What people are involved in it? Why is it important to them? How does the owner use it? Value it? What's the cultural background behind it? After recording your informant's responses, read your observational notes to each other to verify or clarify the information. 


\section{Name}

\section{Cultural Artifact Interview: Part 3}

Theorize. Do this part at home. Think of a metaphor that describes the object. How does the artifact reflect something you know about the informant? Could you find background material about the artifact? Where would you look? How does the artifact relate to history or culture? If, for example, your informant wears earrings made of spoons, you might think about researching spoon making, spoon collecting, or the introduction of the spoon in polite society. Maybe this person had a famous cook in the family, played the spoons as a folk instrument, or used these as baby spoons in childhood. You don't need to do any library research for this part, but make note of what you would research if you had more time. Write for 10 minutes or fill up this page. 


\section{Name}

\section{Cultural Artifact Interview: Part 4}

Write. In several paragraphs, using your observations, the interview, and your theories, create a written account of the artifact and its relation to your informant. Write your draft on this page and make a copy of it to give to your informant for his or her feedback. 


\section{Name}

\section{Cultural Artifact Interview: Part 5}

Exchange. Each informant writes a response to the interviewer's written account, detailing what was interesting and surprising. At this point, the informant can point out what the interviewer didn't notice, say, or ask that might be important to a further understanding of the artifact. In responding to the interviewer's description of your artifact, please answer the following questions. Make a copy of this form so that you can give a copy to the interviewer.

1. What is your cultural artifact? Did your interviewer correctly identify it?

2. Where does the interviewer describe your artifact well? Include part of the passage.

3. Are there any places where you can share more information about your artifact to add to the description? Is so, include that information here.

4. Are there any significant stories about your artifact that didn't come out in the interview? If so, please share them here.

5. What have you learned about your artifact from your interviewer's description of it? 
Writing in the Contact Zone 321

\section{Name}

Cultural Artifact Interview: Part 6

Revise. Rewrite your written account of the informant's artifact here, including information that you learned from your informant's response to your first draft. 
Writing in the Contact Zone 322

\section{Name}

\section{Cultural Artifact Interview: Part 7}

Reflect. Write about what you learned about yourself as an interviewer. What are your strengths? Your weaknesses? What assumptions or preconceptions did you find that might have interfered with your interviewing skills? How might you change this? Write without stopping for 10 minutes, or fill up this page. 
Writing in the Contact Zone 323

Take-home Writing-Progress Note 1

Describe the culture you belong to. Write without stopping for 10 minutes, or fill up one page. 
Take-home Writing-Progress Note 2

Describe your informant for your ethnography. What culture is he or she from? Why did you choose your informant? Or, if you're still trying to find an informant, write about a potential informant. What culture would you like to learn more about? Why? Write for 10 minutes without stopping or fill up one page. 
Take-home Writing-Progress Note 3

What do you know about the culture you've chosen to write about? (Think about what you might have known or thought about this culture previously as well as what you know right now.) What do you hope to learn? Write for 10 minutes without stopping or fill up one page. 
Writing in the Contact Zone 326

Take-home Writing-Progress Note 4

Describe how you established rapport with your informant. Write for 10 minutes without stopping or fill up one page. 
Writing in the Contact Zone 327

Take-home Writing-Progress Note 5

As you turn in "The Grand Tour," take time to reflect on your ethnographic project so far. What have you learned? What challenges have you encountered? Write for 10 minutes without stopping or fill up one page. 
What is your focus for the "Mini Tour"? That is, what themes have emerged from your interviews with your informant? How have these themes emerged? Were they initiated by you or your informant? Write for 10 minutes without stopping or fill up one page. 
Take-home Writing-Progress Note 7

As part of your ethnography project, you are asked to write "thick, rich description." To practice this, close your eyes and visualize an activity that takes between five and ten minutes to complete. This could be an everyday activity, such as walking to the mailbox, or a special occasion, such as the first few minutes of a Japanese tea ceremony. This activity can be something related to you or your interviews with your informant. After you visualize the activity, write about it using description that includes all five senses-sight, touch, taste, smell, sound. Write for 10 minutes or fill up one page. 
Take-home Writing-Progress Note 8

In this class so far, we've discussed several theories related to cross-cultural learning. Have any of these theories been particularly helpful to you as you complete the ethnography? Which ones? Why? Write for 10 minutes without stopping or fill up one page. 
Take-home Writing-Progress Note 9

The ethnographic essay assignment originally asked you to "step as fully as possible for a brief period of time into another culture via your informant." Take time now to consider your experience with the ethnography project. Has the project been challenging or effortless? Typical or inspiring? Do you feel like you've experienced your informant's culture? What factors may have facilitated or limited your experience? Write for 10 minutes without stopping or fill up one page. 
Take-home Writing-Progress Note 10

As you approach the end of this ethnographic project, take time to reflect on the process of this assignment. Think back to your initial expectations (what you hoped you'd learn from the project, what you thought you knew about your informant's culture, etc). Did the project meet your initial expectations? What did you learn from this assignment? What did you learn about yourself? Write for 10 minutes without stopping or fill up one page. 
Writing in the Contact Zone 333

In-Class Writing- "Arts of the Contact Zone" by Mary Louise Pratt

In "Arts of the Contact Zone" Pratt talks about the difference between ethnography and autoethnography. Describe what each of these terms means for you. How would you describe your ethnography for this class in relation to these terms? 
In-Class writing- "Deep Play: Notes on the Balinese Cockfight" by Clifford Geertz

Geertz writes that "the culture of a people is an ensemble of texts, themselves ensembles, which the anthropologist strains to read over the shoulders of those to whom they properly belong." Think about this quotation in terms of your ethnography project. How are you a reader of your informant's culture? What part of your informant's culture does your ethnographic project represent? 


\section{Appendix D}

\section{Midterm Exam}

This exam should be typed, double-spaced with an approximate length of 3-5 pages. Please follow APA reference citation format in the body of the text and include a page titled "References" at the end of the exam which also follows APA format. Please note that the packet index contains the correct information for each of the articles in the packet, but the Index does not follow the APA citation format! You can pick up the APA citation handout in the Writing Center in Cramer Hall. Question not to exceed six pages double spaced (references excluded).

The Question:

Through your work with the course lectures, the packet readings, and graduate students-through Kramsch, we have looked both at intracultural communication and intercultural communication with an eye towards defining intercultural competence for the professional language educator. In a concise essay with an explicit thesis,

--provide an overview of three theoretical concepts which have been personally meaningful for you as you work to define intercultural competence on your terms. Explain why these concepts have been useful.

--Then synthesize these concepts and provide your personal definition of intercultural competence.

--Finally, discuss why it is or is not useful for you to have a well-formulated notion of intercultural competence for your professional goals. 


\section{Appendix E}

\section{Class Beginning and Ending Freewrites}

Mark

\section{Beginning of class}

American (USA) culture is multi-faceted and complex. There is no "one" culture. Your original ethnic group, geographical location, economic/educational status: all these can effect what your culture is.

I was raised in a middle-class family. We were always comfortable, but never wealthy. My parents had high school educations.

We were taught to respect others $\&$ their differences. I think general American culture is moving towards this. With the growing media and lines of communication, people of different cultures are coming more $\&$ more coming [sic] into contact. This creates many chances for cultural exchange \& cultural confusion.

In essence, American culture seems to be based on a fast paced, disposable life style. At least my connection to it. Personal relationships are shifting to impersonal. I think that sooner or later there will be a shift back to the personal, though how this will be I do not know.

\section{End of class}

America-The great open expanse that is Americamy culture is based on a strong sense of individualism and personal identity. From what I have read \& seen, many 
Americans denounce any sense at all of a national culture. This may be related to our strong sense of individualism.

At the beginning, I thought my culture was fairly uneventful. Upon reflection, I can see that there are some parts of my culture that are noteworthy. The sense of individualism, of critical thought - they are part of me.

I am not sure what else to say. Learning about another culture (Finland) has helped me learn about my own. By looking at others closely, we can see ourselves in a different point of view, in a sense. It made me think of what I am $\&$ what I come from.

Laura

\section{Beginning of class}

I am American. I think this term means very little by itself. My culture is my national heritage, my country of birth, my language and my geographic and (cultural) region. I am a mixture of Swedish, Norweigan, English and Irish blood. I feel the Irish most strongly and the Scandinavian to a lesser extent. My family ate a lot of Scandanavian food on holidays when I was a kid and I remember hearing Irish folkmusic and stories from the time I was very small. If course I grew up speaking English and wasn't formally taught another language until highschool, I did pick up some Swedish words from my grandparents. These things set you apart, make you feel different from your peers. I liked these differences! I think I am also my geographic region. I grew up in Wyoming and lived on the 
prairie for a long time. "Cowboys and indians" were a very real part of my life as a kid. Practices not common in other states or areas (such as riding horses, shooting guns and learning the cattle brands of the area) were very familiar to me at one time. All of these things are my culture. When a foreigner asks me about my culture, simply saying I'm American doesn't express enough.

\section{End of class}

I am American. By itself, this term doesn't mean much.

My family is European in background. German, Irish, Swedish, and Norweigan. The cultures of these countries have affected a lot of things in my family (food, celebration of holidays, how I view history,...). I grew up in Wyoming, in an area full of Germans and Scandanavians. It's a ranching community where hard work and self-sufficiency are valued. These values are very strong in my family, both from living in this area and from grandparents who were very poor laborors. Frugality is still very much an issue in my parents' home and is valued over other concepts, such as having a lot of things to show your worth. It's much better to save every penny than to buy something with it. All of these things have shaped my culture. I don't see myself as being culturally (exactly) the same as my parents or sister. I started out the same but because of traveling and living in some places very different from home, I have 
changed. I think my culture (now) shows the influence from places like Bulgaria, Pakistan and Korea.

Kelly

\section{Beginning of class}

I belong to American culture. It has recently become disappointing to me that our society here in the USA is so politically correct and multi-cultural that we can no longer call Christmas, Christmas and we can't sing songs about Jesus in school as part of Christmas. This is just one example but I think it is a very important one. Ours is the only country that I know that does this. People from our country and others do not minimize the importance of cultural celebrations for others. There is also the point of these areas that have Spanish as an official language. I don't think I need to explain how language reflects culture and although I support speaking other languages and retaining ones own cultural customs, I truly believe that in order to have cultural cohesion in the USA we should all speak English at one level or another. At the very least English schools should be in English. I am an ESL teacher and I know the importance of knowing English for clear communication. Other things that represent our culture are things like our obsession with thinness and looking young. I believe American culture is represented by our focus on moving quickly and always being able to communicate with the rest of the world no 
matter the time or day. We are also represented by our politically correct language and our love of seeing people. We have developed a very independent culture. We see ourselves as an independent nation although we aren't. We also put a lot of importance on being independent individuals. We are a culture that enjoys having strong opinions and expressing those opinions. We focus a lot on equality between races and sexes although there is almost no equality between the classes. From where I sit in society I find it hard to see the differences between the classes in the classroom but it is more evident by the things one has. In my circles of interaction, I find our culture to be very informal and relaxed.

\section{End of class}

My culture. . .

values honesty

distrusts authority

believes itself to be self reliant

is motivated by pride and progress

discriminates against those who are

different but does not consciously

persecute them.

values media input and stimulus

is future oriented

does not like to accept blame

avoids finding fault with ones self

values fairness above all else 
believes hard work can get you anything lacks knowledge of the world around it believes itself to be the leader of the developing world (superiority complex) wants everything as quickly as possible "Time is money" $\rightarrow$ impatience

Some people I would have to say value work over family

Fear death

Fear the unknown values money, status, and prestige (These observations do not describe everyone, including myself. They are generalizations.)

Marion

\section{Beginning of class}

I was born into a white middle class suburban family with its

roots in the farming communities of the Southern U.S. Our ancestors were hard-working Protestants who led clean lives and valued education. It was the education that provided upward mobility into the professional class. Correct grammar, manners, and proper dress were drilled into our little heads from an early age. We went to church every Sunday, but rarely took the lessons very seriously. In my high school, everybody was the same: we looked alike (there were no students from other cultural backgrounds), talked alike, dressed alike, and, I suppose, thought alike, 
too. It was stifeling. Nearly all the students went on to college. It was simply expected. Materialism and the accumulation of wealth were all-important-and the acquisition of proper housing, interior decoration, clothing, and jewelry were considered important goals of "the good life."

\section{End of class}

I was born in Minnesota from an upper middle class family whose origins stem from England and Wales prior to the Revolutionary War. The family started out as farmers in the South and advanced into the professional classes via education. Growing up, proper speech, manners, dress and housing were considered very important because those things gave the proper impression of who you were to other people. I would say that we were materialistic because what we worked so hard to have was an indication of who we were. We attended good schools, got good grades and dressed properly. At a very early age we had flawless English and table manners. We went to church every Sunday-it was something good people did. Then we forgot about it the rest of the week. We separated ourselves from the poor and the underclasses by living in the suburbs-in those days it was $\mathrm{OK}$ to consider oneself somehow better than the less privileged. I have never had the slightest desire to return to that stuffy, self-satisfied environment. 


\section{Beginning of class}

This is a hard one to answer because I think of many different ways to do it. When I was in Ecuador for 4 months I thought of my culture as being that of the United States in general. When asked to talk about my culture down there, it was in relation to how we celebrate Halloween, Thanksgiving, and Christmas (since I was there then) or specific questions like do we really eat hamburgers + pizza all the time, or out of a can. Or, do all young people not get along with their parents, etc.

But here when people ask me where I'm from, or where I grew up (which, I guess, gives them a very basic idea or picture of your culture-a very broad general beginning anyway) I have a hard time because my family moved around a lot. So that brings me to an even smaller level of my culture-my personal home culture-my family. I grew up in a strong Christian family with two parents who loved (and still do) each other very much. I have one sister, a year younger, who I get along with very well (in fact we have lived together all through college). My family is very close and we all get along great. Maybe it is because we have moved around so much because at times they were all we had as far as friends or people we knew. I grew up going to church + Sunday school every Sunday and we were all very involved in our youth group-My sister + I as participants, my parents as leaders. So, I guess you could say my home culture was that of a loving Christian family 
who moved around a lot. I was born in Owosso, Mich. We then moved to Cheyenne, WY then to Kirkland, WA then to Vienna, VA then to Chantilly, VA then to Eugene, OR then to Newcastle, WA then to San Ramon, CA. Meanwhile I have also lived in Monmouth OR (to attend WOU) and now are living in Portland.

Other than this I don't know exactly what else to say or how to describe my culture.

\section{End of class}

The culture I come from is that of the United States. This is a question that is hard for me to answer. Do I describe what life is like in the U.S. in general, do I describe my family and my personal way of life? I can't really say I grew up in one specific place because we moved a lot. My family is very close and always have been, we have always gone to church, we have always all sat down and eaten dinner together every night. My sister and I are both good students and have always gotten along. When you think of maybe the "typical" family or maybe the stereotype of a US family-ours may not match up-what comes to my head is a family who doesn't really get along-the kids don't like the parents, cause trouble-the whole "teenage" thing, etc. So how do you describe "the culture you come from"-You could say life is fast paced, fast food, no home cooked meals, kids in daycare, both parents working + often divorced + remarried. This all could be a way of describing my culture because it is what is around me-but so is the 
opposite-my friends + their families are more like mine than you may see, say on TV for example. So for me, describing "my culture" is hard unless it's more specific. Maybe-I don't know-maybe it's just me-I guess you just have to pick one and describe it + say what it is you are describing.

Meg

Beginning of class

I am basically a European American. I have family ties to Native Americans and enjoy their history, but do not have a personal connection with my tribe.

I have a varied culture. I am the daughter of a prision inmate. He is a criminal sexual preditor. I have grown up with him in prision, visited him there and only seeing him behind bars. I have felt the anger from other people talking about 'guys "like my Dad! I have a stepfather (1/2 English) and grew up having afternoon tea + biscuits. I have an alcoholic grandmother who told me to talk about my Dad was shameful.

My mother is a very strong person and has always supported me. She was there through my first marriage and divorce. My pregnancies and back surgery. She is always around but still we can disagree. We can discuss any topic and understand each other's view this wasn't the case always.

My husband + sons keep me busy. Scouting, soccer, play practice, plus family time is a lot of my culture. 


\section{End of class}

I come from a small town that is very tourism based. The people there live for the tourists, with out them we would starve.

The community is very anglo saxon white. A few Native Americans live nearby, but they keep to themselves.

My family is very religious, however I am not so. I am not as materialistic as some Americans but in general, more money is important to have what I want and better computers are nice too!

I am very content to have beautiful old pieces of "junk like" furniture, usefulness is better than style.

I like lots of gardens, but hate to weed.

My family isn't very political because we were all raised that this life is temporary.

TV's, computers, remotes, fast food (faster, quicker, better, now) are all ways to describe general Americans, however I like better things that what I have (new computer, i.e.) but will deal with what I have.

The remote, however, is mine! (HA HA)

Yuko

Beginning of class

My culture, Japanese culture is very different from American culture in many ways. Japanese culture is often described as "high context culture." I think it is true. 
Japanese culture values silence and an indirect communication style.

So, they re required to be good observant of not only others' verbal, but also nonverbal cues.

Japanese culture also values togetherness. Most Japanese people are not good at expressing own ideas, but very good at keeping unity in a group.

Old people are very respected in Japanese culture. Japanese culture is still holding the traditional values, while it's very much influenced by the western culture. Japan is one of the most fast growing cultures in the world.

\section{End of class}

My culture, Japanese culture, is a lot different from American culture. Both cultures are modern and have similar goals in economic and technology. Yet, people I the cultures have different aspects. Japanese culture probably values more solidarity than American culture. This influences people not to have conflict with others. In a classroom, people from my culture is quiet because this is the way in Japanese classroom

They especially don't argue with their teacher or classmates probably because they value to keep harmony in the classroom.

I sill learn a lot in this style of class, yet I found learning is enjoyable when people can discuss freely without worrying about keeping harmony all the time. 
Mostly how people communicate with others makes a huge distinguish about Japanese people from others.

Seeing other cultures also helps me to view my culture from a different point of view.

Lisa

Beginning of class

The culture I belong to-wow. I'm not really sure. Without sounding funny, I guess I'd say a 90's American culture. Meaning, I grew up in the United States, having lived 3 years in Canada as well. I lived in 5 states by the time I was 13. My parents were divorced when I was 4, my mom held a prominent business position w/ IBM, so we were transferred often. Although, I never grew up in a "mom and dad" setting, I think it allowed to experience other things. My mom remarried when I was 10 , and two months later he was diagnosed with terminal brain cancer. We lived for 7 years with my stepfather bedridden and nurses on duty in our home 24-7. With my mom working 12-15 hour days and nurses in our home at every hour, I learned to grow up pretty quick in many ways, I think. I had to younger brothers and began taking care of them on a pretty regular basis early on. We also often had nannies from other countries who lived with us sometimes. The things that our family went through, as any family does, made us definitely have character. My extended family is all very traditionally catholic living the traditional american lifestyle, white picket fence and all. Incidents we've been 
through was definitely given our end of the family some uniqueness. We've never really been very attached to our roots, ancestors, etc. Since we are a combination of many things. So I'd have to say my culture is definitely American.

\section{End of class}

I am American. My dad's family is primarily Polish and my mom's family, irish, english and german. Nothing stands out of things we particularily celebrate from one culture. Besides food, I guess. We eat a few polish things on a semi-regular basis. Which is funny because I haven't lived with my Dad since I was five.

I guess American pretty much sums it up. My family has, but doesn't really talk about specific cities or areas our relatives came from in Europe or anything. My grandmother studies our family tree and every now and then she'll have an interesting story, like relatives (ancestors) on the Mayflower; family found in Ireland... I really don't know about the Polish side very much because my mom pretty much raised me. The only story that's pretty common in conversations about my Polish ancestors is when my great-grandfather came over from Poland and changed the spelling of our last name, Americanized it, because people couldn't understand him. I'm definitely American, the rest is a little of this, more of that... Half Polish, but all-in-all American. 
John

\section{Beginning of class}

I have a good deal of trouble with this question. Having grown up in America I should be able to say American. But I'm not really very comfortable with that. Having grown up in a German family however, doesn't really make me German either. There are, I know, plenty of Americans in the same boat. To call oneself American doesn't really mean much. Especially when traveling (as I have been doing for most of the last ten years) its political significance is huge, and to me, even before I went abroad, largely a source of embarrassment. Many Germans of my generation may have similar feelings (about being German).

I also lack the commonality of having grown up within a strong religious tradition. My parents were very nominally Lutheran, but I was allowed to go my own way in this thing. It always seems to create more barriers to understanding than it lowers (the reverse of what I feel religion should do). Finally I'm not a fan of capitalism. I think there must be a better basis for organizing society. I view the present globalization/ Americanization of the world economy with distrust. Of course to lack strong traditions in these areas I is perhaps very "American." This has been a lot of what I am not. To put it in more positive terms I am certainly "Western" something. How deeply some "Western" viewpoints, especially the emphasis on the individual, have 
been ingrained has certainly been brought home to me repeatedly.

\section{End of class}

The culture I come from is western, and is based largely on European values. Nature is considered separate from man, an object to be manipulated and controlled. There is an emphasis on "doing" rather than "being", and a strong belief in knowledge as a thing obtained by empiricle, scientific inquiry. There is a strong emphasis on the importance of the individual as having a priority over social groups--(though at the same time a tremendous urge towards conformity which is largely denied and kept "outof-arareness." [*Note: there is a curious but deep belief that American cultures values are "value free" (i.e. rational, reasonable, and universal, especially in the areas of politics and economics)] There is almost an obsession about time and efficiency that is deeply ingrained in most culture members. At the same time little reflection on the meaning of existence or the value of being in itself. One is judged by what one does or has done rather than what one is. I find myself at odds with most of these notions and attitudes, though I recognize how deeply they affect me. I have different notions of ideal culture that I would prefer to claim membership in. 
Naoko

Beginning of class

I guess I have two cultures I think I belong to-but one is more dominant than the other. The culture I belong to dominantly is Japanese. It is a culture which the members recognize or "want to recognize" what's shared by everybody frequently. I think people want to show ho much they already know as background contextual info. whenever native speakers communicate. They do this through variety of signals, gestures, and other non-verbal stuff. I came to realize this because I am interested in discourse, and also I realize how little I share with people from my other culture when I carry conversation with them. The culture I am talking about is pretty hidden or covert, but I consider it to be very critical.

\section{End of class}

I come from a culture that holds many different cultural norms from the culture in this culture. I was just working on my First Lang Acquisition paper, and there was a scholar (Pat Clancy in U of Santa Barbara) who talked about the cultural norms that Japanese mothers promote in mother-child interaction. According to Clancy, the ability to anticipate the speakers' intentions $\mathrm{w} /$ out being told them directly is one such cultural norm in Japanese communicative style. I think this holds true for even adultadult interactions in Japanese and those who cross 
cultures using different languages in a difference culture would be problematic.

Culture of Japan has been discussed and promoted very ostentatiously everywhere nowadays-you can get so much info about the country and what's so called "Japanese culture"; however, I see it remain at very surface level-namely informational side of culture: what people (esp. in langague learning setting) need is more of behavioral culture, which concerns cultural norms in Japanese communication, for instance.

I see my culture I belong to from more $3^{\text {rd }}$-world perspective now; this was already taking place before this class, but enabled me to delineate what's going on! Thank you.

Rachel

\section{Beginning of class}

I am a product of the melting pot we call the United States, although I possess "blood" from several central European countries. Because of several circumstances such as distance, embarrassment about German heritage following WWII and family conflicts limiting exposure to family I feel that I have adopted the culture of the U.S.; eg a combination of several ideologies shared by many. My original home practiced the Protestant religion-church on Sunday, dress in special clothing, prayers to God at night and most importantly "Do unto others..." We lived in 
northwestern US in a wood frame house with six family members-my father worked outside our home, my mother inside. Children were to remain at home until they started school at age 6; roles were clearly defined. Cleanliness, high performance in school respect for elders were all valued norms, as were independence and self-sufficiency. We practice monogamous marriage as a norm, with serial monogamy rapidly replacing it as the most common type of union. Independent, isolated biological family units are common and often at the exclusion of extended family. Young and old alike are separated from their kin for either short or long periods (e.g. child care or residential elder care). Monetary wealth and youth are highly valued, as are the trappings of such values. My culture is becoming more diverse over time-culture seems to be an "individually defined" state, as I would define my culture differently than my sister based on her different life experiences and alliances.

\section{End of class}

My culture is that of the Northwestern United States; unique within the broader definition of the American culture because of our connection to Nature and our inherent resistance to moisture. I could reiterate that I am caucasian, born into a middle class family that values independence, education, Christian morality and collective responsibility; that within my lifetime I have experienced social, political, economic and historical change that 
continues to redefine my culture, and that I see myself as one manifestation of exposure to many cultures surviving together, or attempting to do so. As part of one of the words "dominant" cultures, I recognize the ethnocentricity of our worldview and strive to overcome this handicap on a personal level.

Honestly, I'm just tired (today) and can't seem to summon a good description of my culture.-

Takae

Beginning of class

Right now, it is a difficult question for me. I grew up in Japan, so I think that I'm familiar with Japanese culture (e.g. we eat raw fish, society is patriarchal, we have 3 different writing systems, we sleep in futons, we eat rice, we have several traditional arts, martial arts, etc), but I'm not sure if I belong to Japanese culture because I am not in Japan right now.

I don't think I belong to American culture because I'm still not quite sure what American culture is.

"Culture" is a very difficult term to define. We had to discuss about this subject in other class, but we could not come up with any good definition. I think that culture has a lot to do with how people think and act. In that sense, I think I belong to Japanese culture because I value harmony among people and have a tendency to avoid disagreement and conflict, and have a difficulty in talking about my 
feelings to people I don't know deeply. I also tend to put up with situations which I am not very satisfied because I think of the relationship between that situations and people who are involved in that situations. If I do anything about the situations and affect involved people in undesirable ways, I do not dare do anything.-I don't know if it is just my character, or values I acquired from growing up in Japan.

\section{End of class}

Describe the culture you come from-Japan

My culture values harmony among people.

- We care about how other people perceive us, thus individualism is highly discouraged My culture respects people who are older than us

- Age is an important factor, and has to use formal and polite language to the people who are older than him/her This expectation applies to people whose ages are not so distant-until the older ones tell the younger ones that they can use informal speech.

My culture makes a clear distinction between ingroup and out-group. Examples of in-groups are: family, employees in the same company, friends, etc. Examples of out-groups: employees from other companies, non-family members, etc.

- We use different formalities of speeches depending on members of which group we are talking to. 
Our culture does not make clear distinction among breakfast, lunch and dinner.

We basically eat same food for breakfast, lunch and dinner. We often left leftover from dinner in the morning.

\section{Hannah}

\section{Beginning of class}

This paper will be an extension of what I started in class the other day. What I started to write then was about my personal 'cultural history,' specifically what I experienced growing up on Grizzly Island, in California, in the Sacramento Delta of the Central Valley. As I mentioned in my in-class paper, I was fortunate to be raised in that area, with my grandparents, in such an incredibly dense area of silence and wildlife, with the companionship of my animals-cats, dogs, horses. I was spared much of the suffering that was unleashed by my parents, with their drug use and criminal activity. With my grandparents I had a relatively normal childhood. At the very least, even though there was suffering then, I can look back and know that I was always loved by them, however imperfect it was at times.

My home was an older, simple house that my grandfather had bought from the State Department of fish \& Game; he bought the house and pulled it to his property behind his tractor. The way of life out there was very different from the way many people live-then and now. We had no close neighbors. Once a week we would drive to town for 
groceries; that was about a 25 mile drive. It took around half an hour. The only people I saw, besides when I took the bus to school, were fishermen, duck hunters and our neighbors whenever our cattle got loose, or sometimes driving back and forth from town, we'd stop when we saw a neighbor and talk for awhile by the side of the road. I heard little 'news of the world' as a child-I remember hearing the name 'Eisenhower,' and my grandpa told me that he was the president. As far as other news, I don't remember any, although my grandfather was rather political, I don't consciously remember any of those conversations. I also remember that, though my grandfather said he was a conservative Republican, he was very tolerant in his views of the world. He was always very fair-minded with people, and judged all based on a code of conduct, which included a strong work ethic and, I remember, an integrity toward animals, in that they not suffer needlessly. There could have been other things, but my child-memory remembers these most. WE had a number of family friends, but didn't see them often, since we were always working and lived so far away from everyone. One family I remember was Hispanic/Mexican. Their name was Vallero. The dad's name was R------, The mom's name was G----, but she was not Hispanic, but white, a pretty woman, and they had 7 children-- two older sons, one about 16 named R---- Jr 8 I forget the other son's name, two older girls in their teens, a son about $10 \&$ twin girls about 6 years old. I'm telling this story because it 
was so large in my memory. Raymond St. workded for my grandfather \& my grandfather really liked him. Apparently the family was poor and suffered a lot. It must have been really hard for them, because there weren't so many marriages between people from different cultural backgrounds then, and if thre were there was usually talk about it. My grandfather wasn't like that. He payed $\mathrm{R}-$ well, I remember my grandmother saying that. Well, the kids would come over to play, \& my grandparents always said, "Share everything you have," and I would usually give my toys away, and we would play, especially the little girls and I. I remember once that they had saved money for a birthday cake for one of the boys $\&$ when we got there (it was an old two-story house), G----- told us that the dog had found it in the closet and ate it. They weren't too sad, but I could tell it was not a good thing. Then, it must have been a few months later, $\mathrm{R}$ - and his two older sons were working in a well, drilling it or something. One of the sons lifted a pipe and it touched a power line $\&$ they all died-the father and his two older sons were electrocuted. It was only about six months later that G---- and her younger son, older daughter and the twin girls were riding in a truck that the family had bought, with great difficulty they had saved the money for it. The truck stalled on some railroad tracks at a little junction called Cordelia, about halfway between Sacramento \& San Francisco. A train was coming. It was just a little spot in the road, but it's where they lived. The mom got the kids out of the truck and went back to try to 
get it started. Her son and older daughter ran back to help her and they died, the three of them hit by the train. All that was left of the family was the two little twin girls. They went to live with an aunt. I must have only been about 8 years old myself, but I never forgot them. The life was hard and I remember my grandparents' sorrow over this family's pain. Culturally, there was an incredible richness of values and judgements going on around me. Even in a conservative little community like where we lived. It was lonely and I remember feeling overwhelmed a lot, even as a child, by things I couldn't understand-the beauty of the landscape, the lonliness, the suffering of folks, my own good fortune. I must have been touched by something....I can remember clearly so much, the sunlight, the wind across the bay, $\mathrm{R}$ - working with my grandpa, branding and castrating the calves in the spring...

\section{End of class}

It would be impossible to describe the culture I come from in 10 minutes! I grew up here, in the United States.... what I can do is talk a little about the "culture" of my childhood in California. My childhood was actually rather unique compared to a lot of experiences one could have in the U.S.

I was born in San Francisco and, after a couple of years, I went to live with my father's parents. This would be grandmother and my (step) grandfather. I was lucky. My parents were very unstable-my dad and mother were 
involved in drugs and criminal activity (they robbed a bank \& were sent to jail). My older brother and sister were put in foster homes, but I was sent to my grandparents. It was another world....

My grandfather was a farmer. His parents came from Holland at he turn of the century and settled in California. My grandfather's land-800 acres-was located in the Sacramento Delta of the Central Valley. I was raised in almost total isolation; our nearest neighbor was 2 miles away. Our property bordered the Suisien Bay. I grew up in this beautiful, desolate, quiet place. I lived there for 18 years. We had cattle-usually 50 to 60 head-and horses (I had 4 horses at one point). Our property was also located on the Western Flyway. I'm sure that living there "saved" me-the Quiet, the bird life: geese, ducks; other wildlife; my horses, the bay. It was a world away from the suffering of my parents $\&$ their alienation from themselves.

Oops-out of time!

Georgine

\section{Beginning of class}

The culture that I belong to is primarily American culture, however, I was raised with a wide range of cultural values and traditions. My mother is Filipino American. She came to the U.S. when she was a teenager. Her cultural reference point(s) have been both Filipino and American culture. Her experience in this country has influenced how I see myself as a second generation mestiza. The word 
"mestiza" means a mix of two cultures (usually Spanish culture with another)-my father is white and my mother is Filipino. So I am a mix of both cultures. It is interesting for me to reflect upon what culture I belong to because I feel that I belong to many cultures. I grew up in a community that was mostly white, however, my mother had many friends that were Chinese, Korean, Filipino, and Japanese-so I learned about food, religion and family values from the children of these friends of my mothers'. These are my key reference points when I begin to navigate where I belong culturally. I also am very comfortable with mainstream American culture. My father and his family (Midwestern stock) provided me with the 'Americana', the values that they felt were important. I think about my Father's mother and her experience on a ranch in Illinois where she had worked both on the land and in the kitchen making pies and bread. 'I think about how I understand America through her eyes: The Great Depression, the isolation that she experienced that shaped her world view. I see what it is like to feel shame when I think about my mother and how my father's family did not understand who she was, what her culture was about. I am a bridge between two worlds, two cultures-my mother's \& my father's. I understand both of their experiences as I see myself in American culture as an American and as a product of a intercultural marriage. 
Writing in the Contact Zone 363

\section{End of class}

Georgine did not complete the end of the class freewrite. 